\title{
Realistic expectations of prepulse inhibition in translational models for schizophrenia research
}

\author{
Neal R. Swerdlow • Martin Weber • Ying Qu • \\ Gregory A. Light $\cdot$ David L. Braff
}

Received: 17 September 2007 / Accepted: 3 January 2008 / Published online: 21 June 2008

(C) Springer-Verlag 2008

\begin{abstract}
Introduction Under specific conditions, a weak lead stimulus, or "prepulse", can inhibit the startling effects of a subsequent intense abrupt stimulus. This startle-inhibiting effect of the prepulse, termed "prepulse inhibition" (PPI), is widely used in translational models to understand the biology of brain based inhibitory mechanisms and their deficiency in neuropsychiatric disorders. In 1981, four published reports with "prepulse inhibition" as an index term were listed on Medline; over the past 5 years, new published Medline reports with "prepulse inhibition" as an index term have appeared at a rate exceeding once every 2.7 days $(n=678)$. Most of these reports focus on the use of PPI in translational models of impaired sensorimotor gating in schizophrenia. This rapid expansion and broad application of PPI as a tool for understanding schizophrenia has, at times, outpaced critical thinking and falsifiable hypotheses about the relative strengths vs. limitations of this measure. Objectives This review enumerates the realistic expectations for PPI in translational models for schizophrenia research, and provides cautionary notes for the future applications of this important research tool.

Conclusion In humans, PPI is not "diagnostic"; levels of PPI do not predict clinical course, specific symptoms, or individual medication responses. In preclinical studies, PPI
\end{abstract}

Neal R. Swerdlow and Martin Weber contributed equally to this work.

N. R. Swerdlow $\cdot$ M. Weber $\cdot$ Y. Qu $\cdot$ G. A. Light $\cdot$ D. L. Braff

Department of Psychiatry, UCSD School of Medicine,

La Jolla, CA 92093-0804, USA

N. R. Swerdlow $(\square)$

Department of Psychiatry, University of California, San Diego,

9500 Gilman Drive,

La Jolla, CA 92093, USA

e-mail: nswerdlow@ucsd.edu is valuable for evaluating models or model organisms relevant to schizophrenia, "mapping" neural substrates of deficient PPI in schizophrenia, and advancing the discovery and development of novel therapeutics. Across species, PPI is a reliable, robust quantitative phenotype that is useful for probing the neurobiology and genetics of gating deficits in schizophrenia.

Keywords Animal models · Antipsychotic - Dopamine . Prepulse inhibition $\cdot$ Schizophrenia $\cdot$ Sensorimotor gating · Startle

\section{Introduction}

Among the paths to understanding the neurobiology of schizophrenia, one heavily traveled, has been the study through preclinical and clinical models of sensorimotor gating and its neural and genetic substrates. A laboratory paradigm frequently used to operationally measure sensorimotor gating is prepulse inhibition of the startle reflex (PPI). Medline lists over 1400 published reports utilizing the key word "prepulse inhibition" and over 580 that also include the key word "schizophrenia". Research using PPI to probe the neural and genetic bases of schizophrenia has crossed every level of the "top down" and "bottom up" investigations of this disorder-from studies of the psychological implications of PPI to those assessing the control of PPI by signal transduction pathways and the genes that regulate them. Arising implicitly and explicitly from such a broad application of the PPI paradigm have been assumptions and expectations that we hope to examine critically in this review. In so doing, we hope to offer some perspectives on both potentially productive directions of this work, and the degree to 
which some assumptions and expectations may, or may not, be reasonable.

\section{Historical overview}

The popularity of PPI as an experimental paradigm for understanding schizophrenia comes from its conceptual linkage to clinical observations that schizophrenia patients are unable to optimally filter or "gate" irrelevant, intrusive sensory stimuli (Bleuler 1911; Kraepelin and Robertson 1919; McGhie and Chapman 1961; Venables 1964). These clinical observations led to the formulation of a construct- "gating deficits" in schizophrenia - that has been extended to refer to deficient inhibition of both sensory and cognitive information. The PPI paradigm was developed as a measure of automatic or preconscious inhibition in normal comparison subjects, as one variant of numerous paired-pulse paradigms in which the presentation of a lead stimulus led to the reduced perceptual or motor response to a second stimulus (Peak 1939; Graham 1975) (Fig. 1). Braff et al. (1978) first merged the construct and its operational measurement by identifying PPI deficits in schizophrenia patients, a finding that has since been replicated by many independent groups and [as reviewed previously (Braff et al. 2001b) and below], has become among the most influential paradigms in the field of schizophrenia psychophysiology. A comprehensive review through the year 2000 of all reports linking PPI deficits to schizophrenia in clinical populations is found in Braff et al. (2001b); reports subsequent to this date are listed in Table 1. Animal studies first linked this finding to a neurochemical (DA) and anatomical (ventral striatum) substrate (Sorenson and Swerdlow 1982; Swerdlow et al. 1986), and subsequent reports centered these substrates within an extended forebrain and pontine circuit that regulates PPI in rodents (Koch and Schnitzler 1997; Swerdlow et al. 1992, 2000a; see Table 4). Animal studies have identified developmental (Geyer et al. 1993; Lipska et al. 1995; see Table 3) and genetic (Carter et al. 1999; Ralph et al. 1999; Geyer et al. 2002; see Table 3) influences on PPI and have led to predictive models for antipsychotic development (Swerdlow et al. 1994) that have been modified and widely applied towards antipsychotic discovery. A comprehensive review through the year 2000 of all reports using PPI in models predicting antipsychotic properties is found in Geyer et al. (2001); reports subsequent to this date are listed in Table 2.

This quantitative physiological abnormality in schizophrenia patients, conceptually linked to an intuitive clinical construct and neurochemical, anatomical, developmental, and genetic substrates, has provided a powerful focus for scientific developments. With the rapid expansion and broad application of variations of PPI measures, new expectations for its use to inform us about the biology of

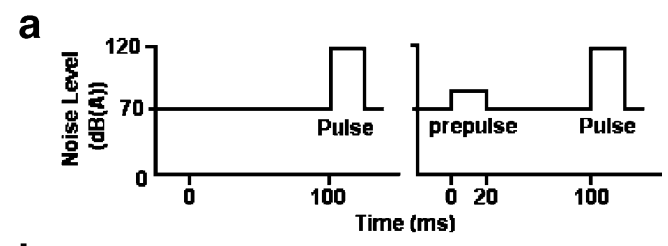

b

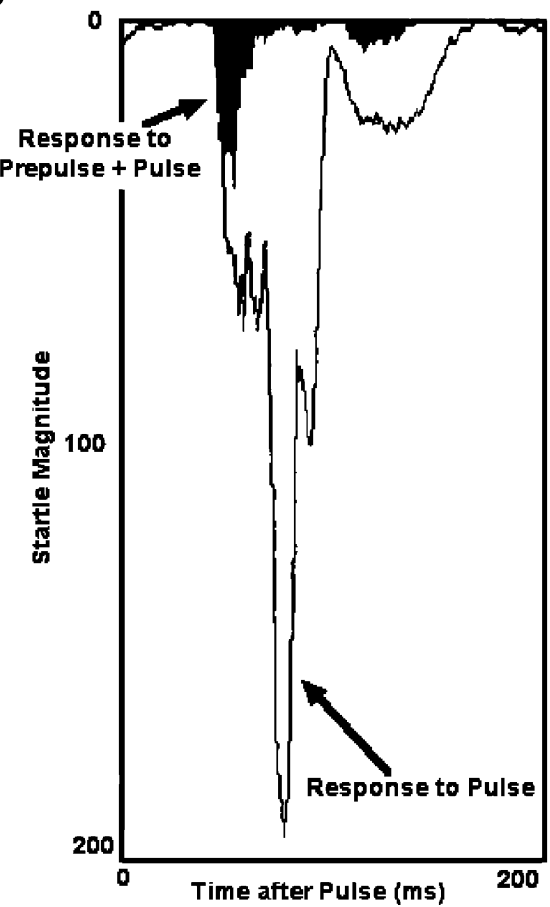

Fig. 1 Schematic representation, adapted from Swerdlow et al. (1994), of stimuli used to elicit PPI in laboratory measures (a). b shows superimposed tracings of electromyography of the right orbicularis oculi in an adult male subject, from sequential trials that included either a prepulse $[20 \mathrm{~ms}$ noise burst $4 \mathrm{~dB}$ over a $70-\mathrm{dB}(\mathrm{A})$ background] followed $100 \mathrm{~ms}$ later by a $118-\mathrm{dB}(\mathrm{A}) 40 \mathrm{~ms}$ startle noise pulse (solid black area), or the startle pulse alone (open area). Tracings in (b) begin at pulse onset. The amount of inhibition generated by the prepulse can be appreciated visually by subtracting the solid area from the open area

schizophrenia have at times outpaced critical thinking and falsifiable hypotheses about the relative strengths vs limitations of these complex studies. Here, we hope to enumerate some of these expectations and the future promises and potential limitations of PPI studies.

\section{Human studies: What can our field realistically expect to learn about schizophrenia based on studies of PPI in humans?}

\section{Diagnosis}

As an isolated measure, PPI is not a "diagnostic instrument". There is substantial variability and significant overlap in PPI distributions among normal and disordered populations. In addition, there are many different disorders 


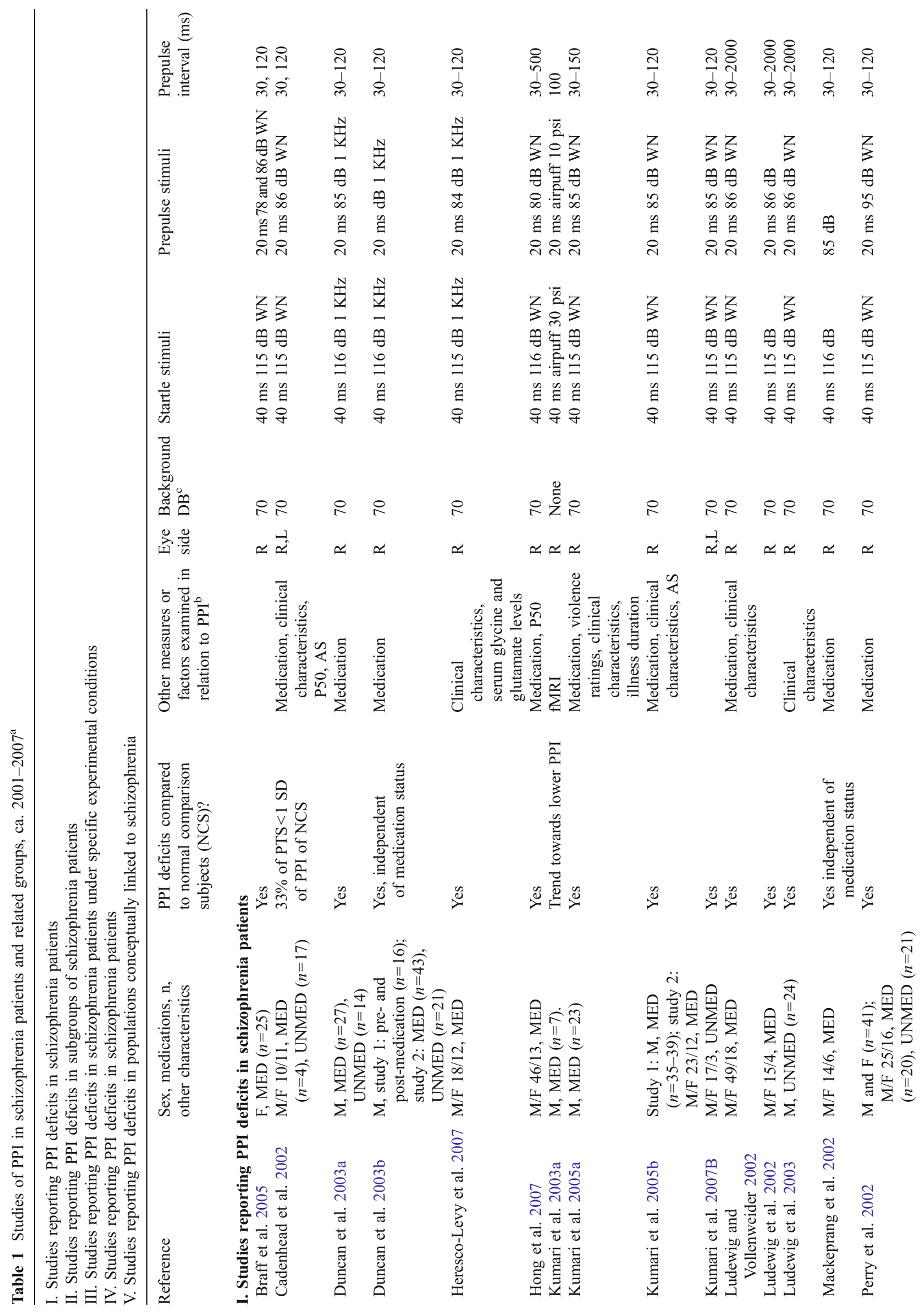




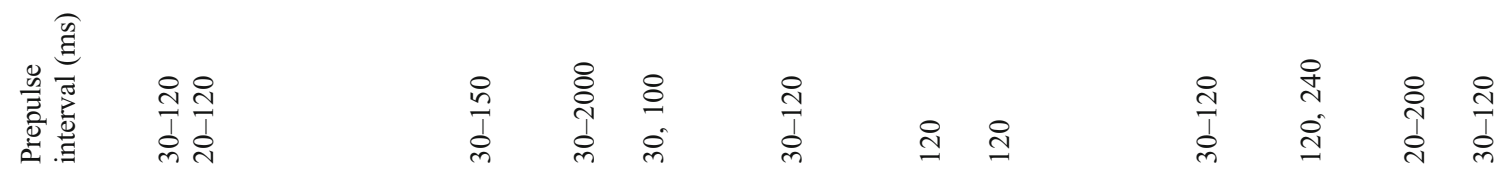

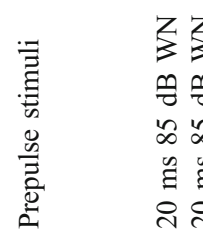

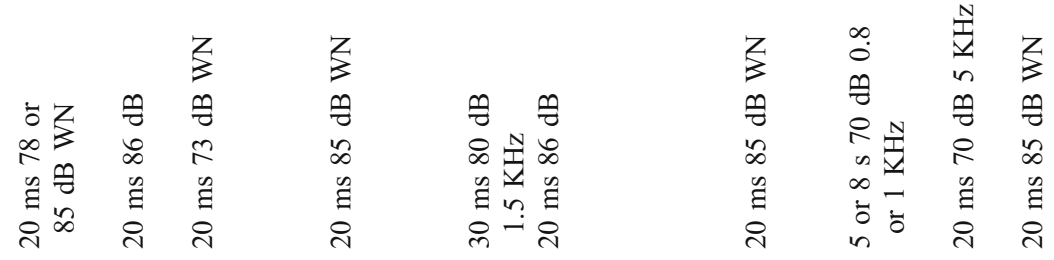

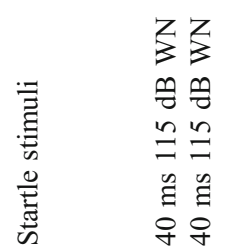

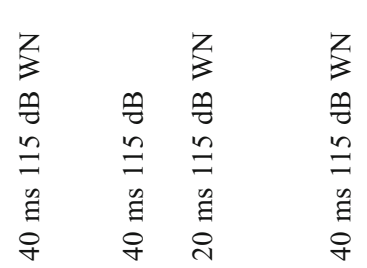

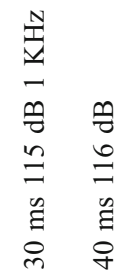

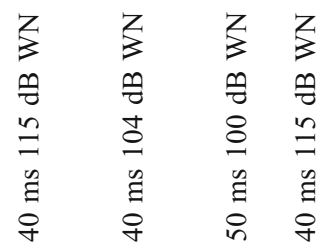

䓂

范 商 尺尺

$\therefore \quad \therefore$

$\stackrel{2}{1}$

Z $尺$

ร 8 \&

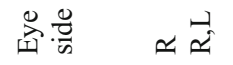

$\simeq \simeq \simeq$

$\simeq \simeq \simeq$

Z $\simeq$ ๘ $\simeq$

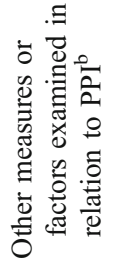

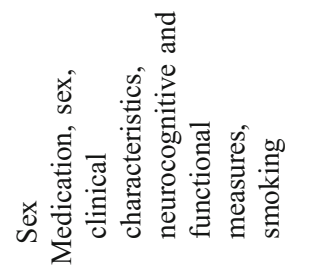

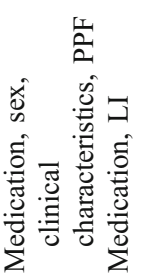

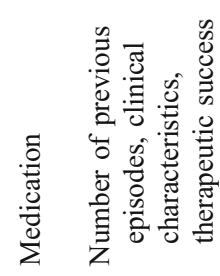

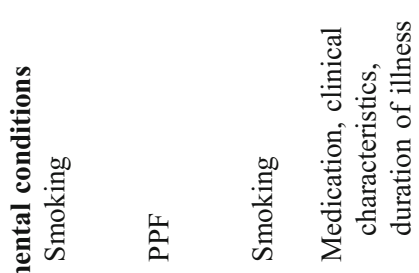

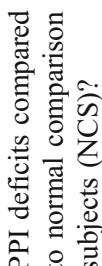

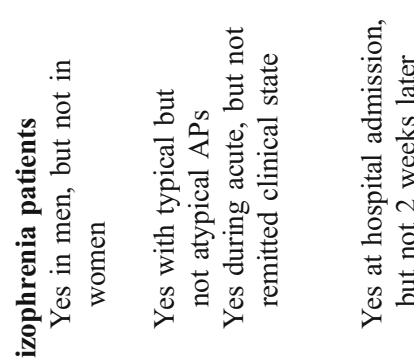

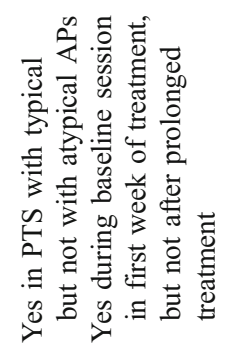

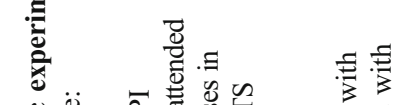

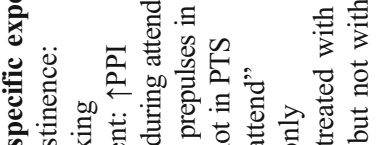

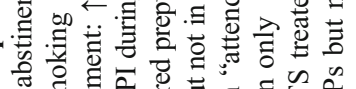

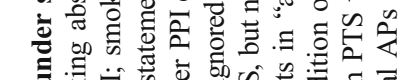

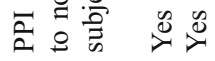

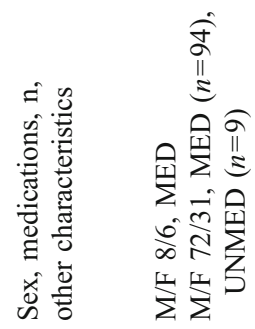

$\frac{5}{0}$

$\frac{8}{\mathscr{D}}$

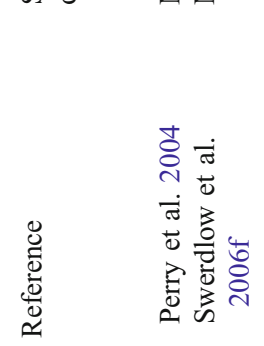

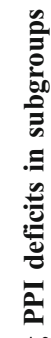
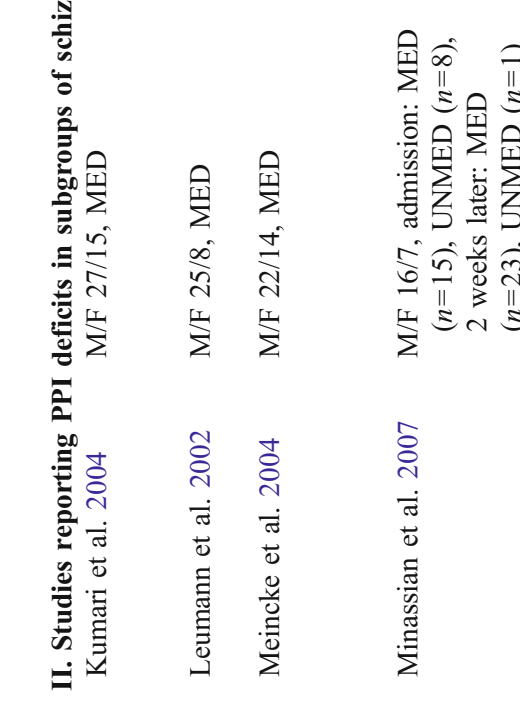

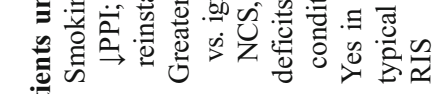

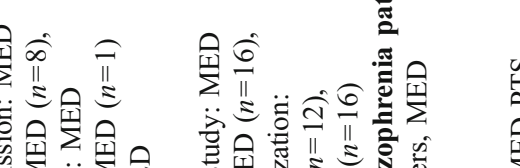

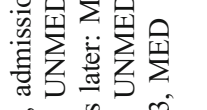

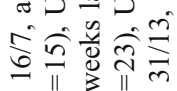

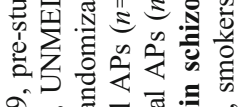

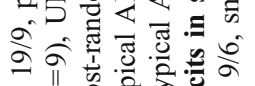

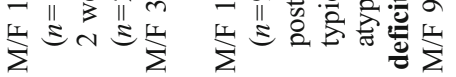

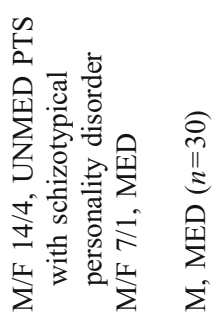

ล

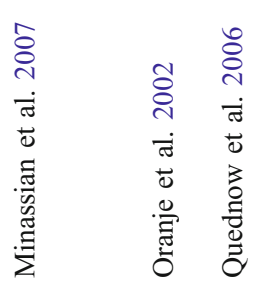

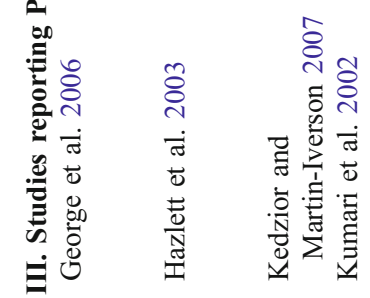




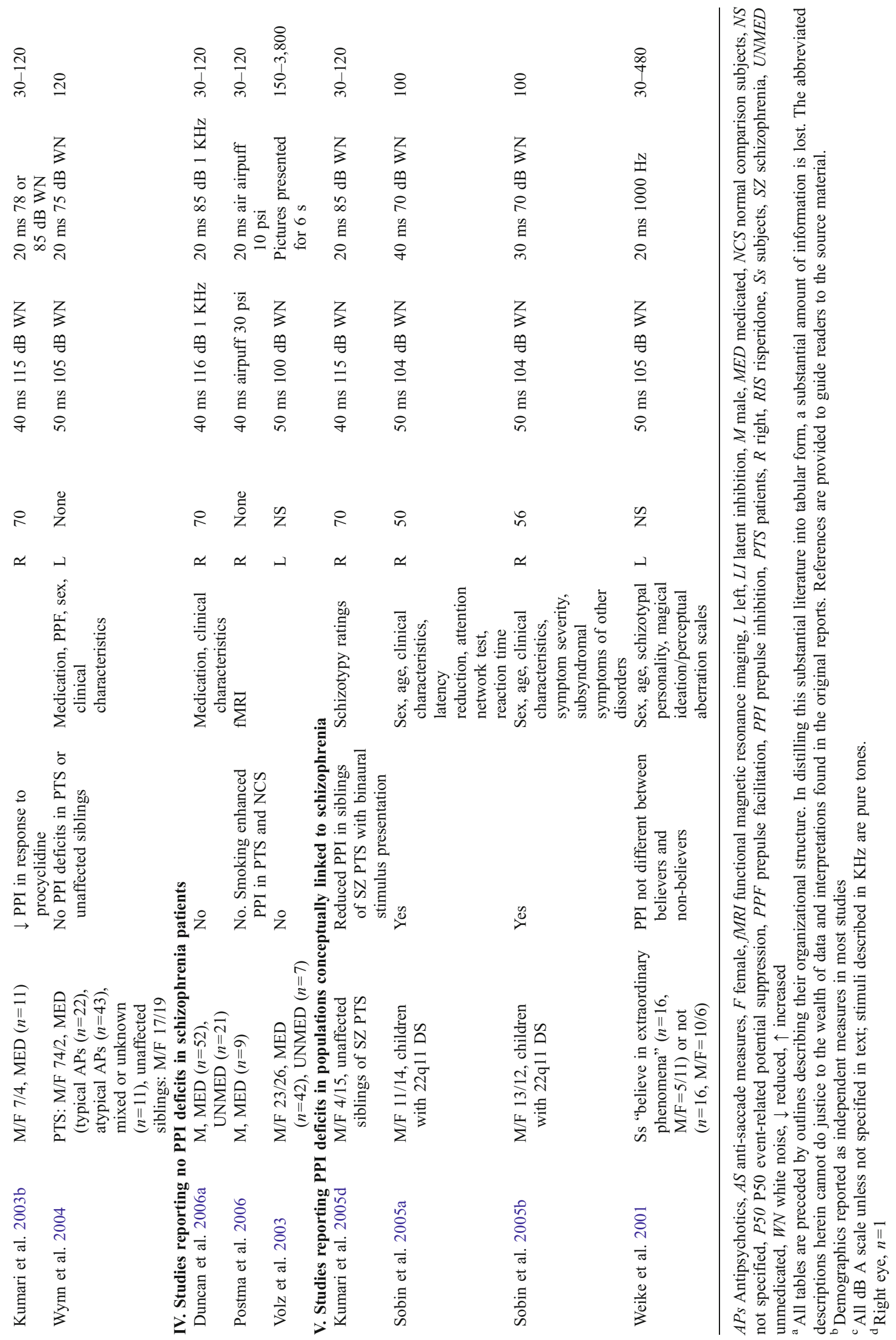


in which affected individuals are characterized by reduced PPI, on average, compared to a normal comparison population (cf. Braff et al. 2001b). The reason for the "non-pathognomonic" nature of PPI deficits is simple: the amount of PPI exhibited by any organism at any given moment reflects activity at many different levels of integrated cortico-striato-pallido-thalamic (CSPT) circuitry and its output via the pontine tegmentum. Low levels of PPI can result from normal variations at several levels of this circuitry; alternatively, disease processes can impact different levels of this circuit, with synergistic effects on pontine activity that mediates PPI. Conceivably, disease processes might even impact this circuitry in such a way as to bias it towards elevated levels of PPI, and compensatory or allostatic changes within feedback or downstream elements of the circuitry might offset the effects of otherwise PPI-disruptive disease processes. Thus, absolute levels of PPI - either low or high - are neither diagnostically nor neurophysiologically specific.

A corollary of this fact - that PPI is not "diagnostic"-is that no simple qualitative value of "normal" or "deficient" can accurately be applied to any particular level of PPI, particularly among clinically normal individuals. It is common in the literature (including our own reports) to describe relatively low levels of PPI as "deficient", "impaired", or "poor". In fact, we know of no clear adaptive or functional advantage of higher vs. lower levels of PPI among clinically normal individuals. Perhaps, this idea is most easily conveyed in the comparison between clinically normal men and women: on average, under specific stimulus conditions (e.g., $20 \mathrm{~ms}$ white noise prepulses, $10 \mathrm{~dB}$ over a $70-\mathrm{dB}(\mathrm{A})$ white nose background, $100 \mathrm{~ms}$ before a $115-\mathrm{dB}(\mathrm{A}) 40$ white noise pulse), men exhibit more PPI than do women (Swerdlow et al. 1993b, 2006f; Kumari et al. 2004; Aasen et al. 2005). Furthermore, there is some evidence that among normal women, PPI shifts across the menstrual cycle (Swerdlow et al. 1997; Jovanovic et al. 2004). Clearly, there is no basis for describing PPI in women vs. men as "deficient", nor for describing luteal- vs. follicular-phase PPI as "impaired". Similarly, drugs that increase PPI in normals cannot be accurately claimed to "improve" PPI.

At a more basic level, at any given moment in time, individuals are not characterized by a single "PPI" value, in the same manner in which they might be characterized by other quantitative traits such as height, Q-T interval, or fasting glucose level. One of PPI's strengths as an experimental measure is its exquisite sensitivity to stimulus parameters and test conditions [as described for the startle reflex by Davis 1984]. The inhibition generated by prepulses under different stimulus conditions likely reflects different underlying physiological substrates. Thus, under a variety of test/stimulus conditions, the same clinical population might conceivably exhibit PPI levels that are reduced, equal to, or elevated, compared to normal comparison subjects. An instructive example from preclinical studies of PPI is found in the report that inbred Brown Norway (BN) rats exhibit "deficient" PPI compared to outbred Sprague Dawley (SD) rats, based on measurements with $100 \mathrm{~ms}$ prepulse intervals (Palmer et al. 2000). Subsequent studies reproduced this finding, but also demonstrated that at shorter prepulse intervals, the opposite relationship existed: $\mathrm{BN}$ rats exhibited significantly more PPI compared to SD rats (Swerdlow et al. 2006a, 2008). Thus, depending on the stimulus parameters, populations can exhibit either relatively reduced or excessive PPI.

PPI is also highly sensitive to state variables and influences, such as medications (Table 1), cigarette smoking (Table 1), fatigue (van der Linden et al. 2006), stress (Grillon et al. 1998), and hormonal status (Swerdlow et al. 1997; Jovanovic et al. 2004). While some of these variables and influences can be controlled under experimental conditions, the notion of using such a sensitive measure in isolation as a diagnostic tool is not realistic. This being said, one potentially valuable strategy in the characterization of clinical populations is the use of PPI in combination with multiple other measures of forebrain inhibitory function, such as P50 event-related potential (ERP) suppression ("P50 gating"; Adler et al. 1982) and antisaccade deficits (Radant et al. 2007), to identify multiple measures and patterns of normal vs. deficient function (Cadenhead et al. 2002; Braff et al. 2008; Sugar et al. 2007). PPI and P50 gating are both deficient but correlate weakly, if at all, in schizophrenia patients (Braff et al. 2007b); similarly, PPI and antisaccade performance are both deficient but do not correlate significantly in schizophrenia patients (Kumari et al. 2005b). Thus, these measures apparently assess forebrain inhibitory processes that are dissociable and nonredundant. More importantly, there are patients who exhibit normal levels of some but not other gating measures (and presumably normal function within brain circuitry regulating some but not other measures), and subpopulations of patients who exhibit different profiles in these deficits (Kumari et al. 2005b; Swerdlow et al. 2006f; Braff et al. 2007b). These subpopulations may reflect different patterns of brain dysfunction and conceivably distinct genetic substrates and treatment sensitivities (Braff et al. 2007a).

Symptoms, course, and outcome

Can we predict the clinical course or even clinical features of schizophrenia based on PPI levels? There is no compelling data to suggest that among schizophrenia patients, levels of PPI predict clinical course, nor are there consistent robust relationships between lower levels of PPI and higher levels of specific symptoms of schizophrenia, or cumulative 


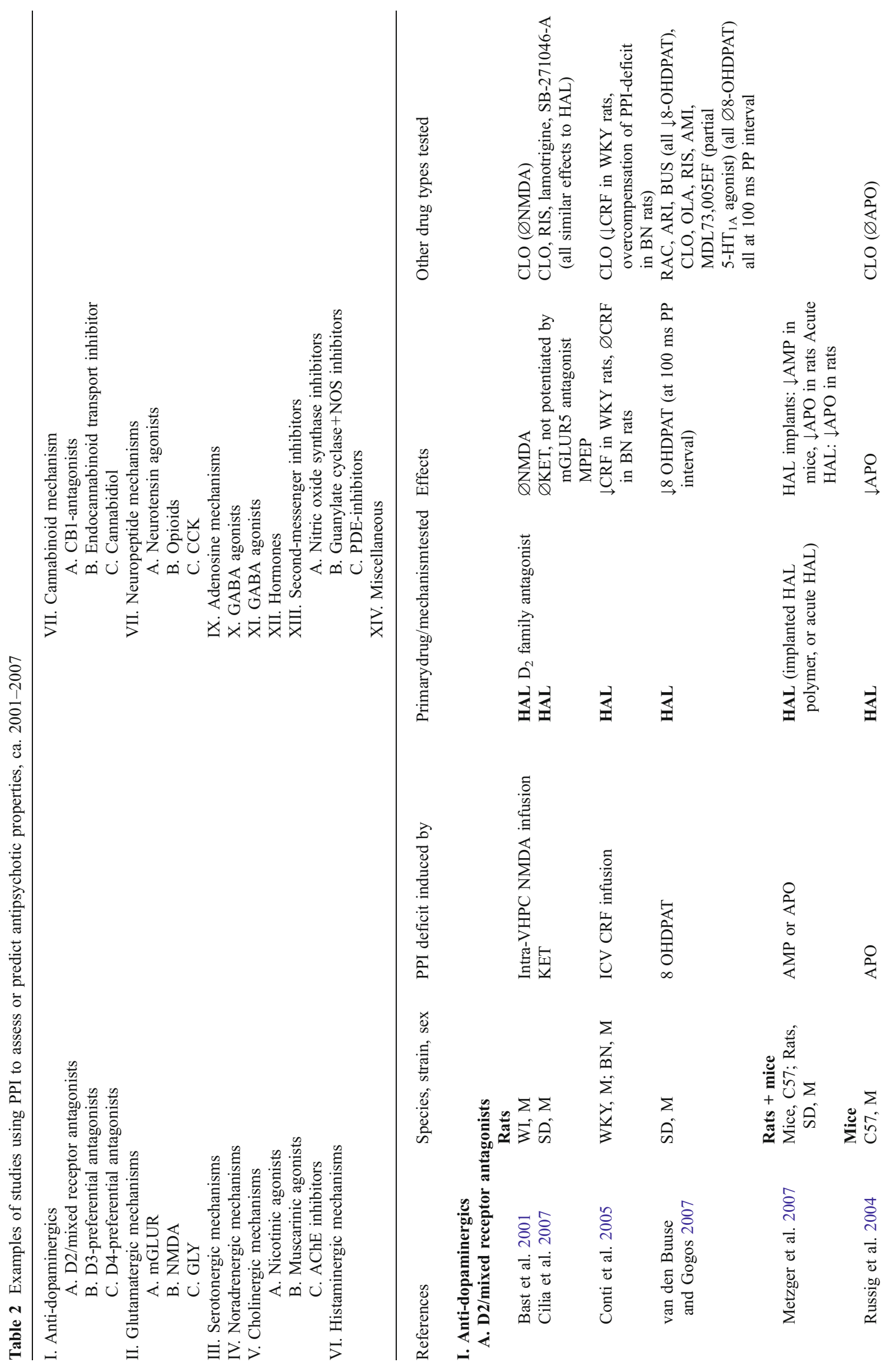




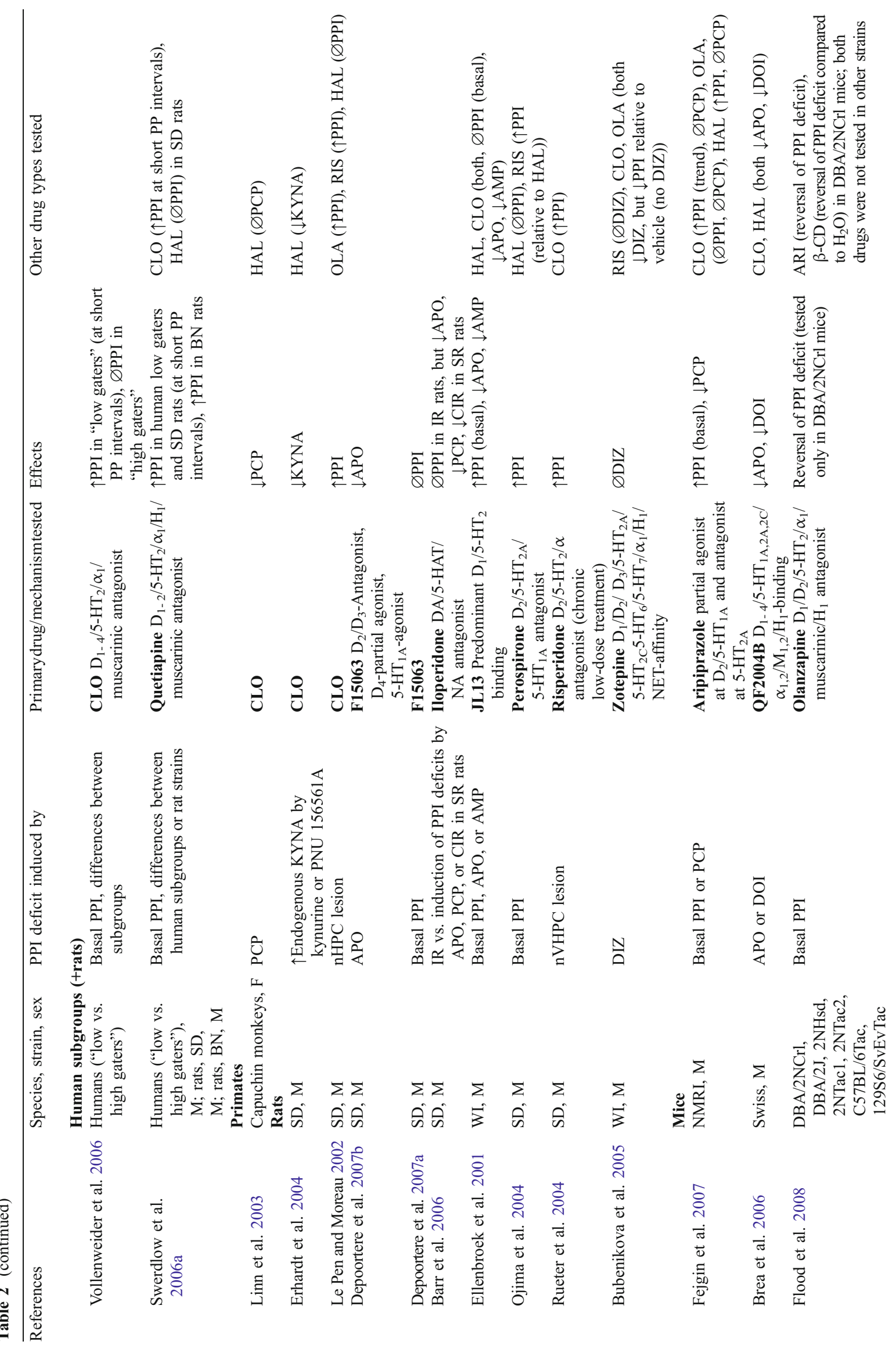



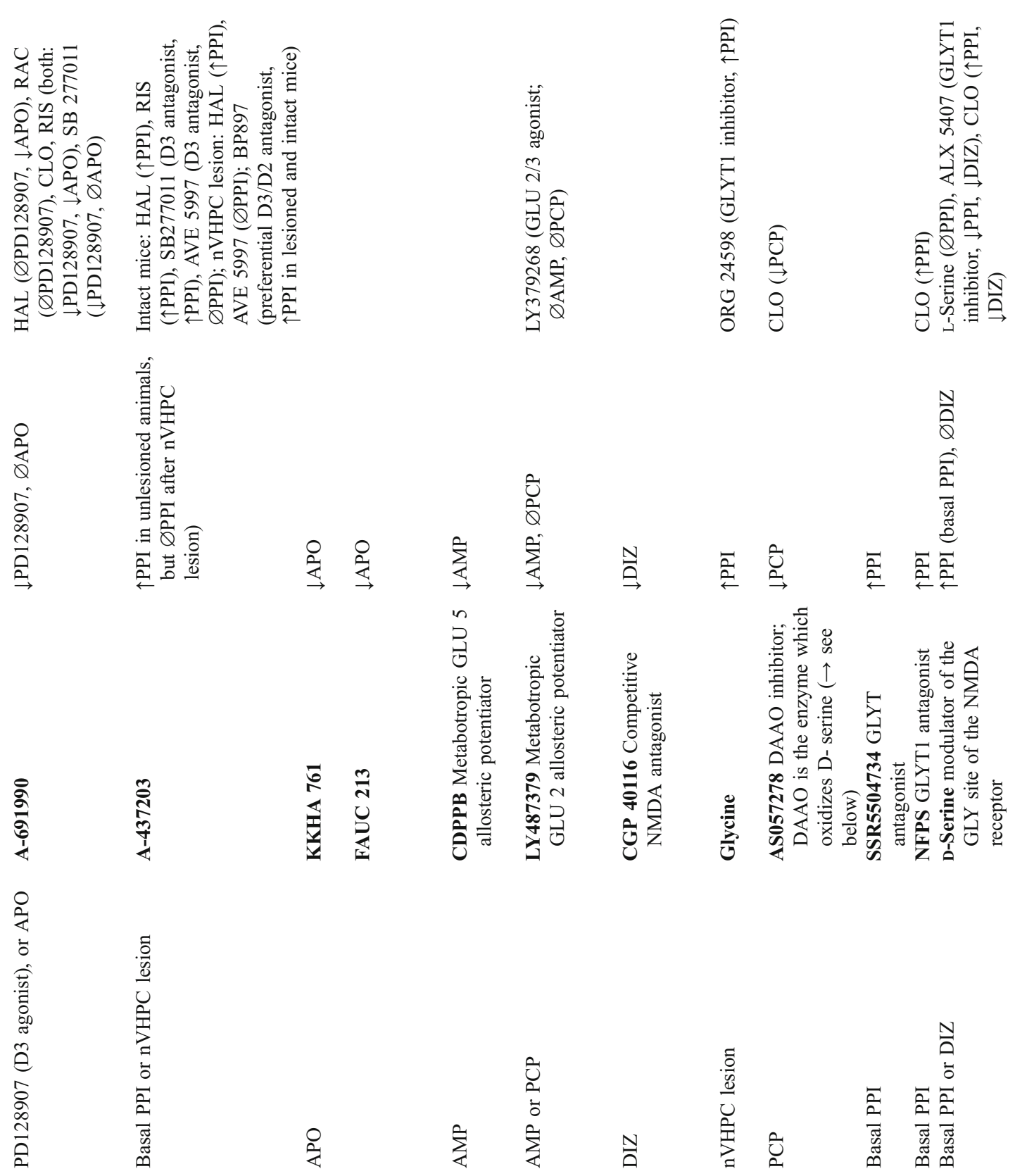

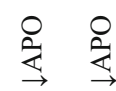

言紊

$\stackrel{\Perp}{g}$

홀

$\stackrel{N}{\bar{Q}}$

$\bar{Q}$

言
可
है
है

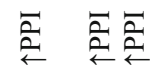

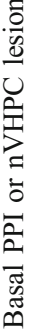

$\stackrel{0}{2}$

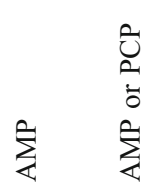

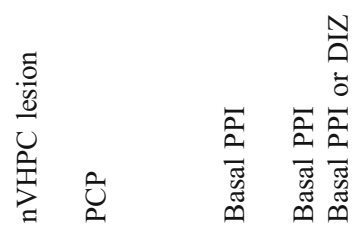

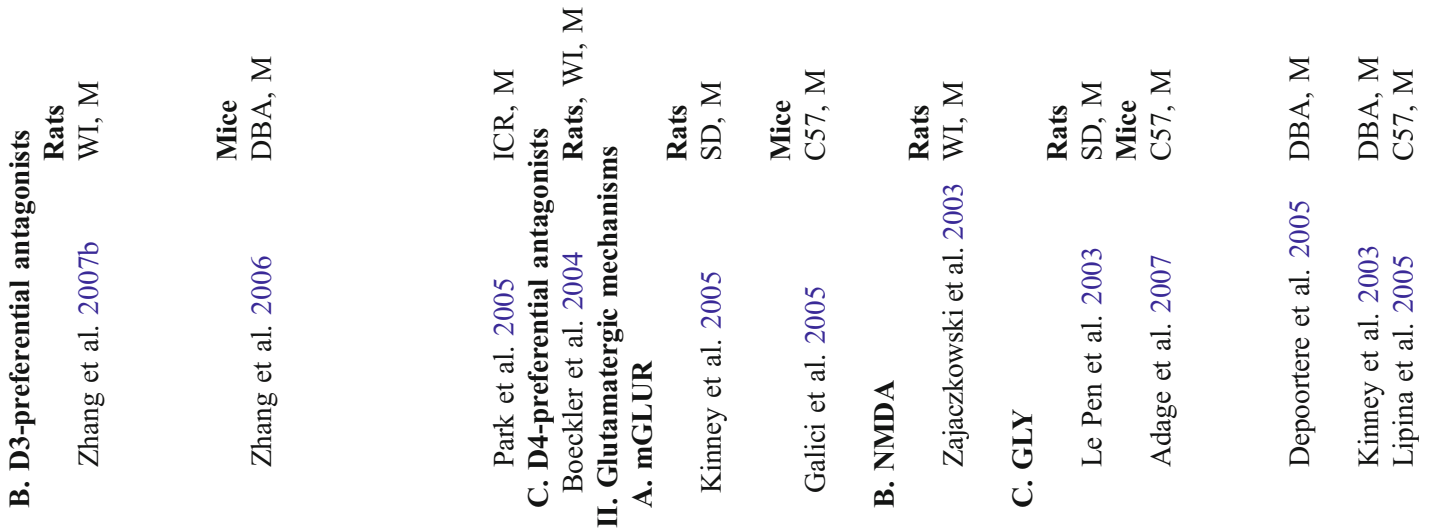




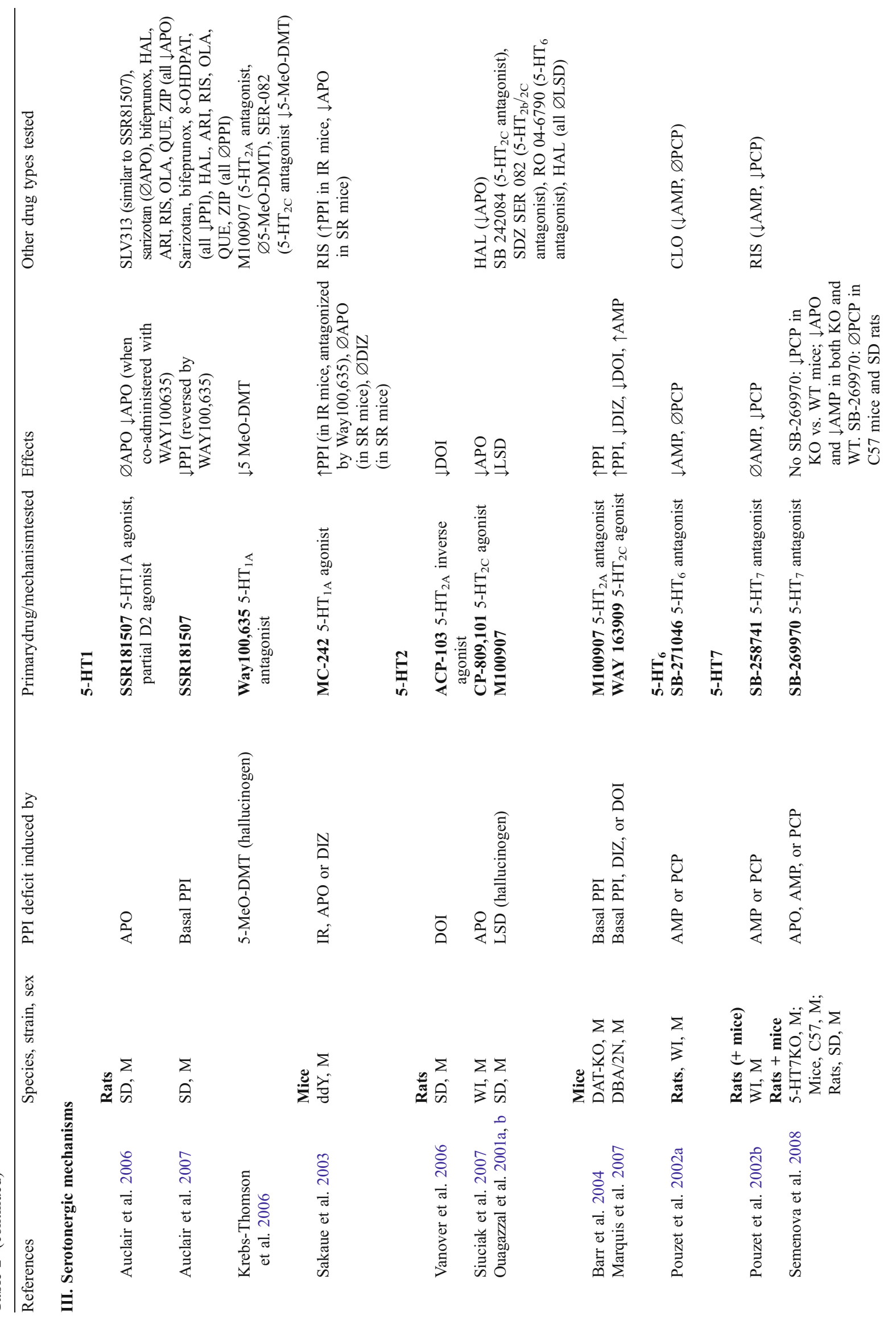



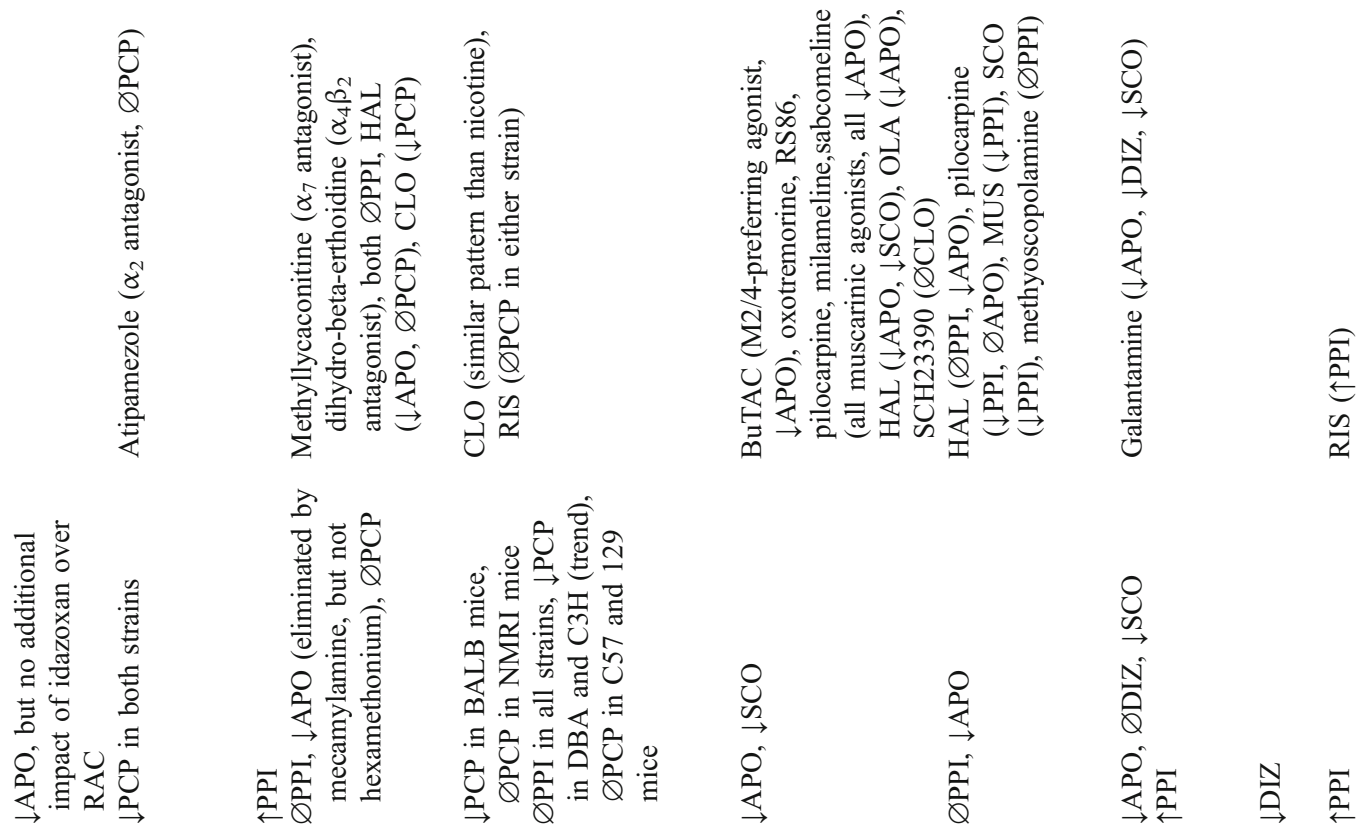

$\frac{8}{30}$

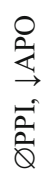

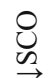

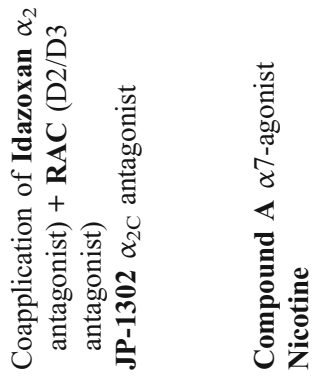

そ气
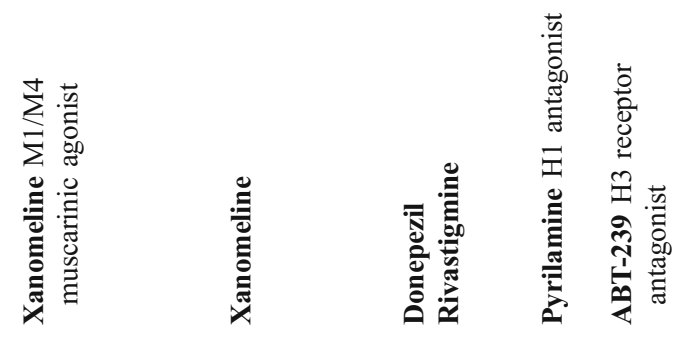

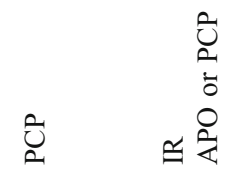

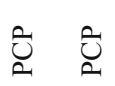

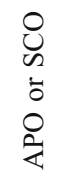
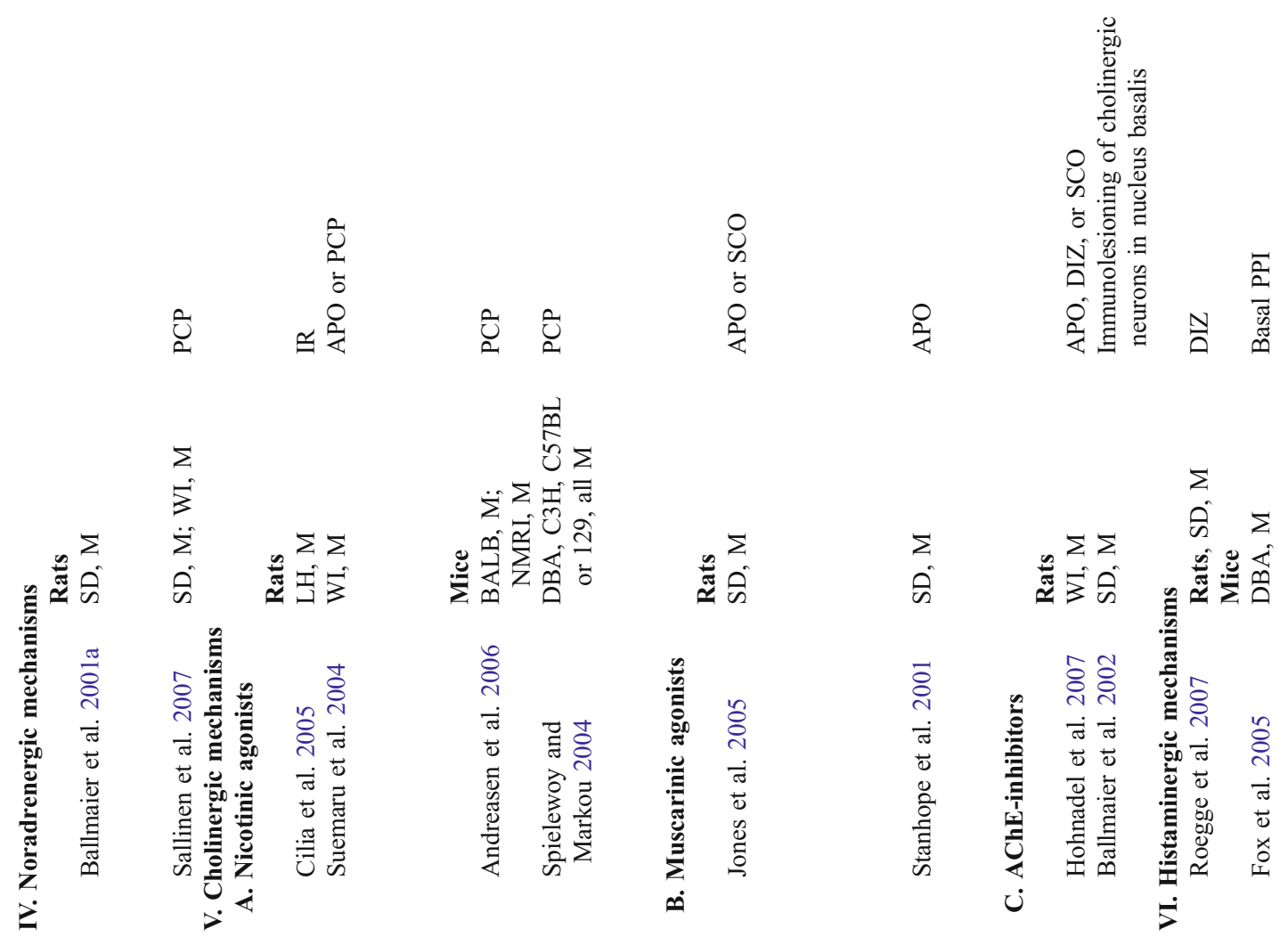

$\Sigma$

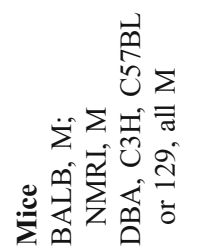

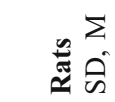

$\stackrel{\circ}{\gtrless}$
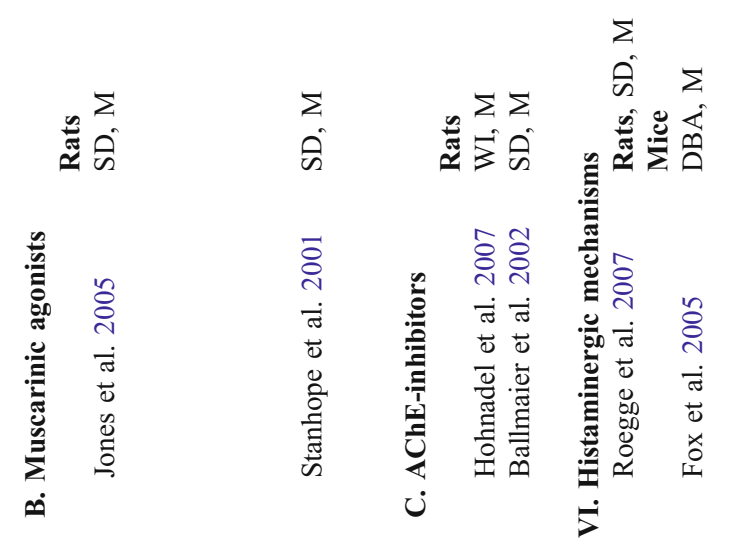


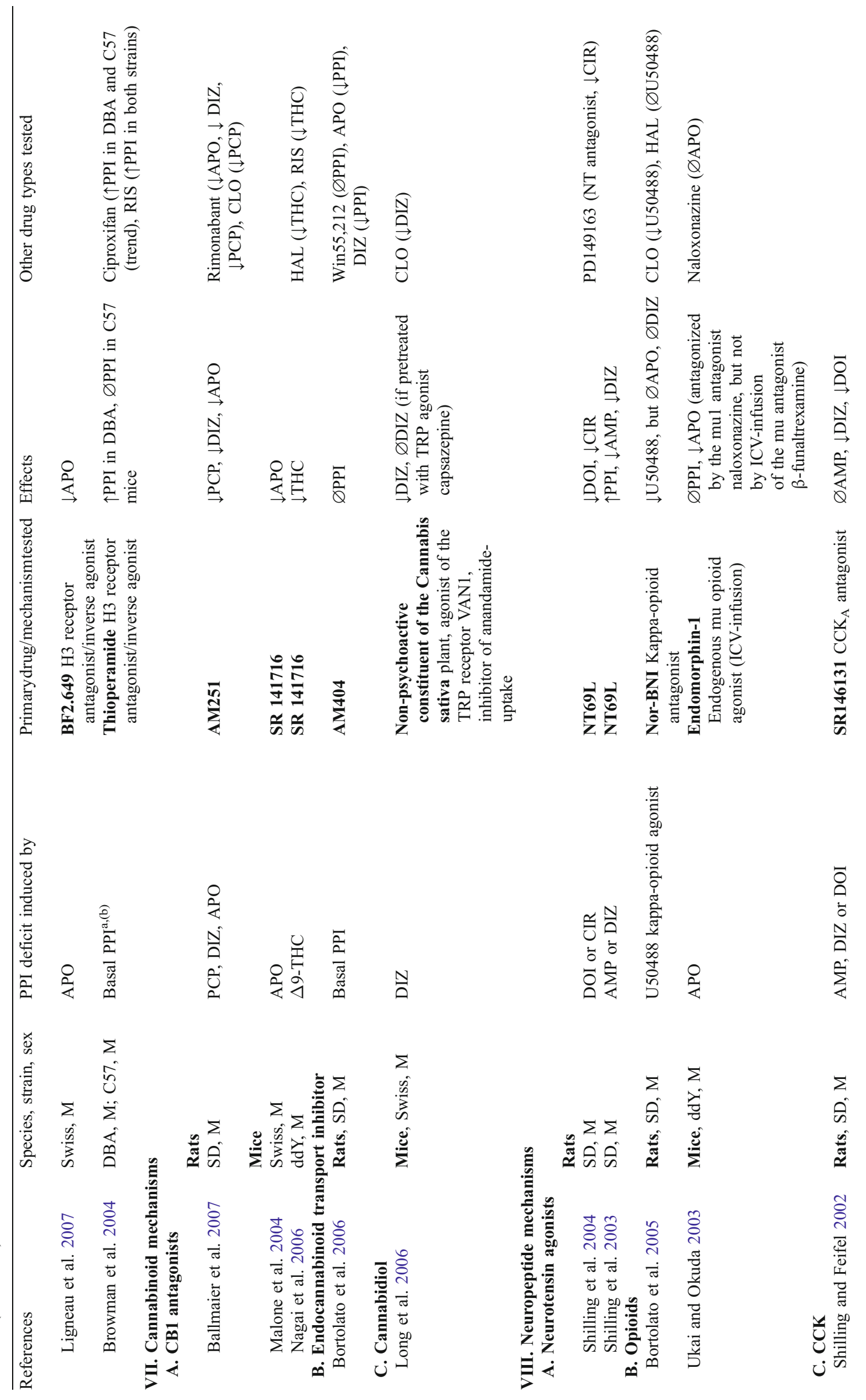



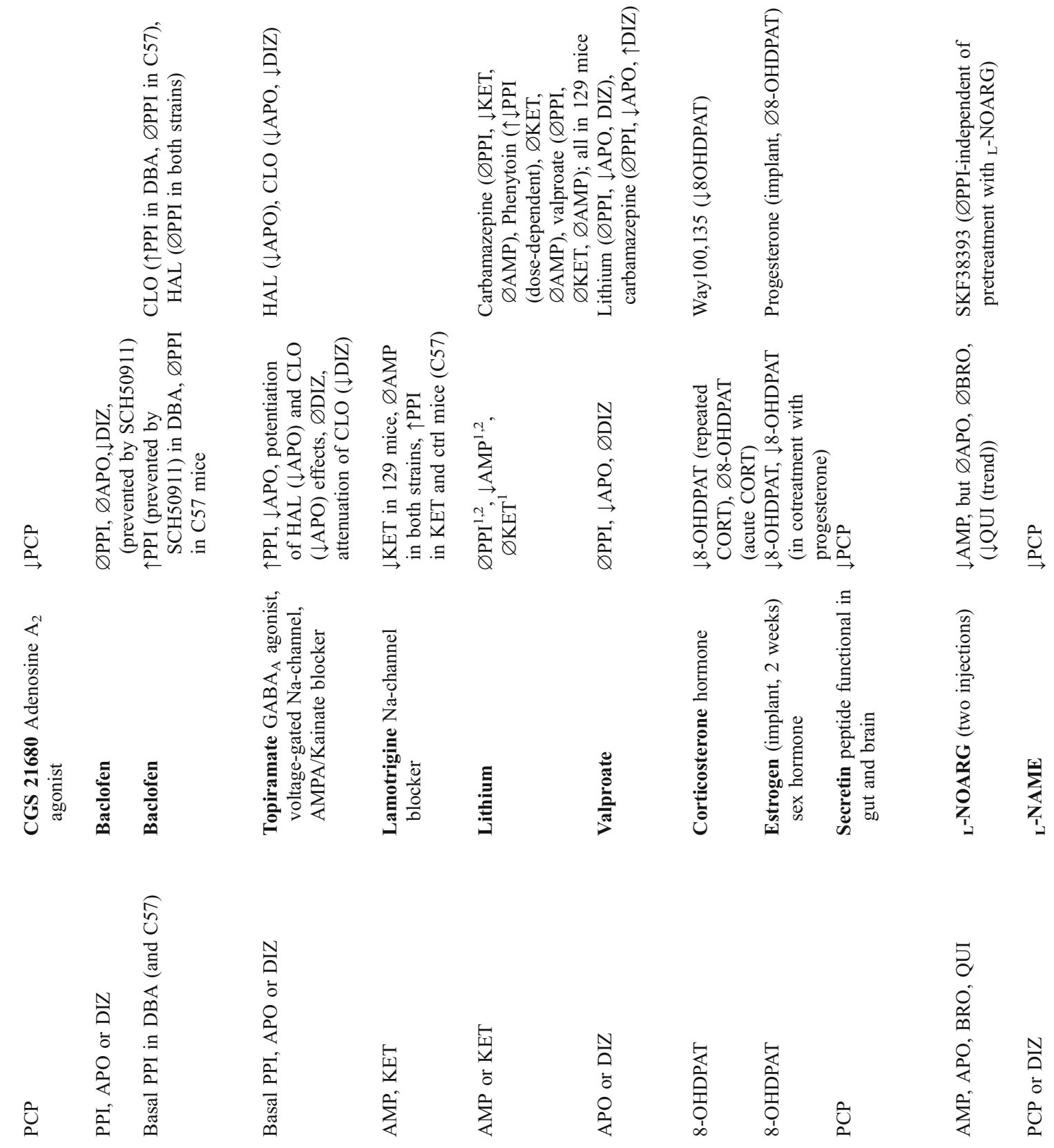

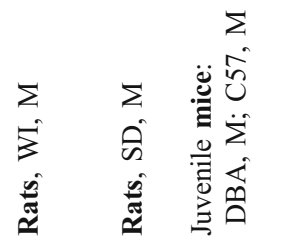
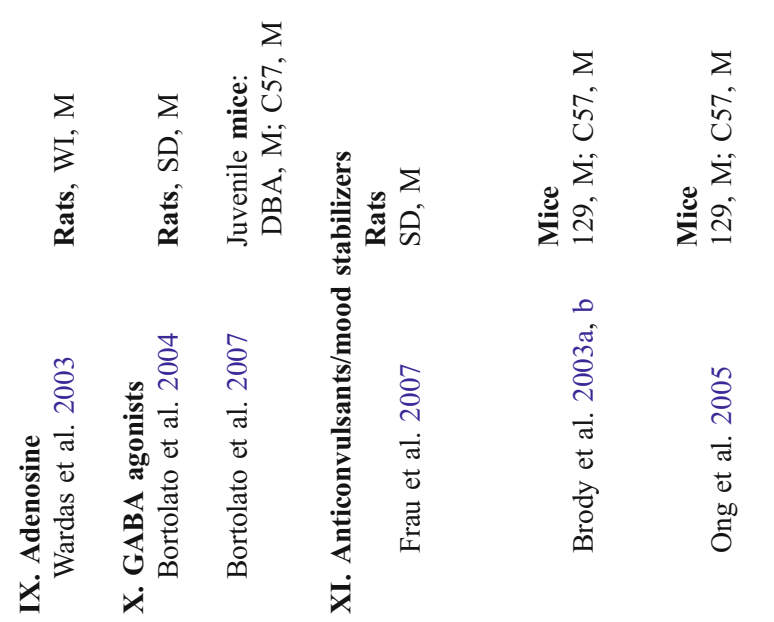

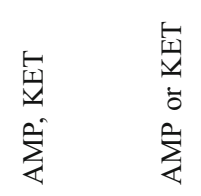

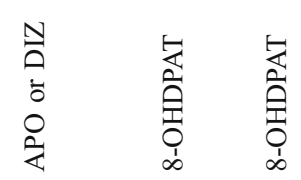

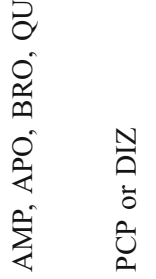
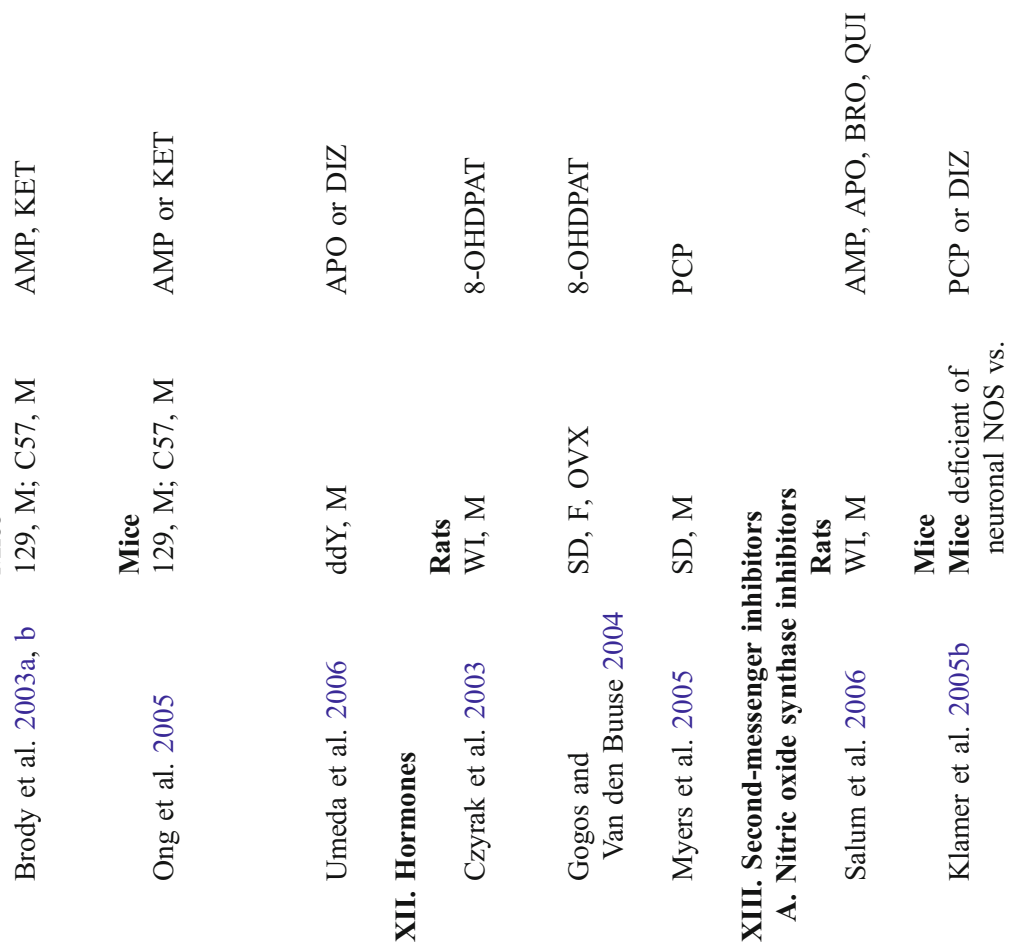


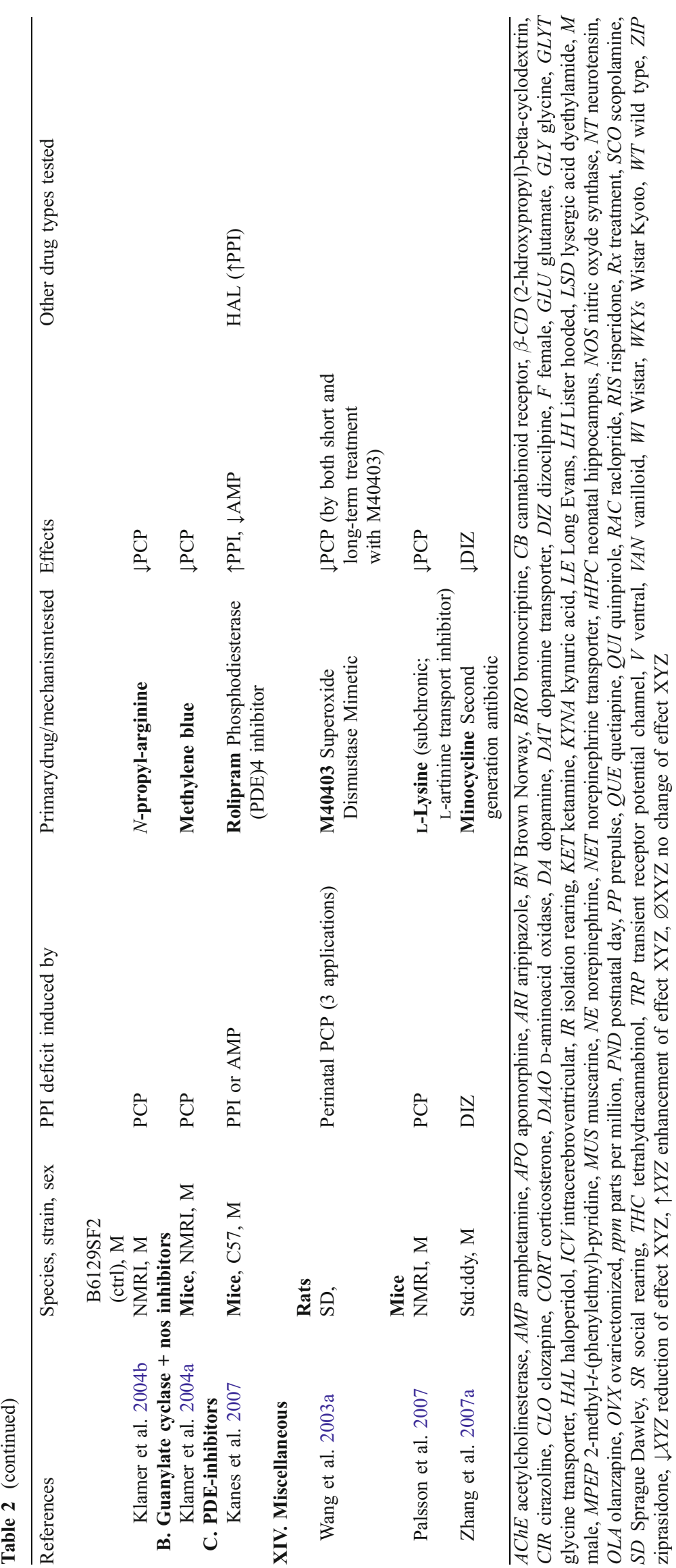



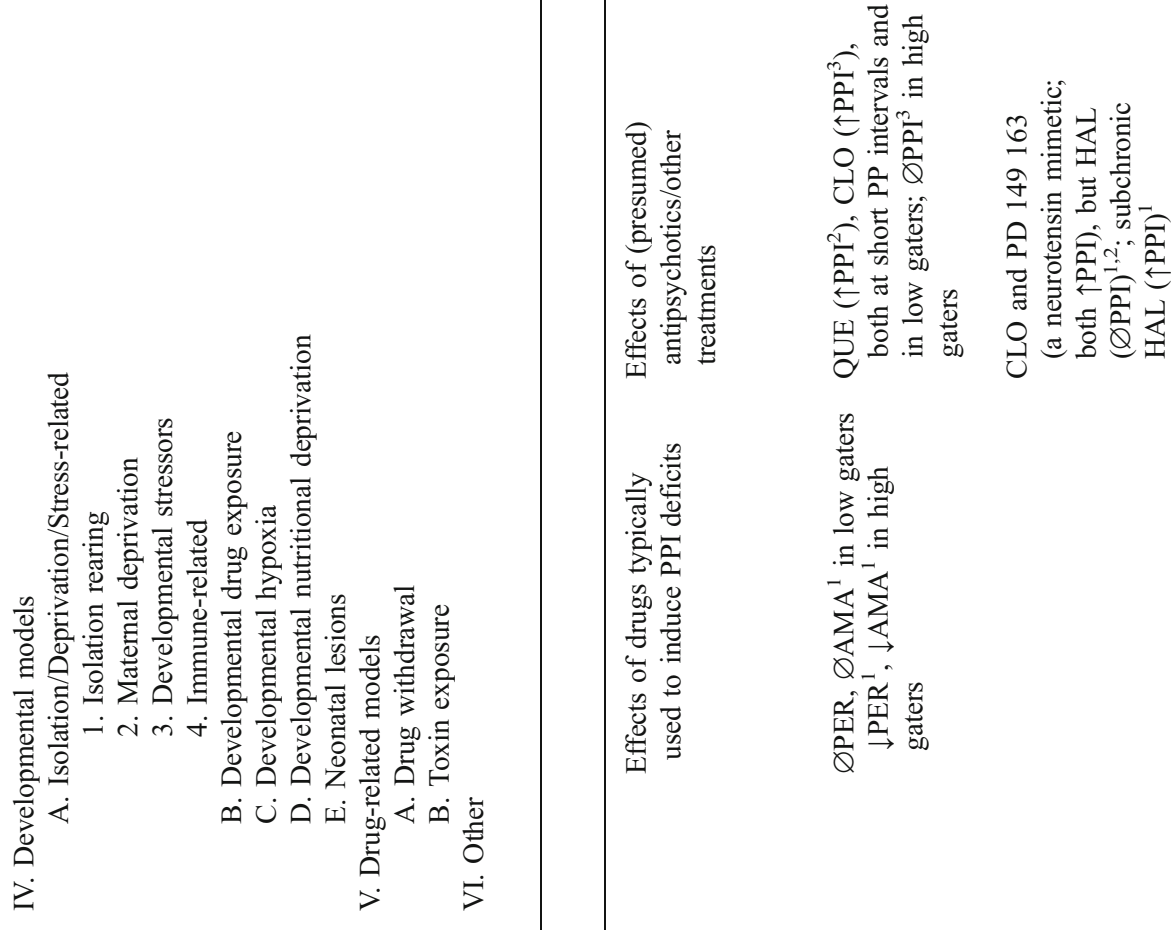

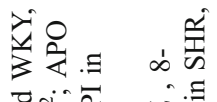

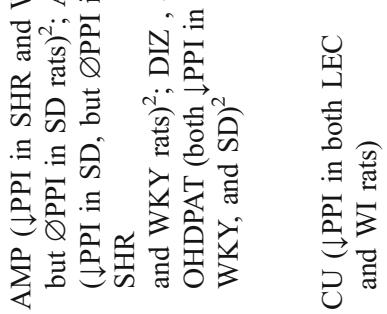

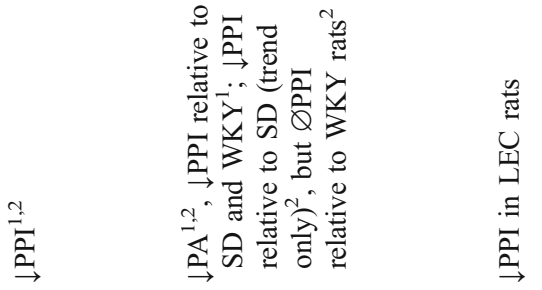

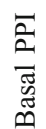
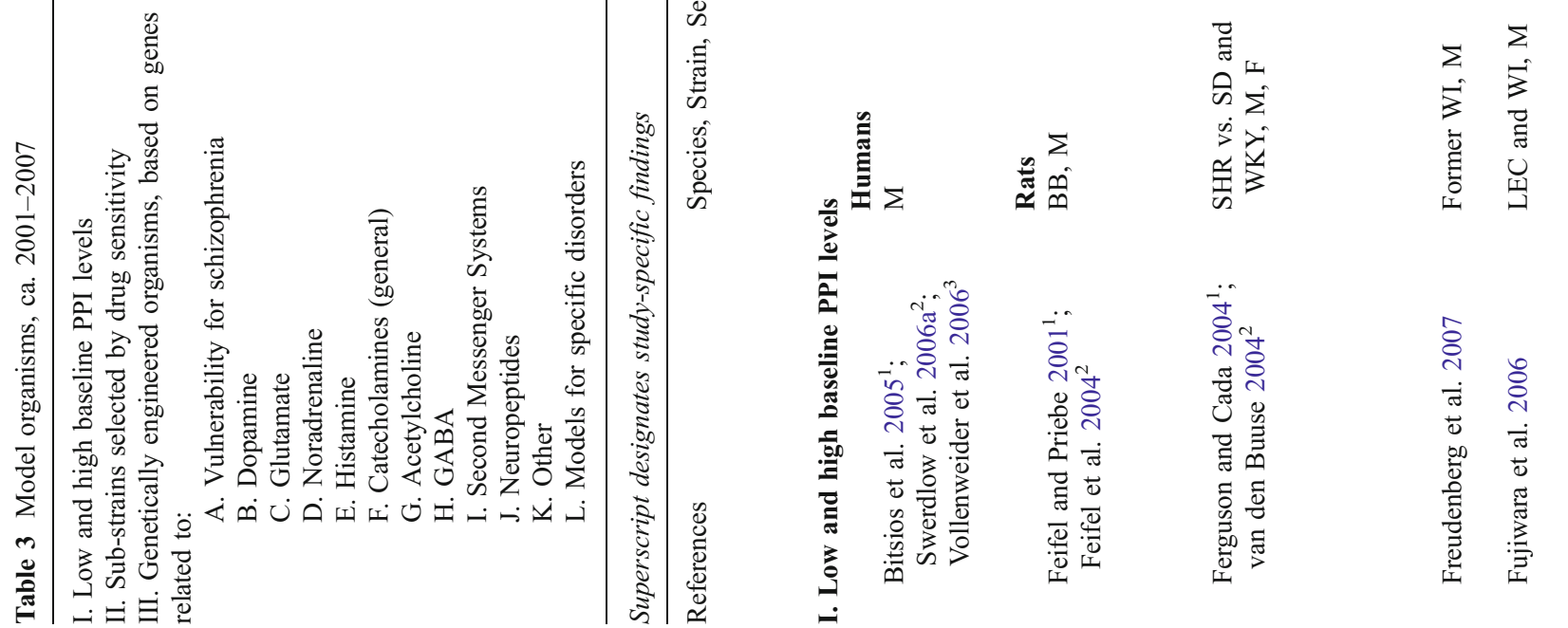

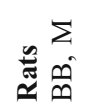

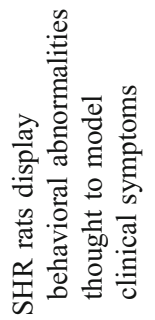

莺完

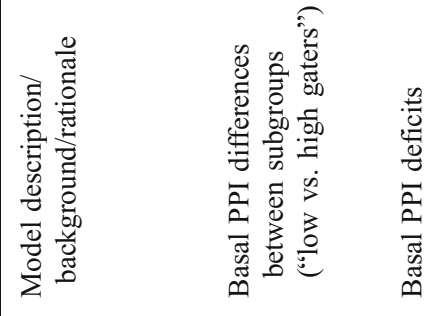
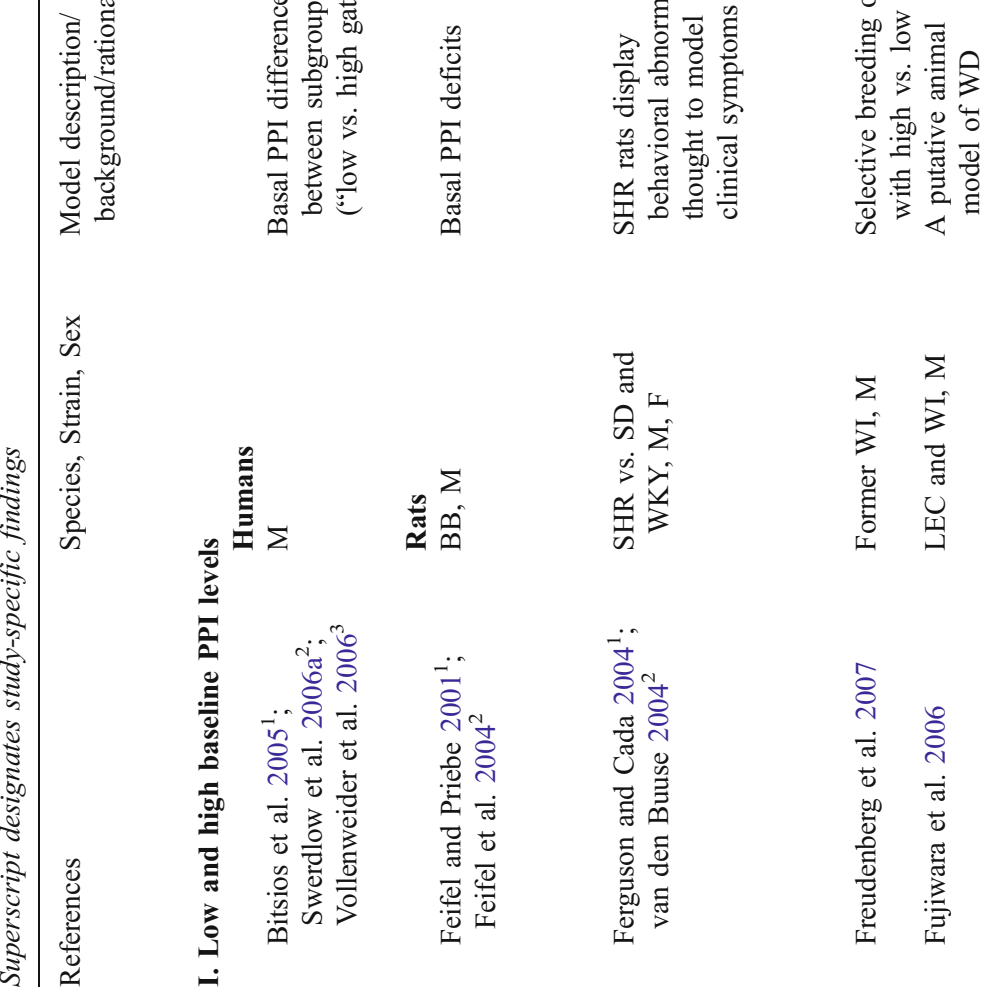


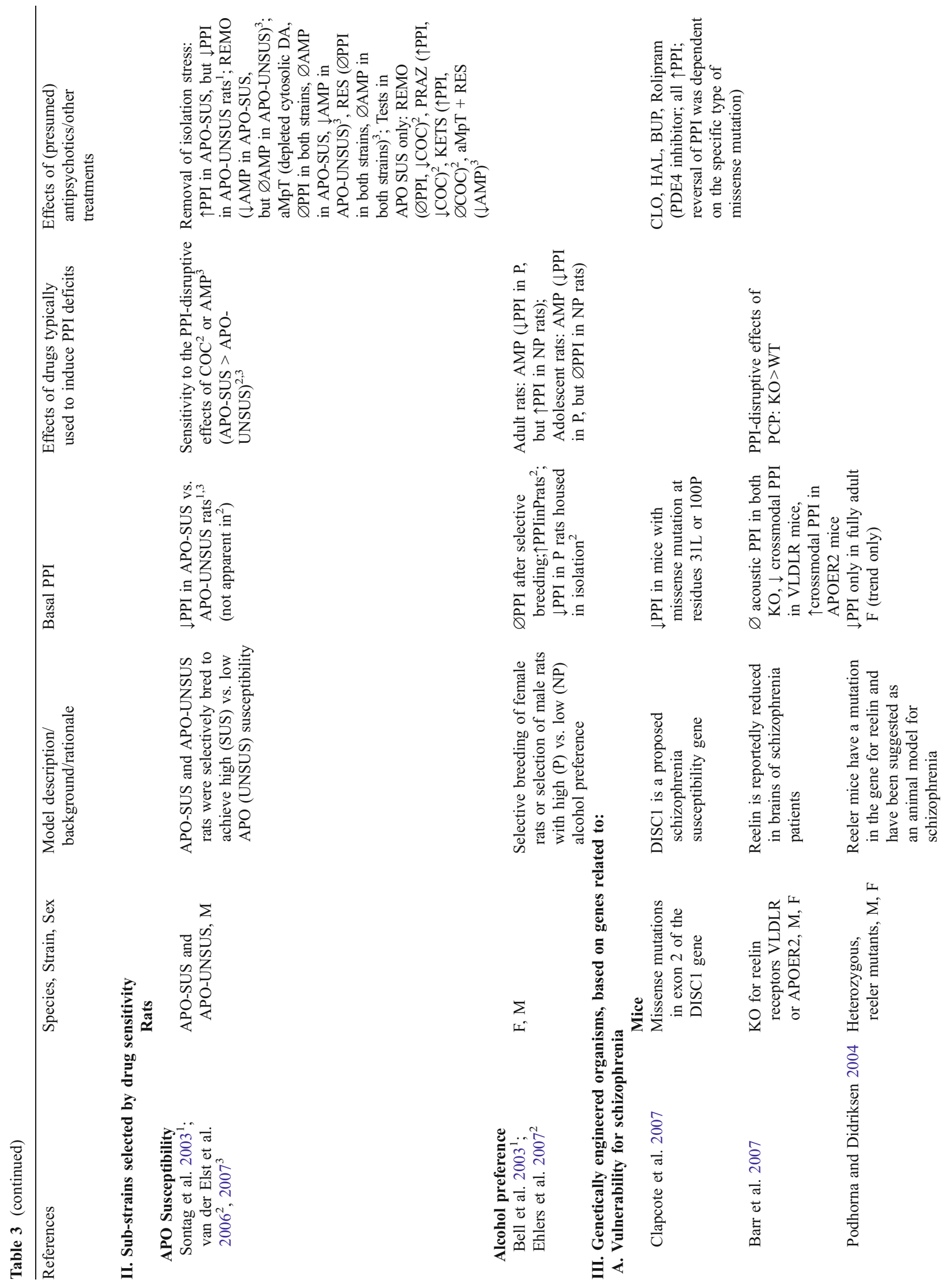




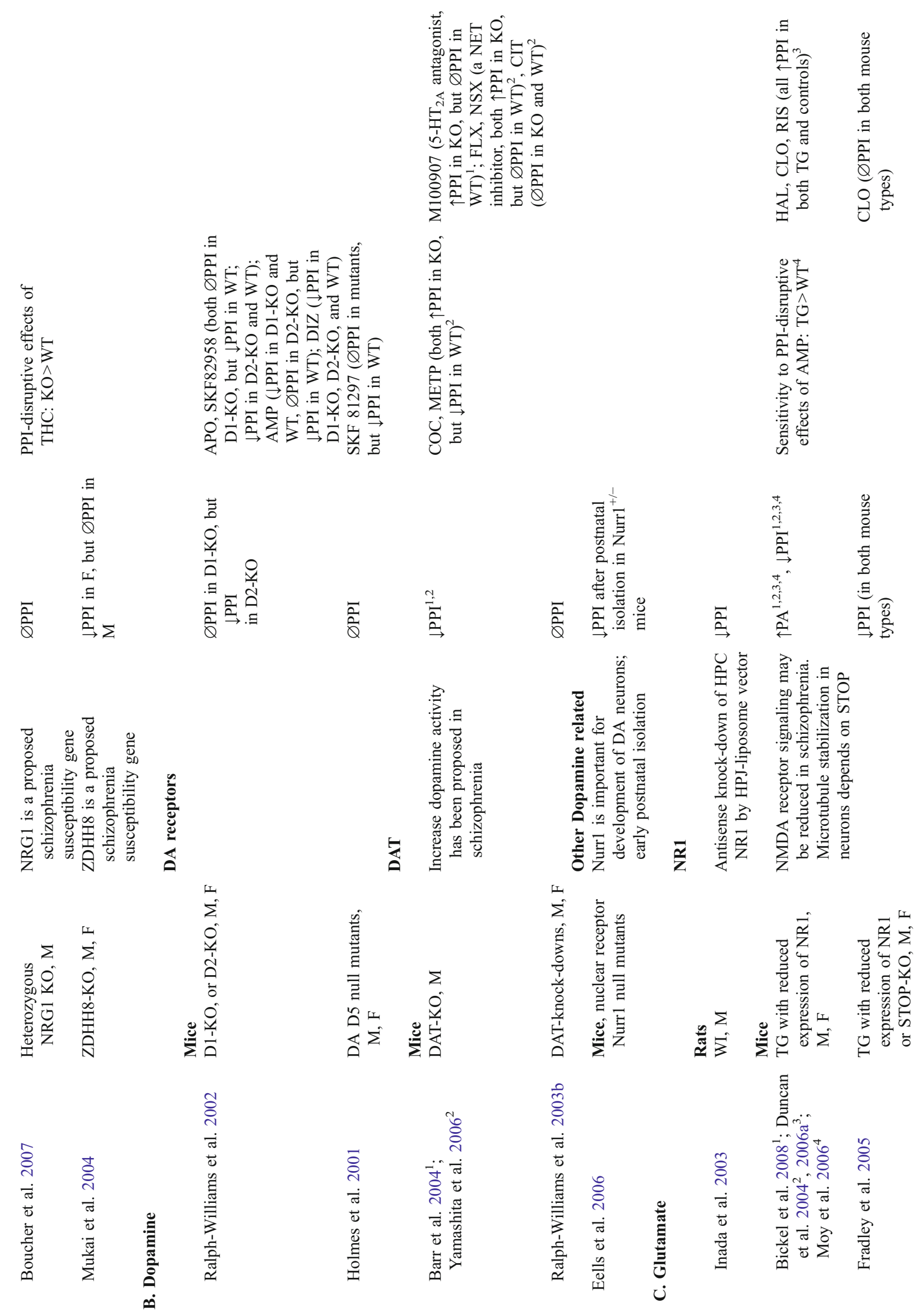




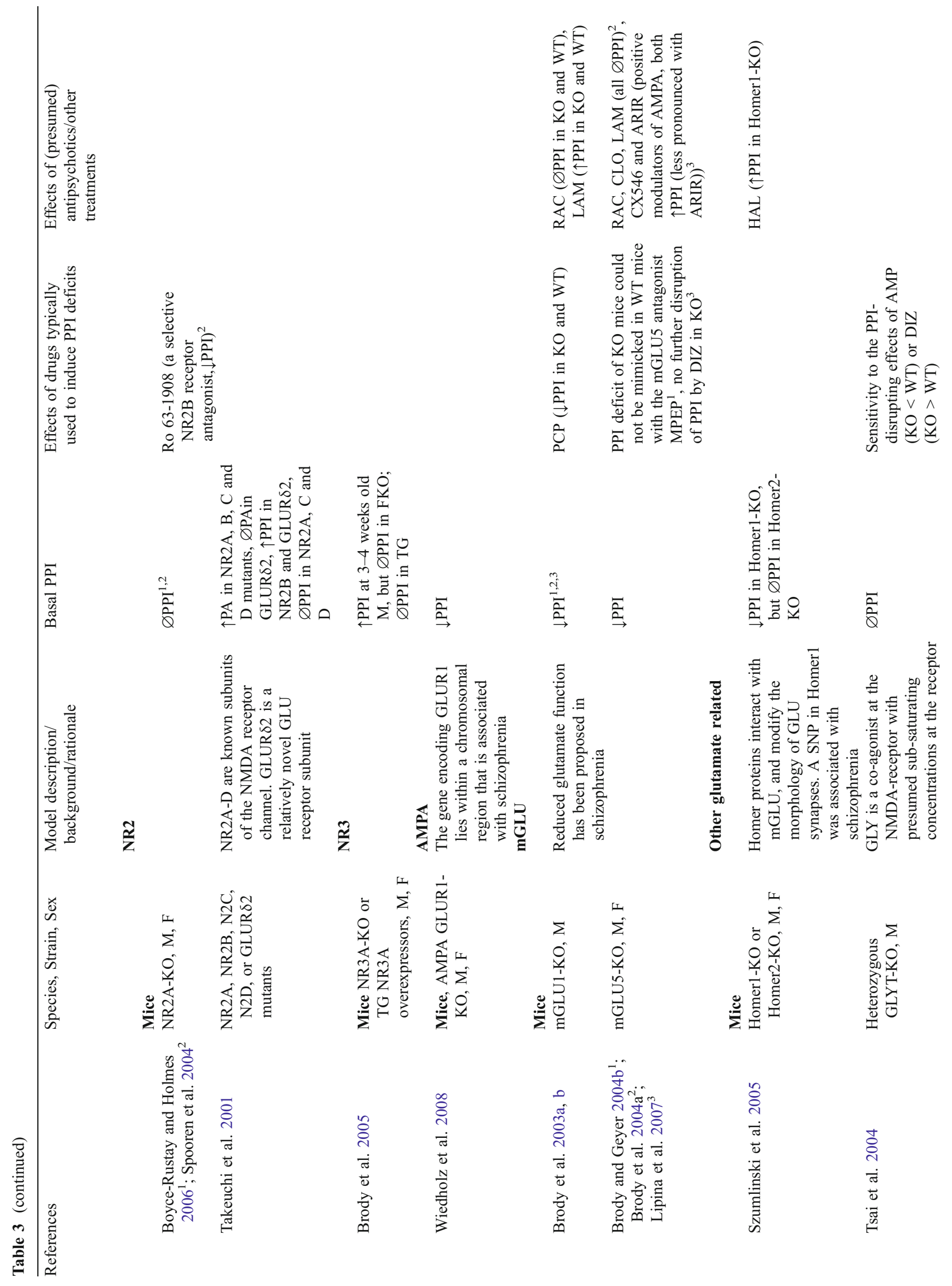



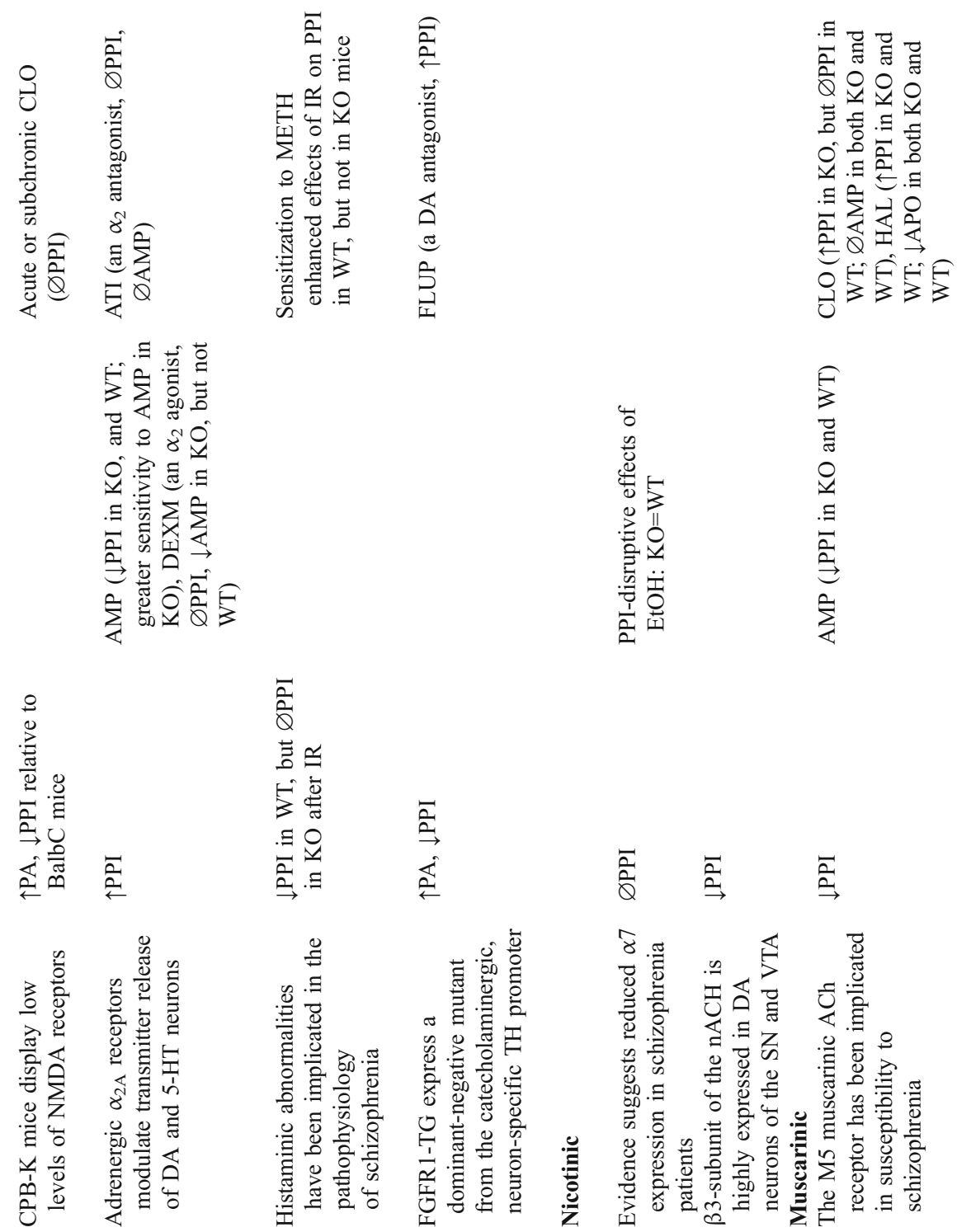

$\overrightarrow{\bar{Q}} \quad \stackrel{\vec{a}}{a} \quad \stackrel{\vec{a}}{\rightarrow}$

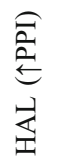

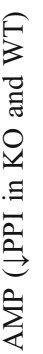

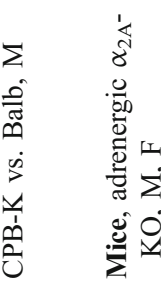

崖

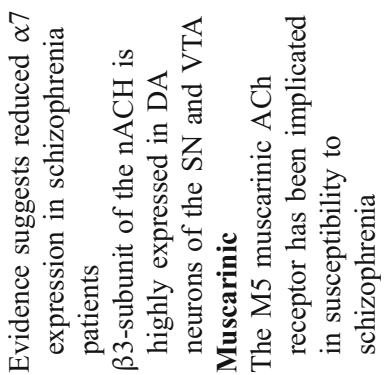

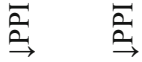

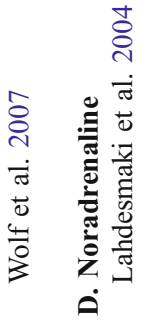

¿̇
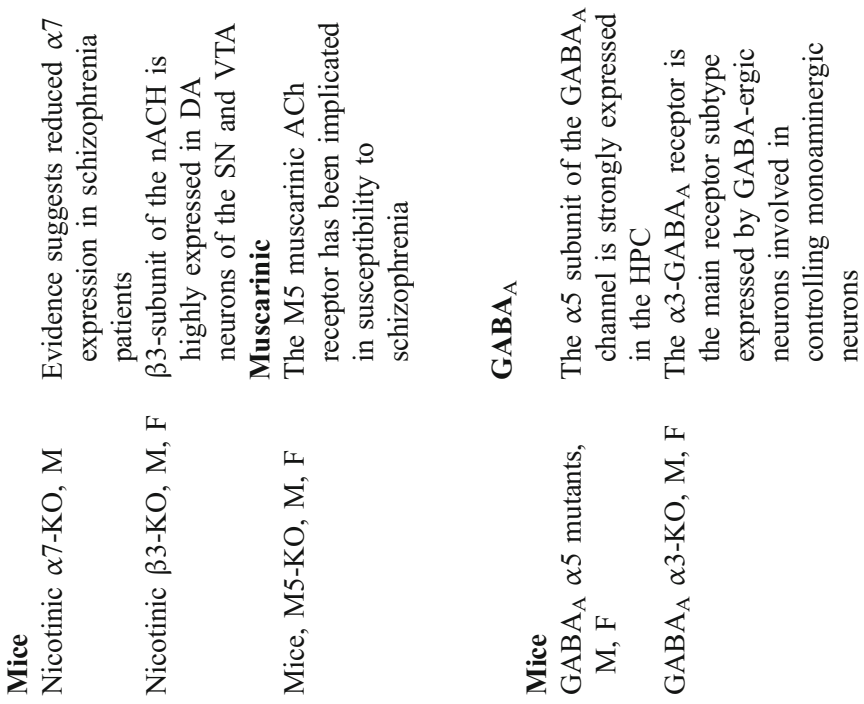

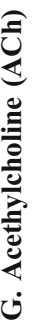

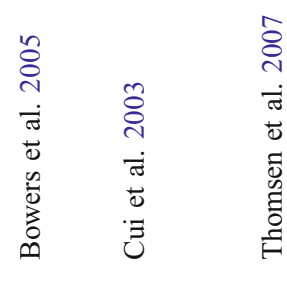
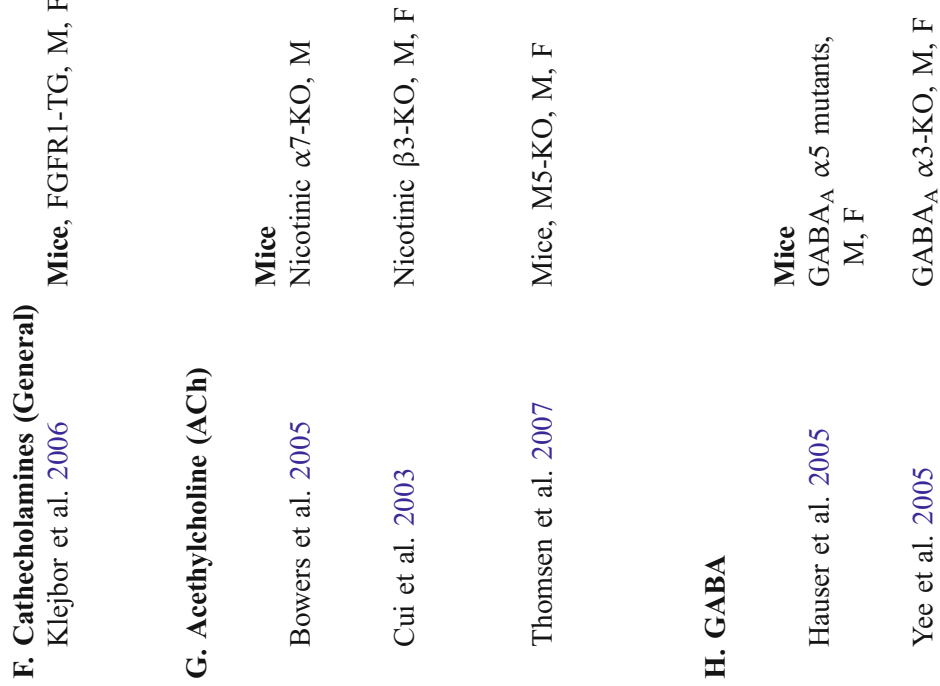

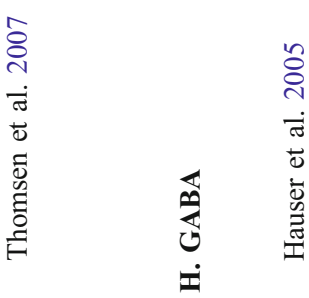

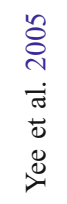




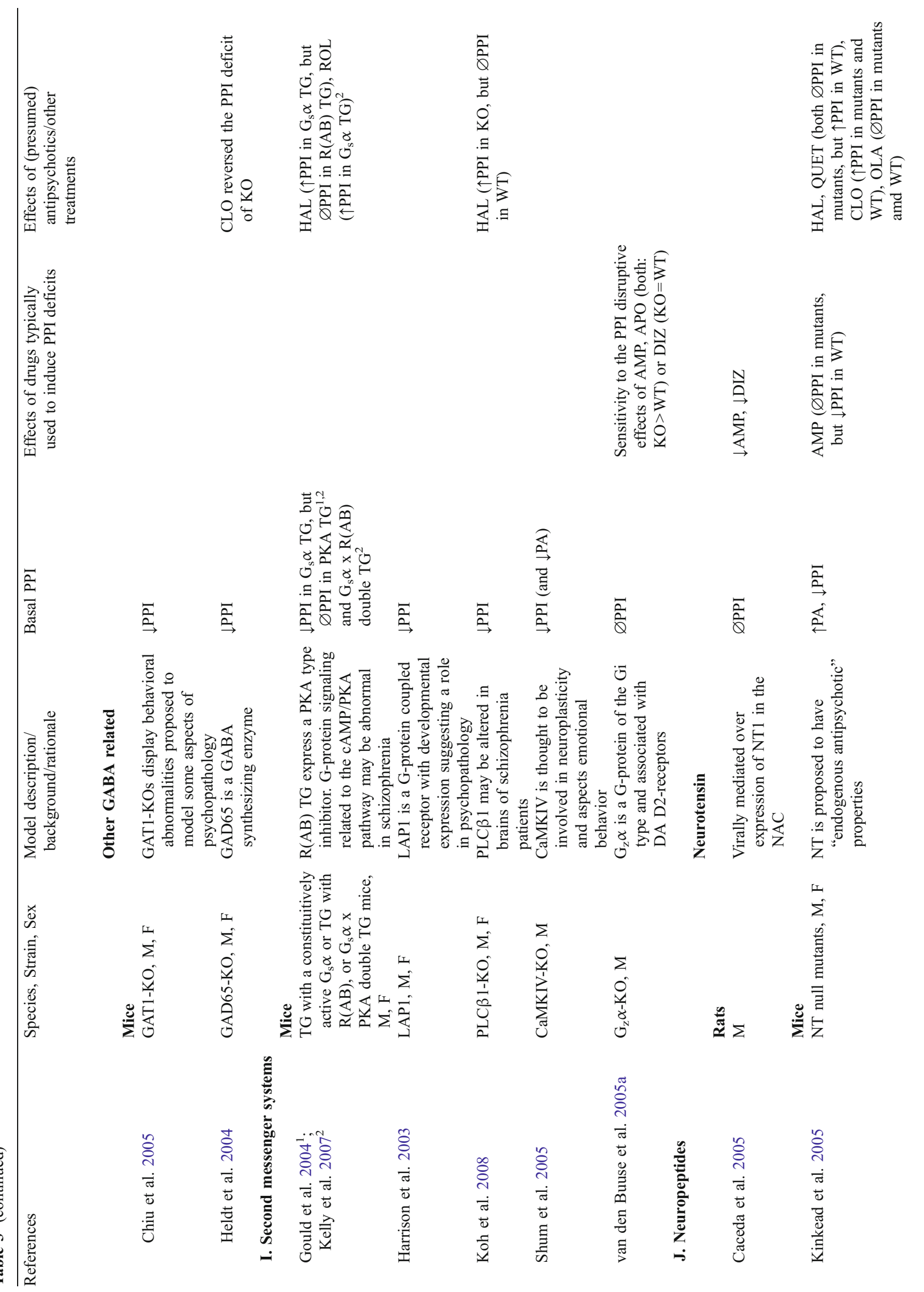



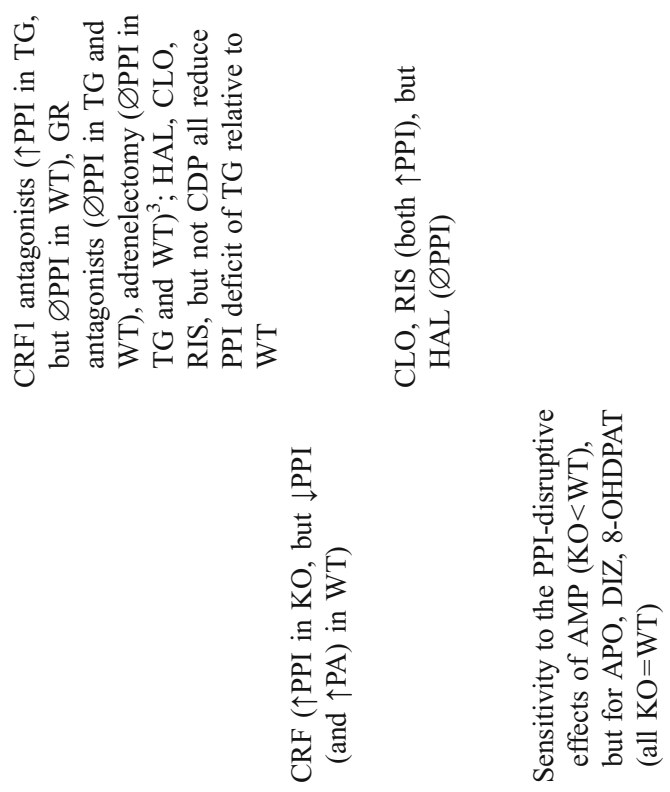

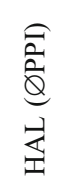

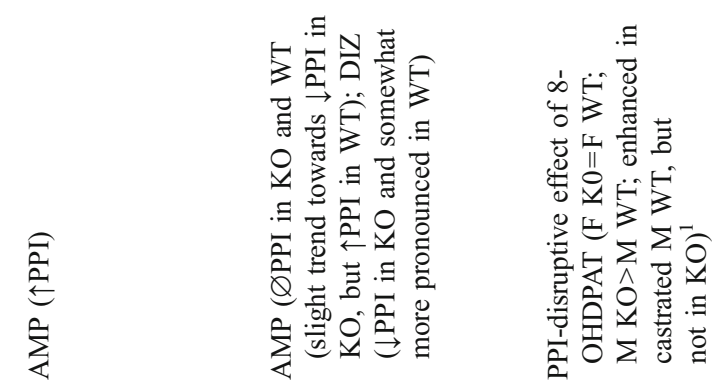

$\stackrel{\vec{a}}{\rightarrow}$

$\underset{\stackrel{a}{\leftrightarrows}}{\stackrel{a}{\leftrightarrows}}$

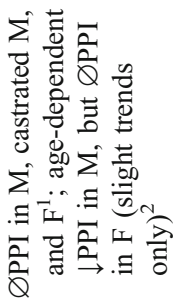<smiles>[CH]1CCC1</smiles>

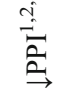

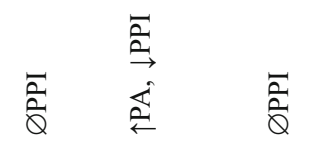

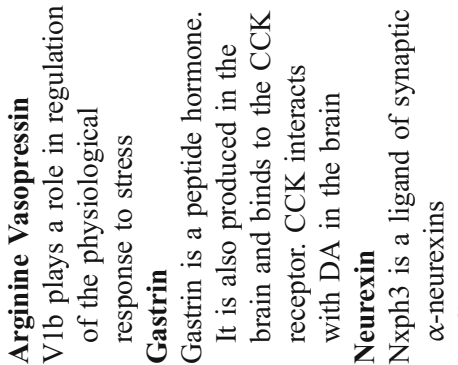

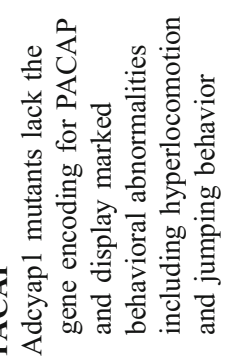

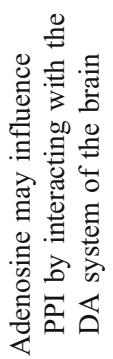

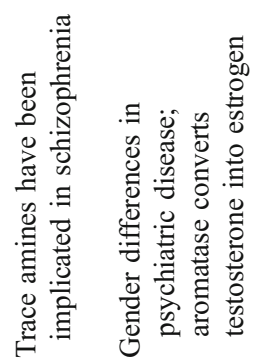<smiles>CC1CCC[C@H]1C1CC1</smiles>

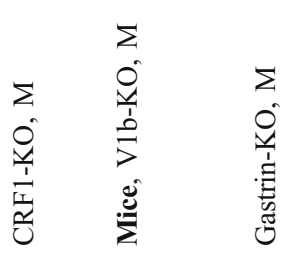

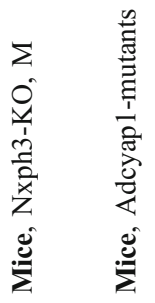

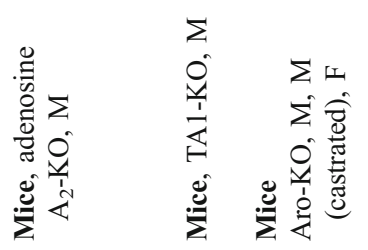

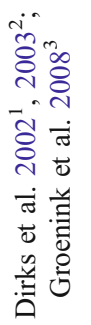

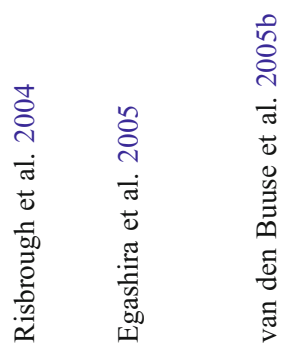

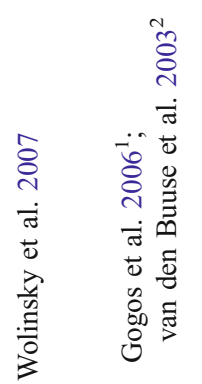




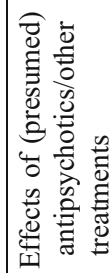

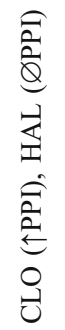

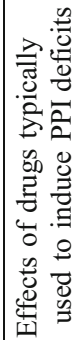

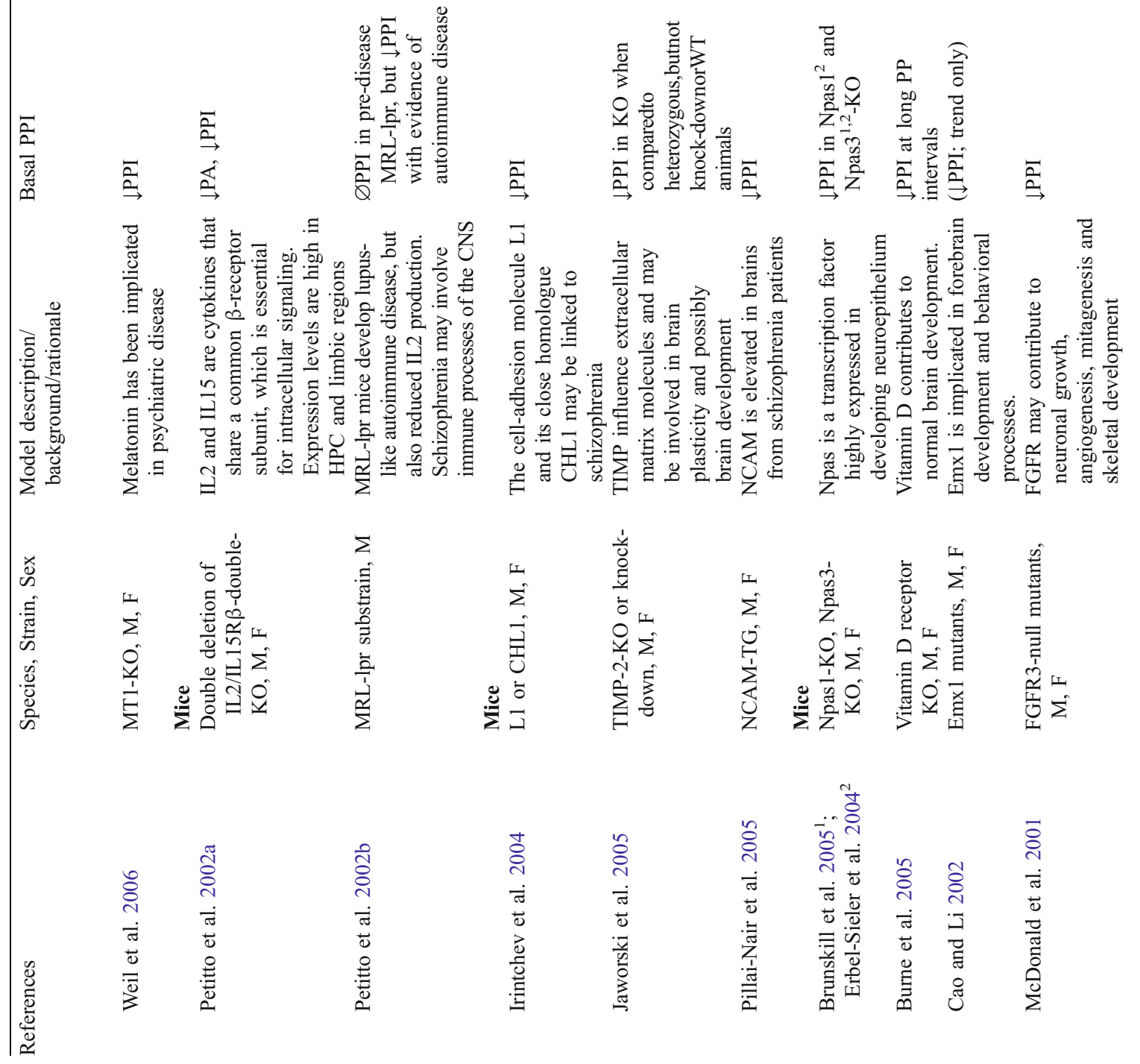




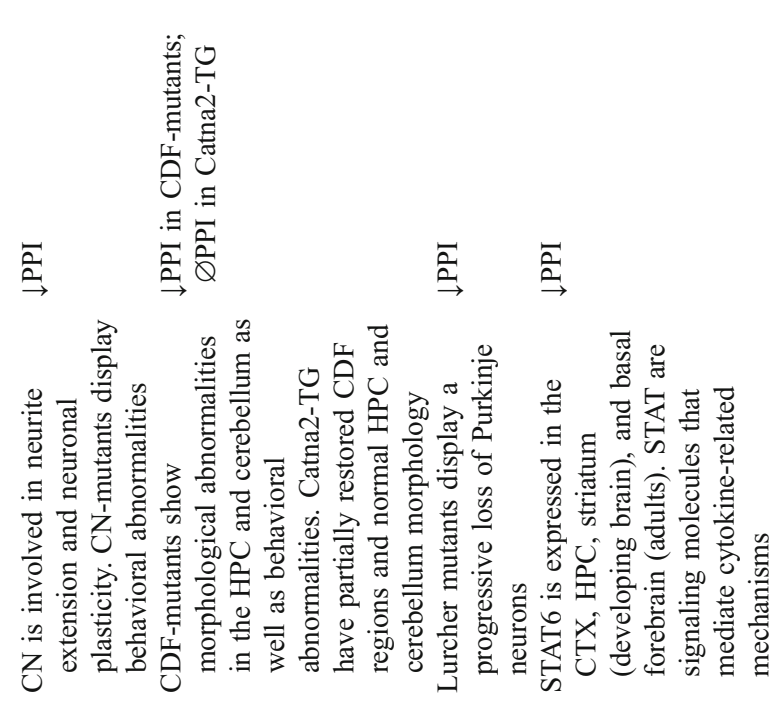

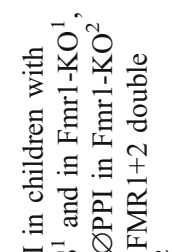

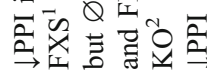
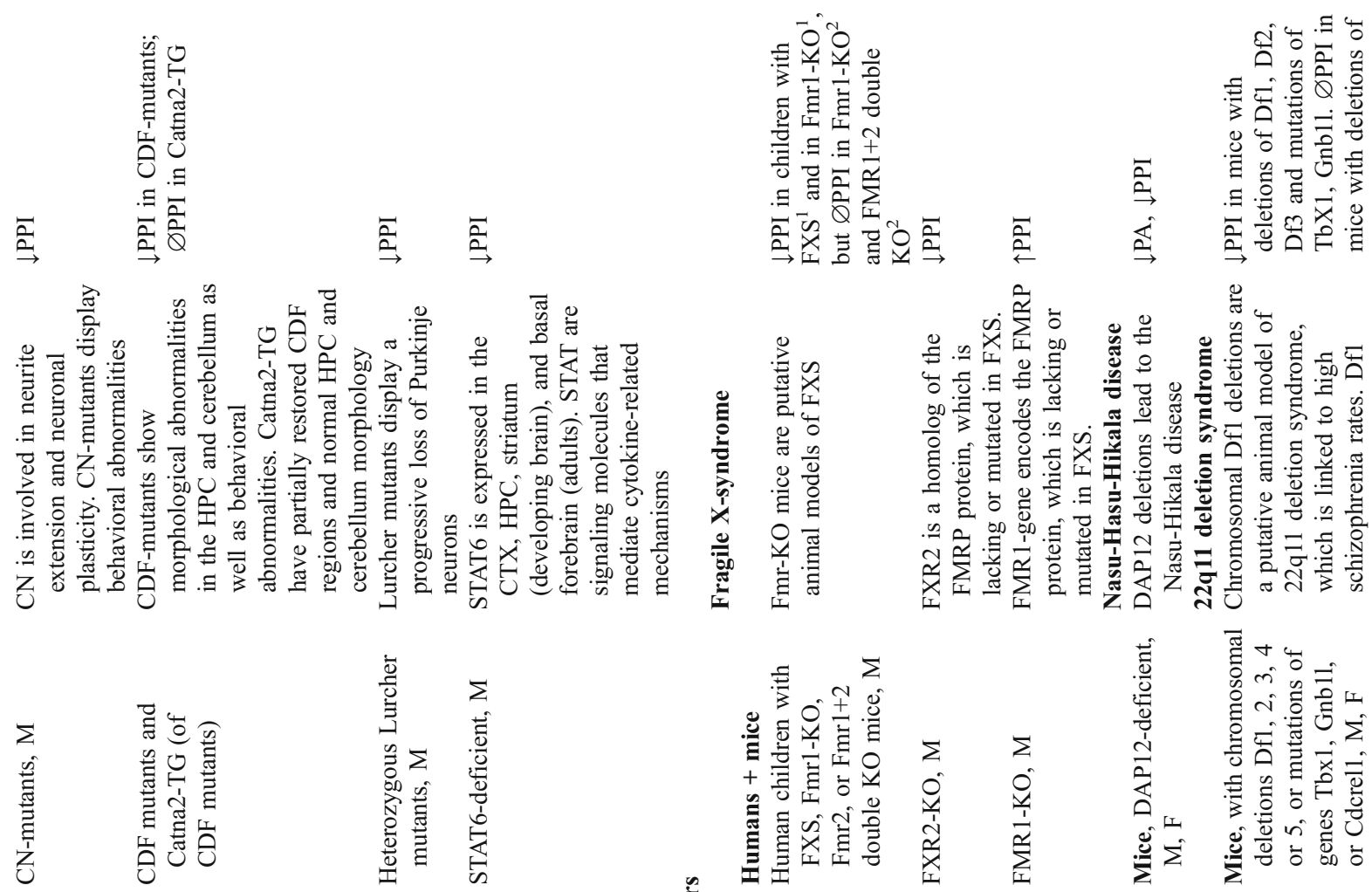

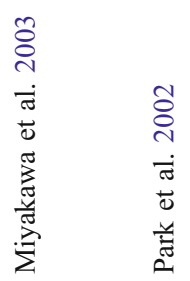
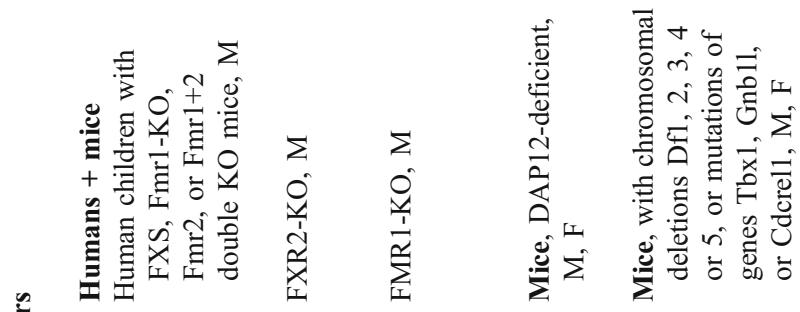

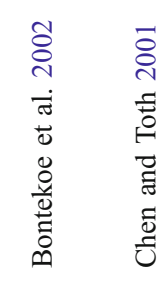

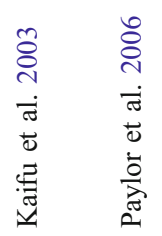



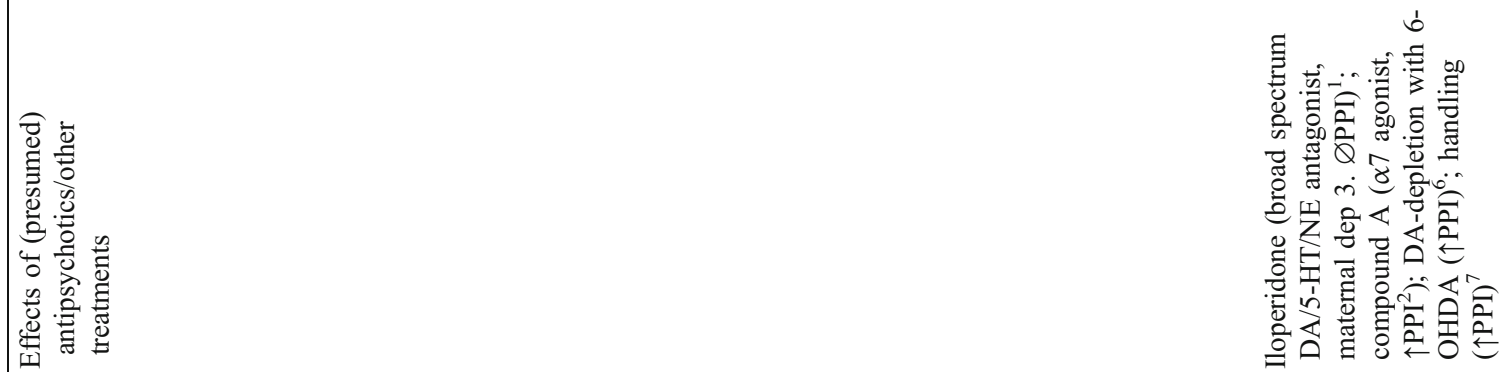

范

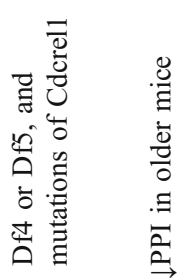
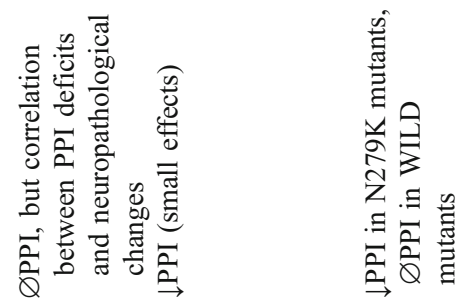

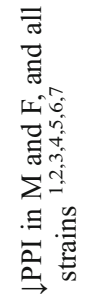
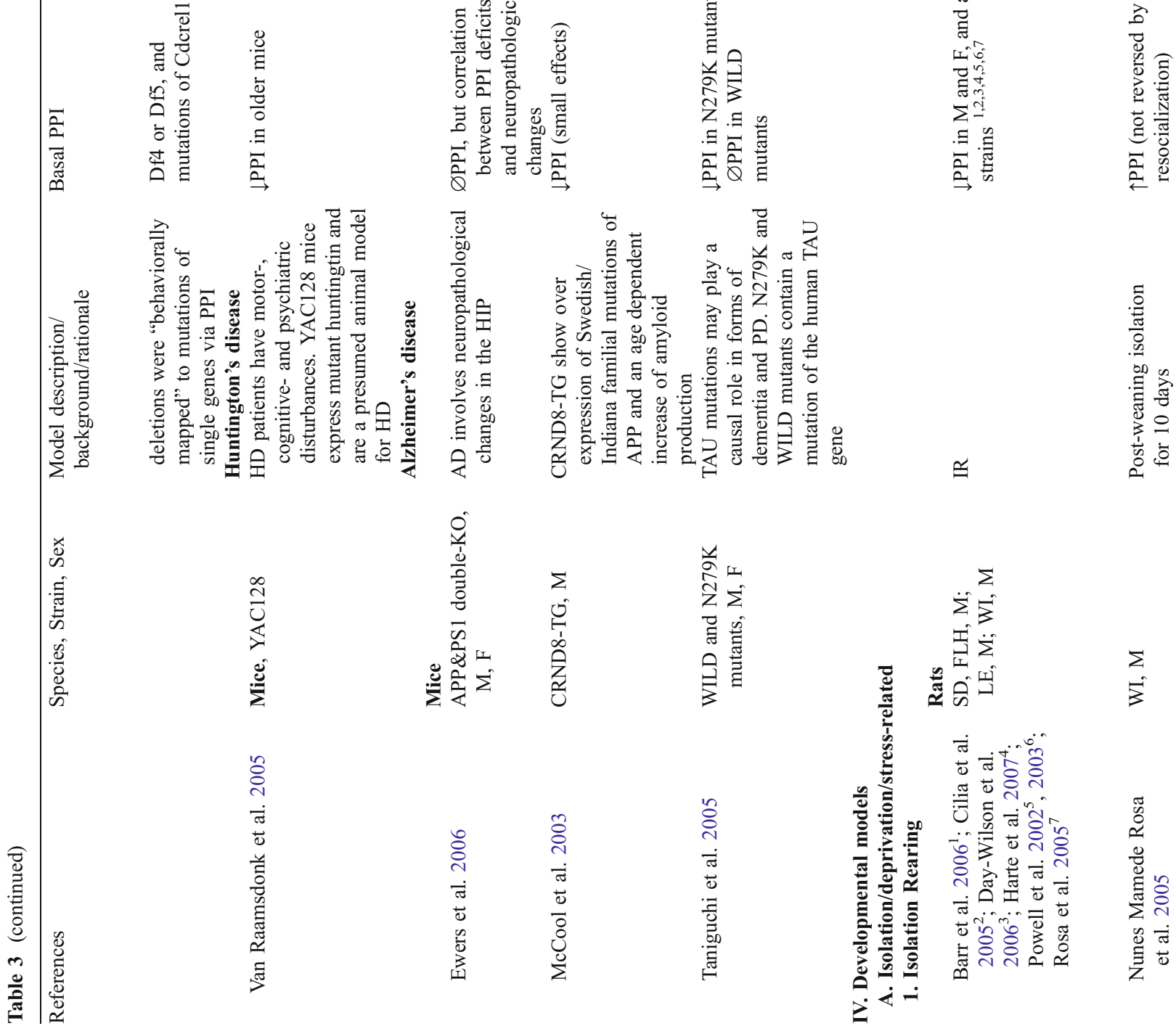

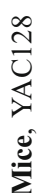

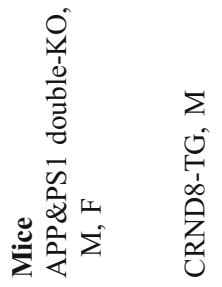

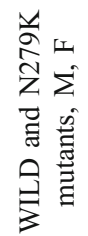

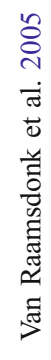

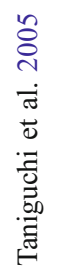

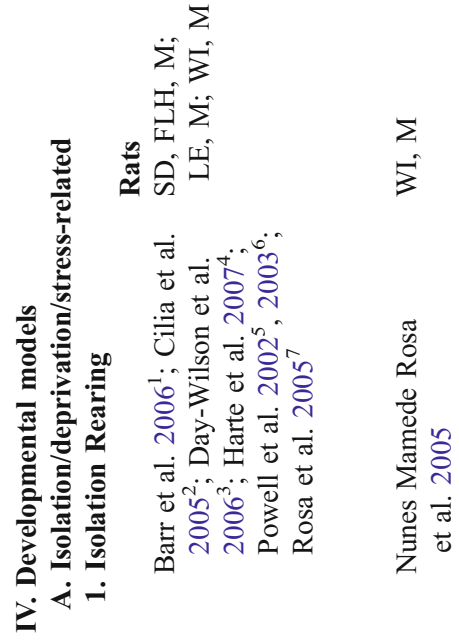



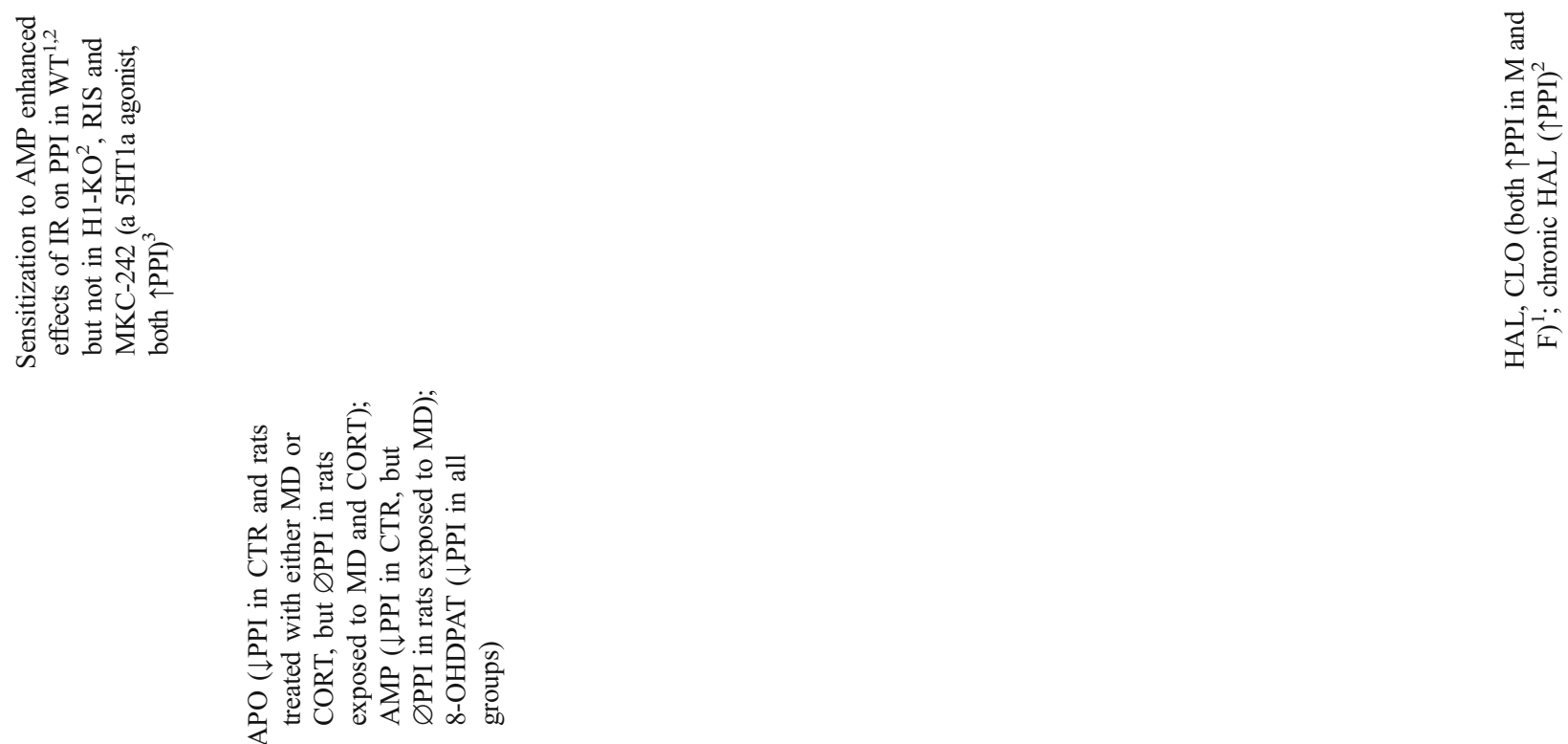

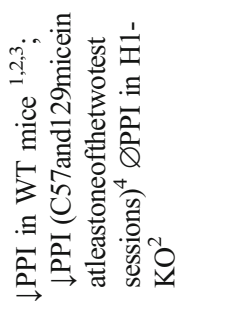

$\cong$

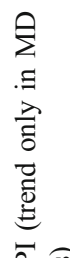

高要

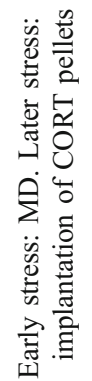

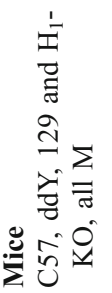

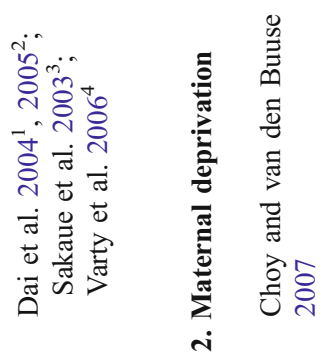

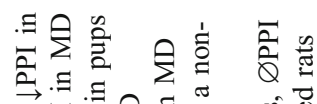

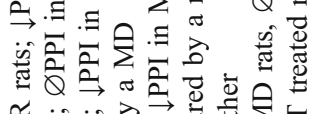

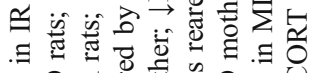

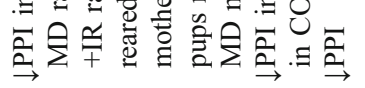

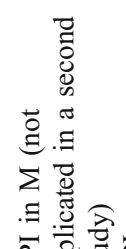

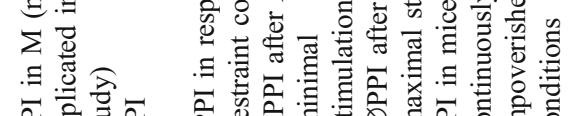

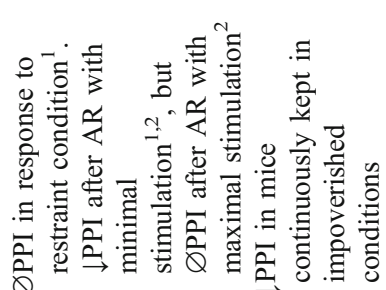

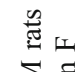
$\sum \Xi$ 高弯 菏

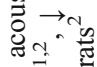
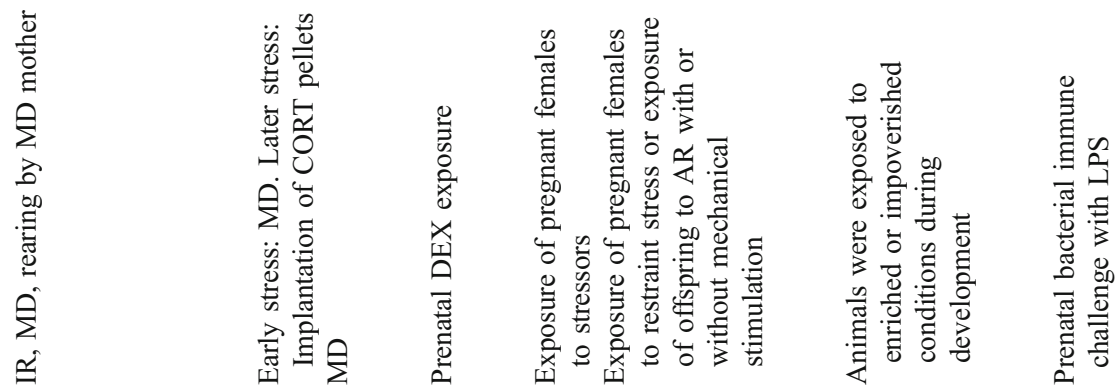

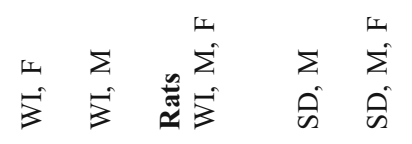

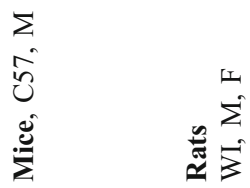

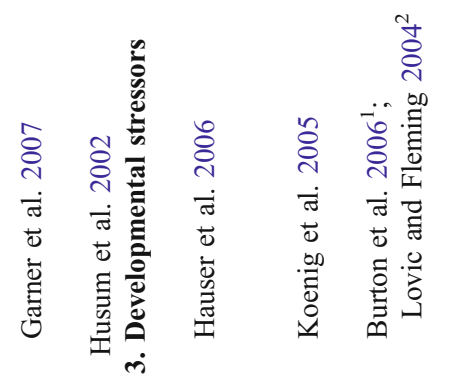

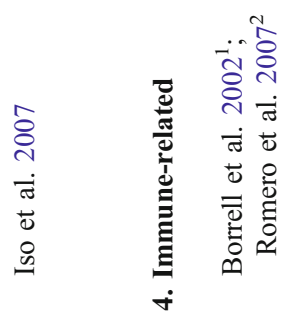



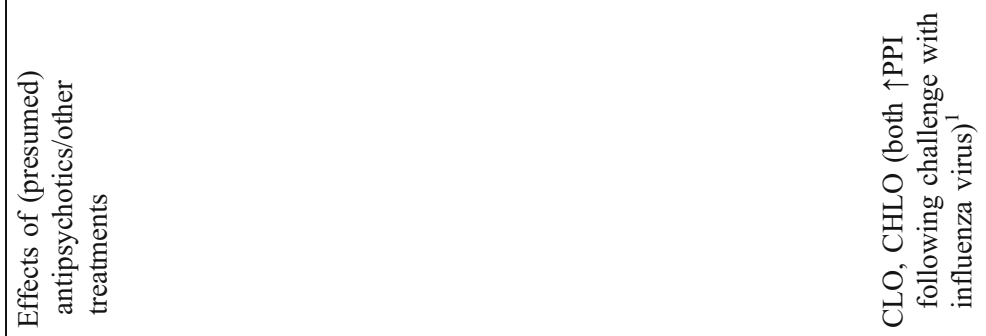

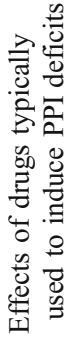

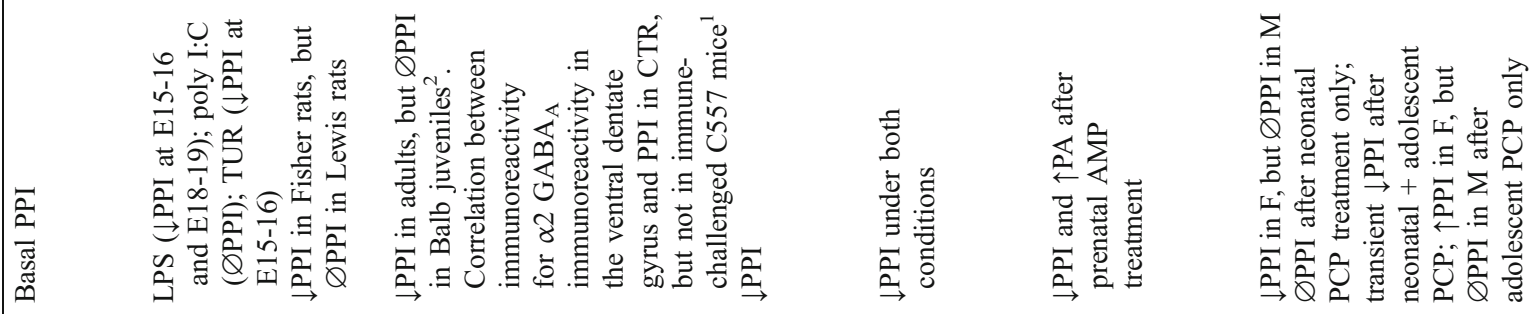
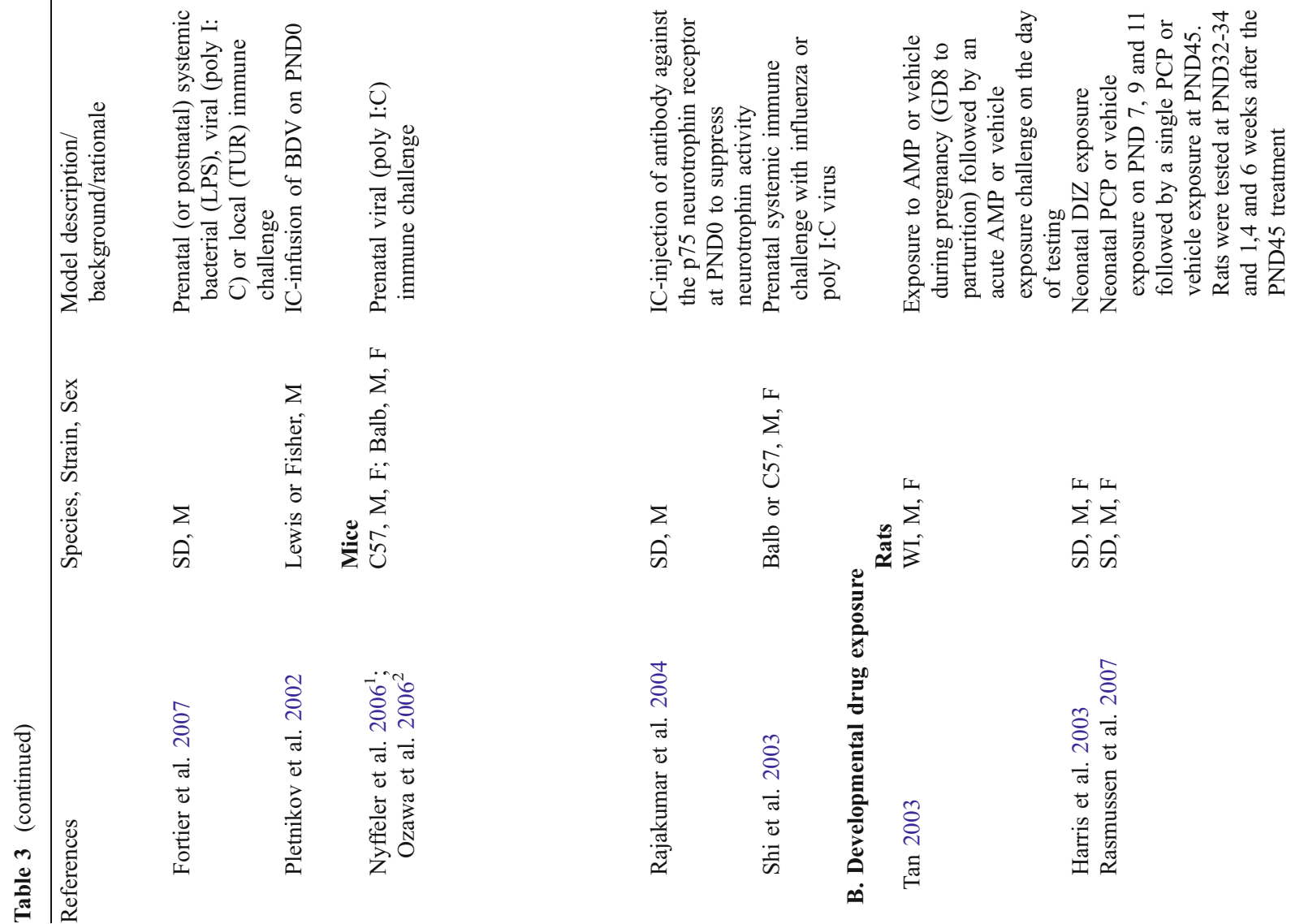

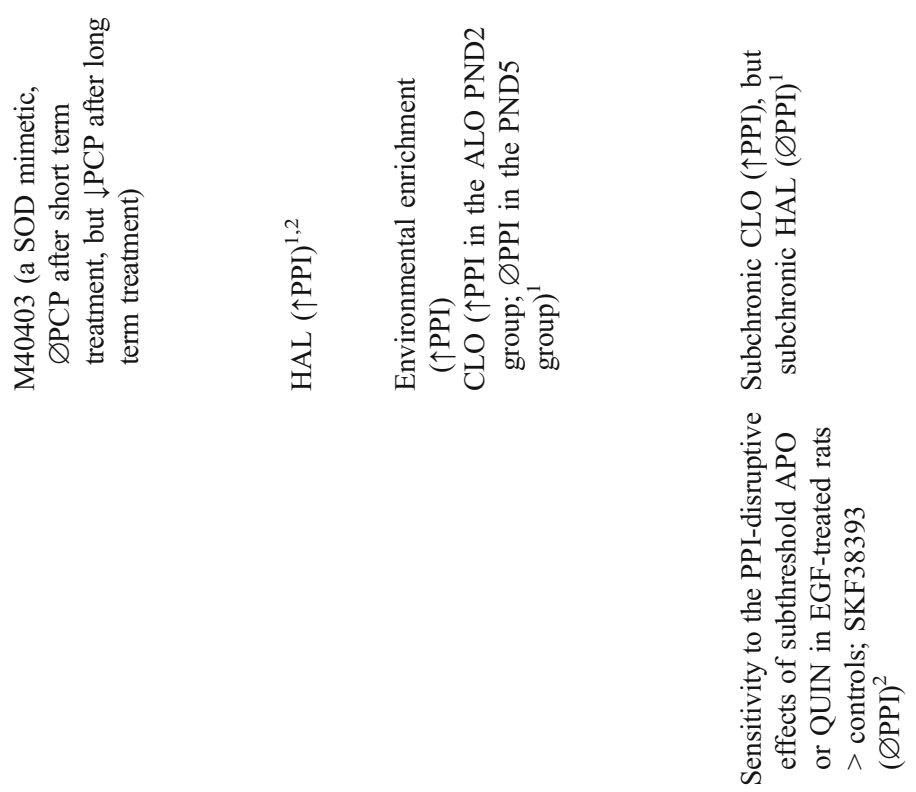

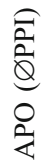
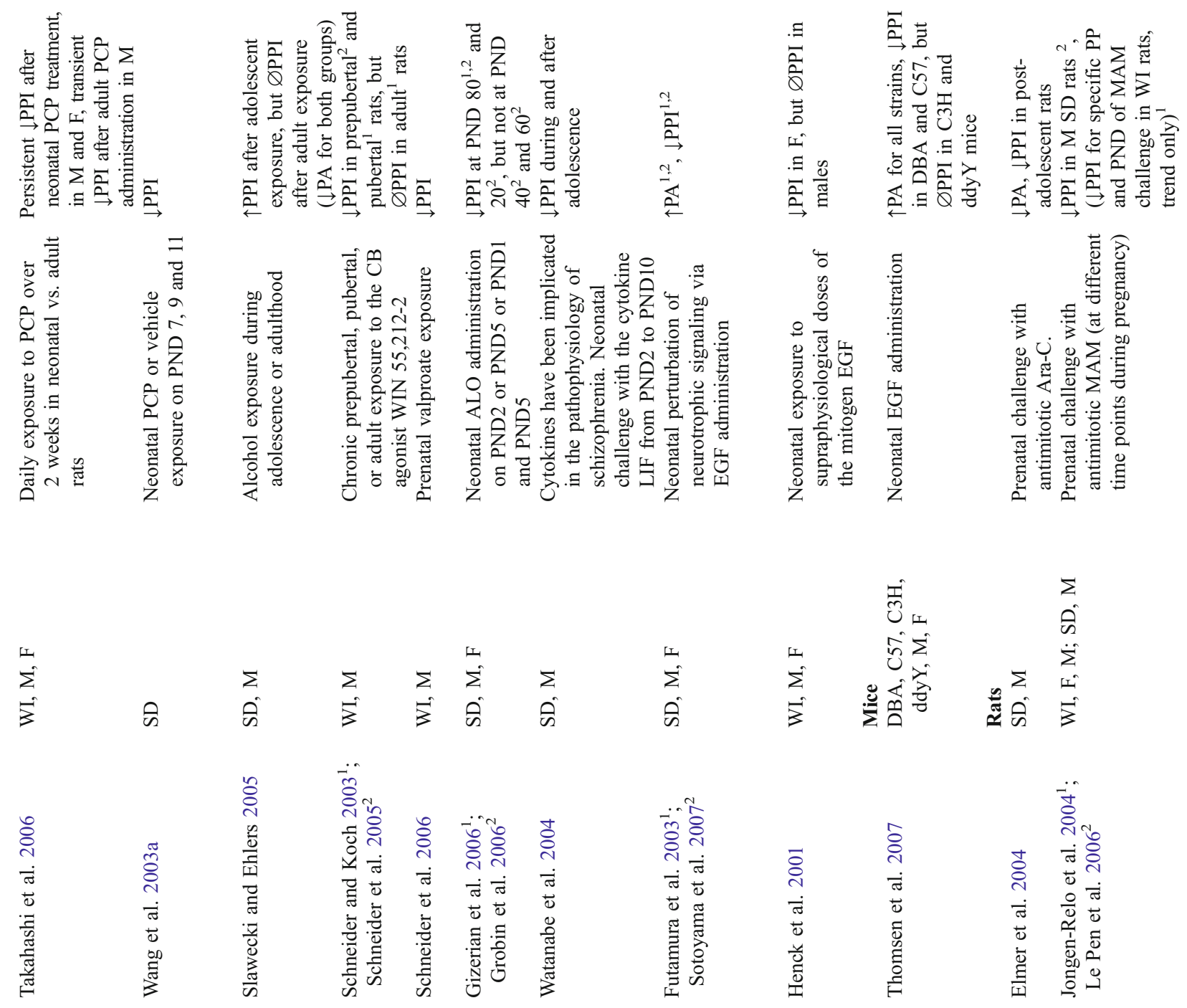


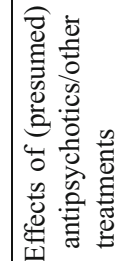

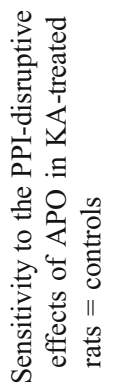

₹

กิ

会文

离

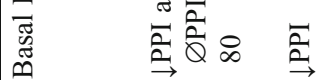

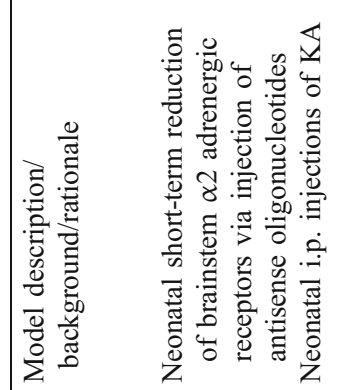

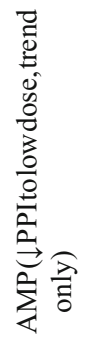

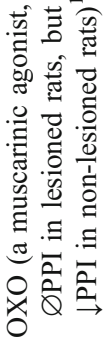

急 咅喀

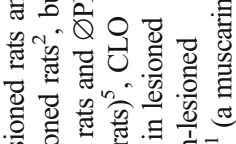

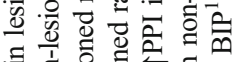

Q.

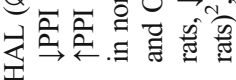

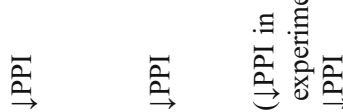

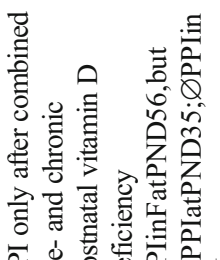

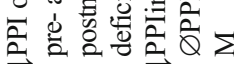
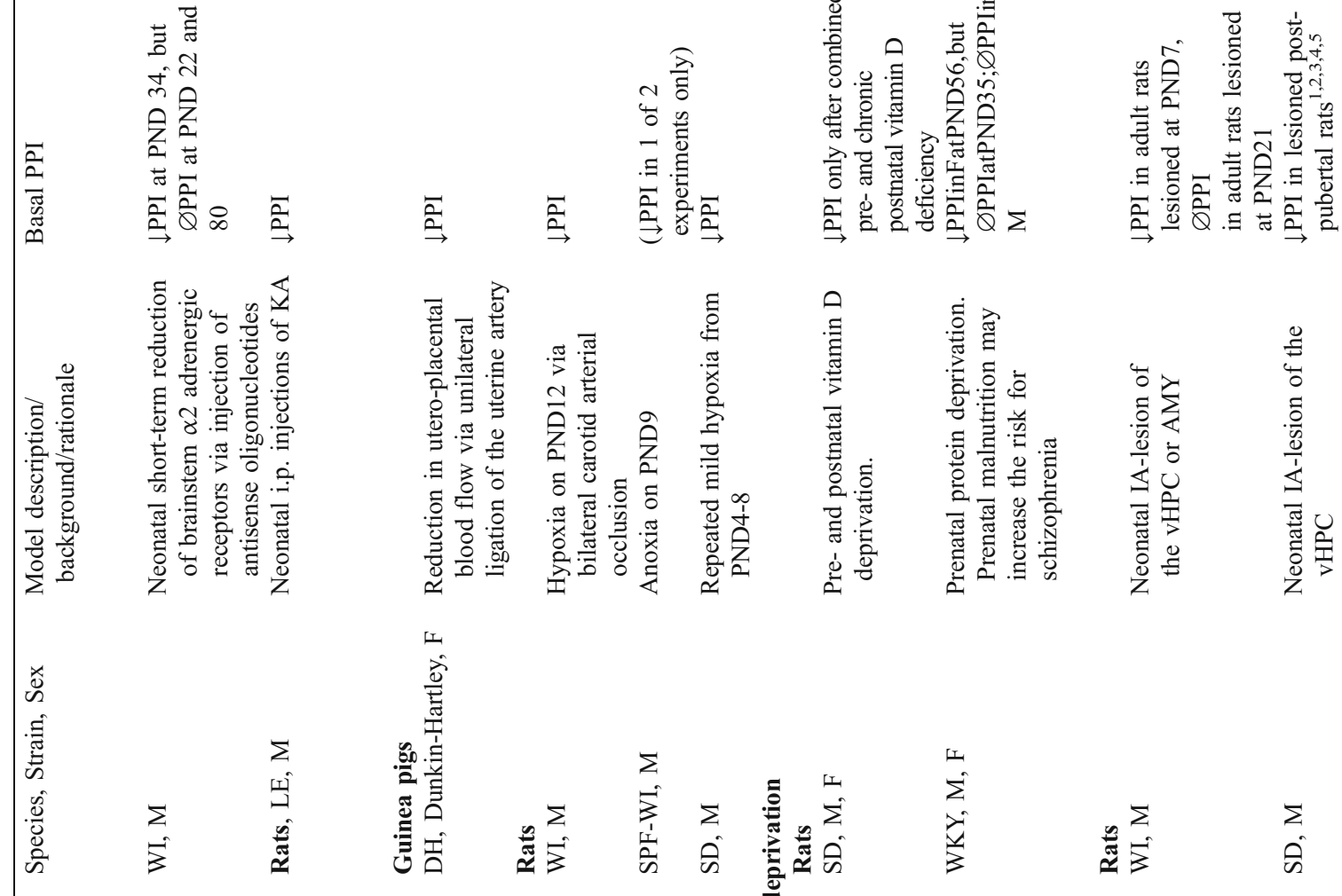

¿

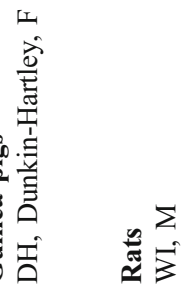

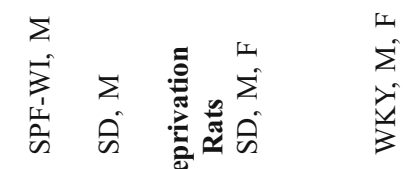

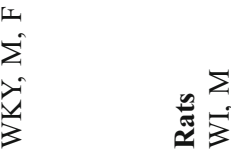

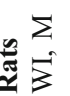

is

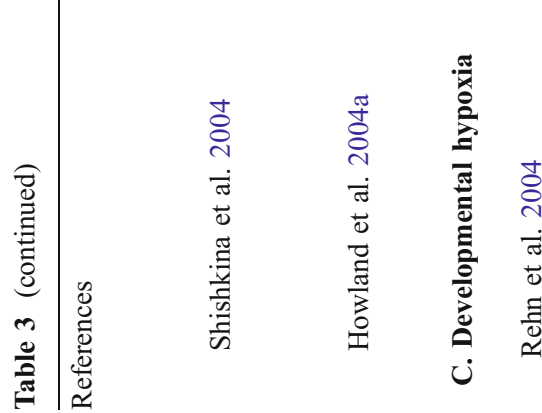

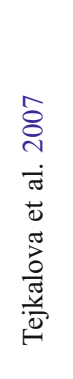

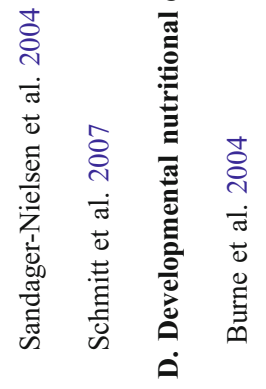

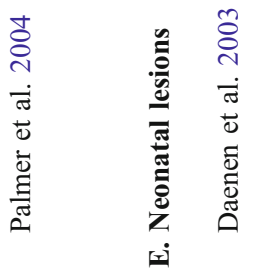

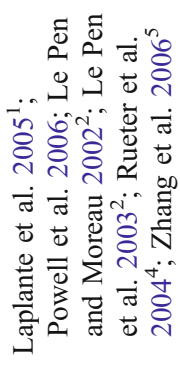



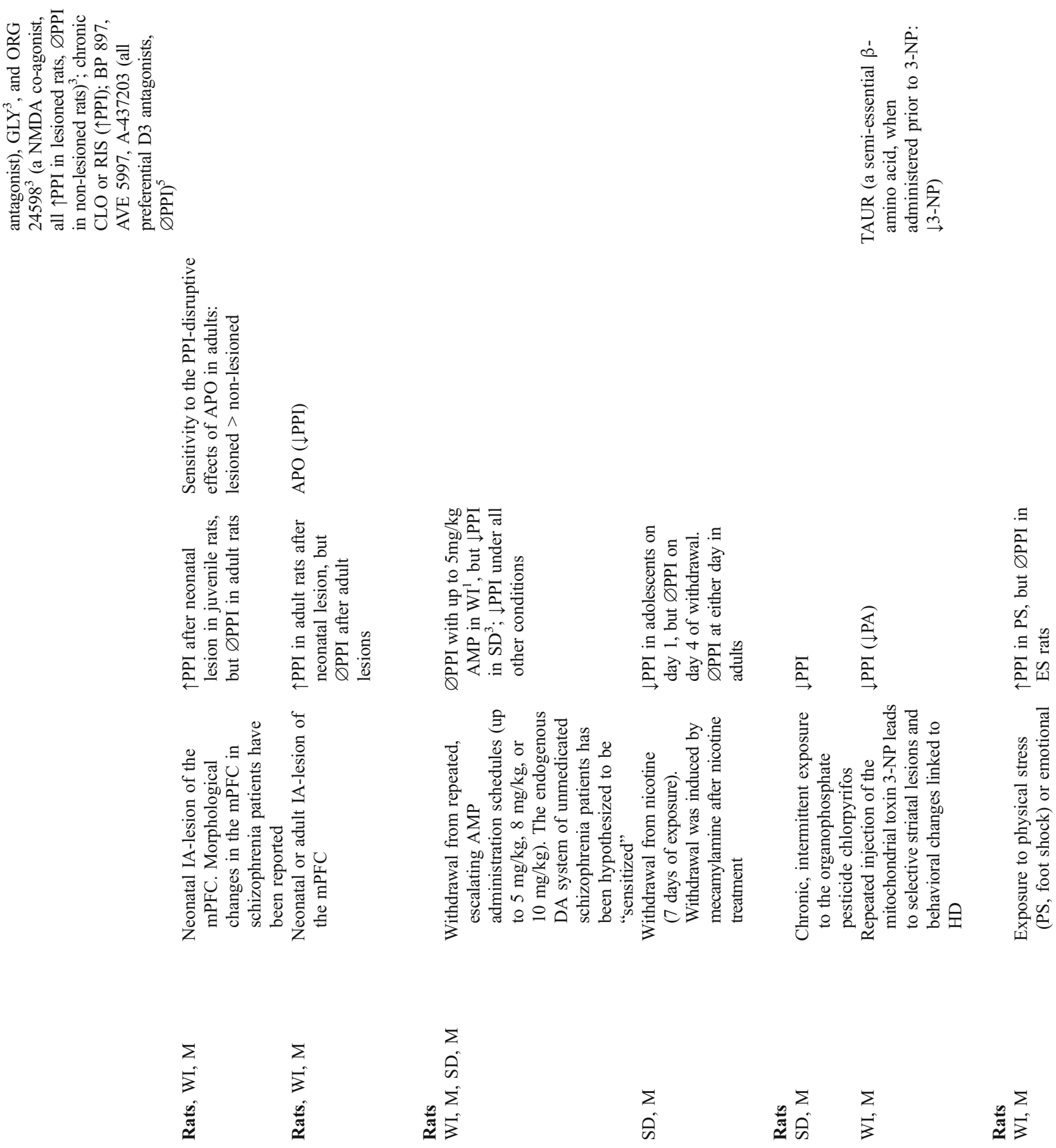

$\stackrel{\Sigma}{\infty}$

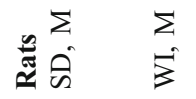

气ุ
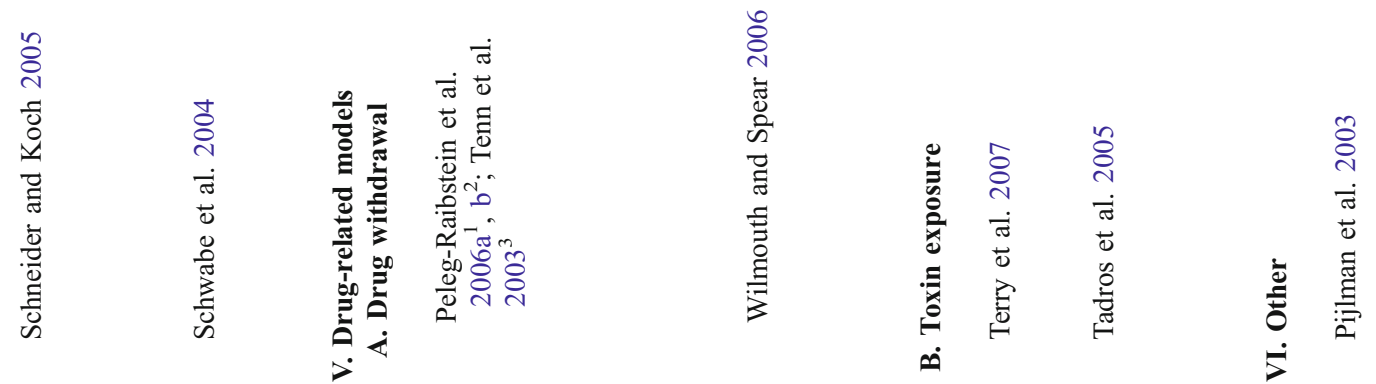


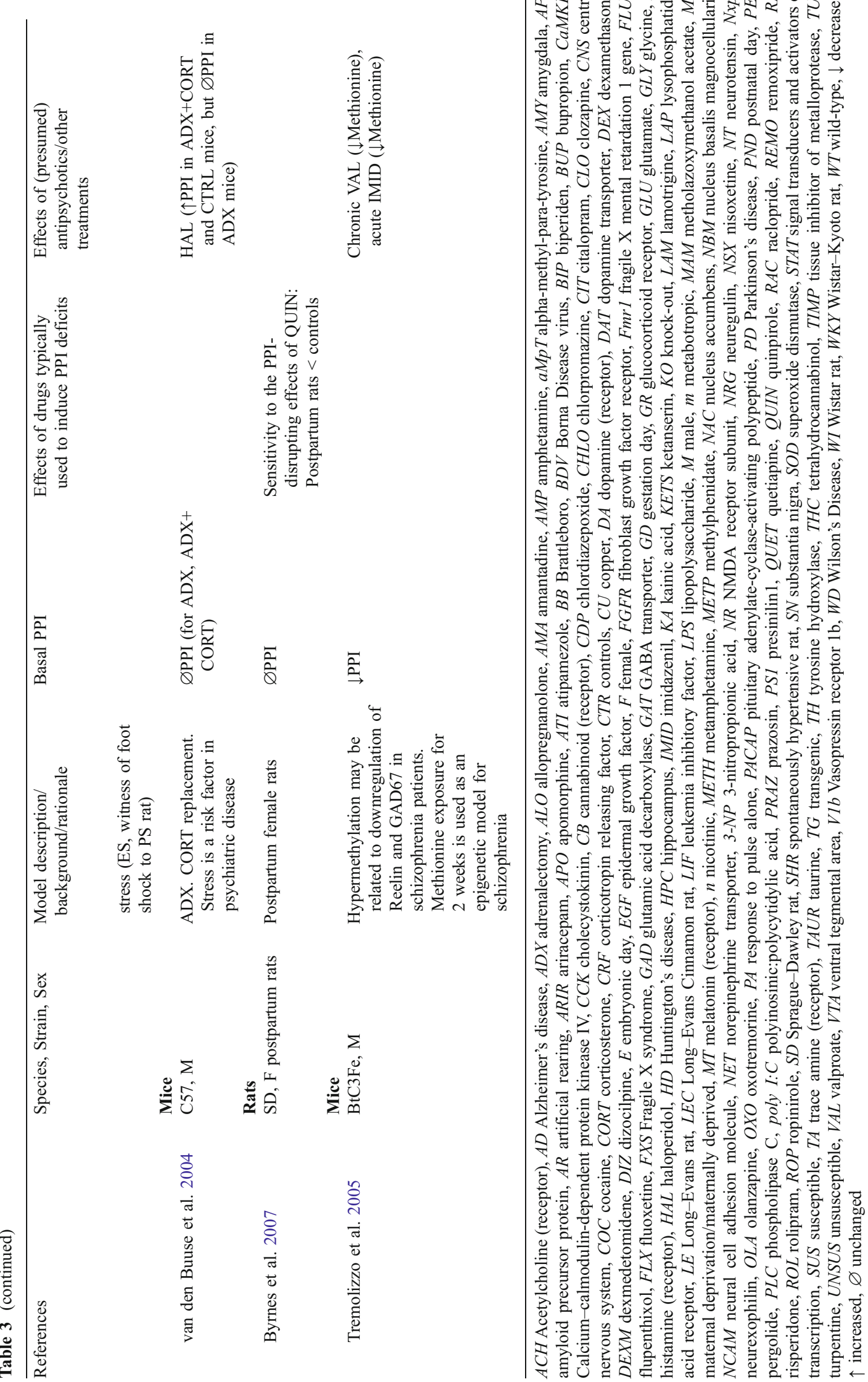




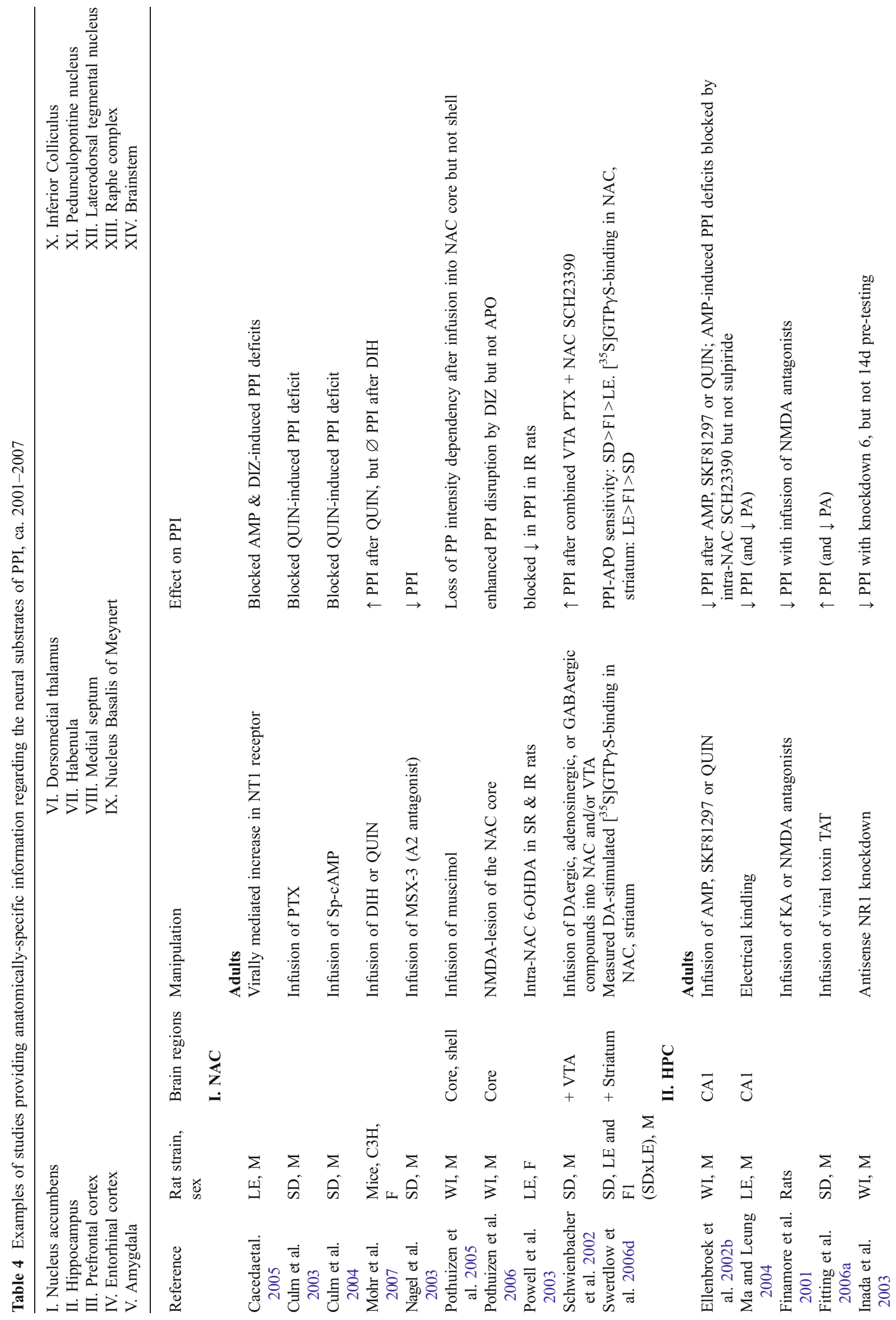




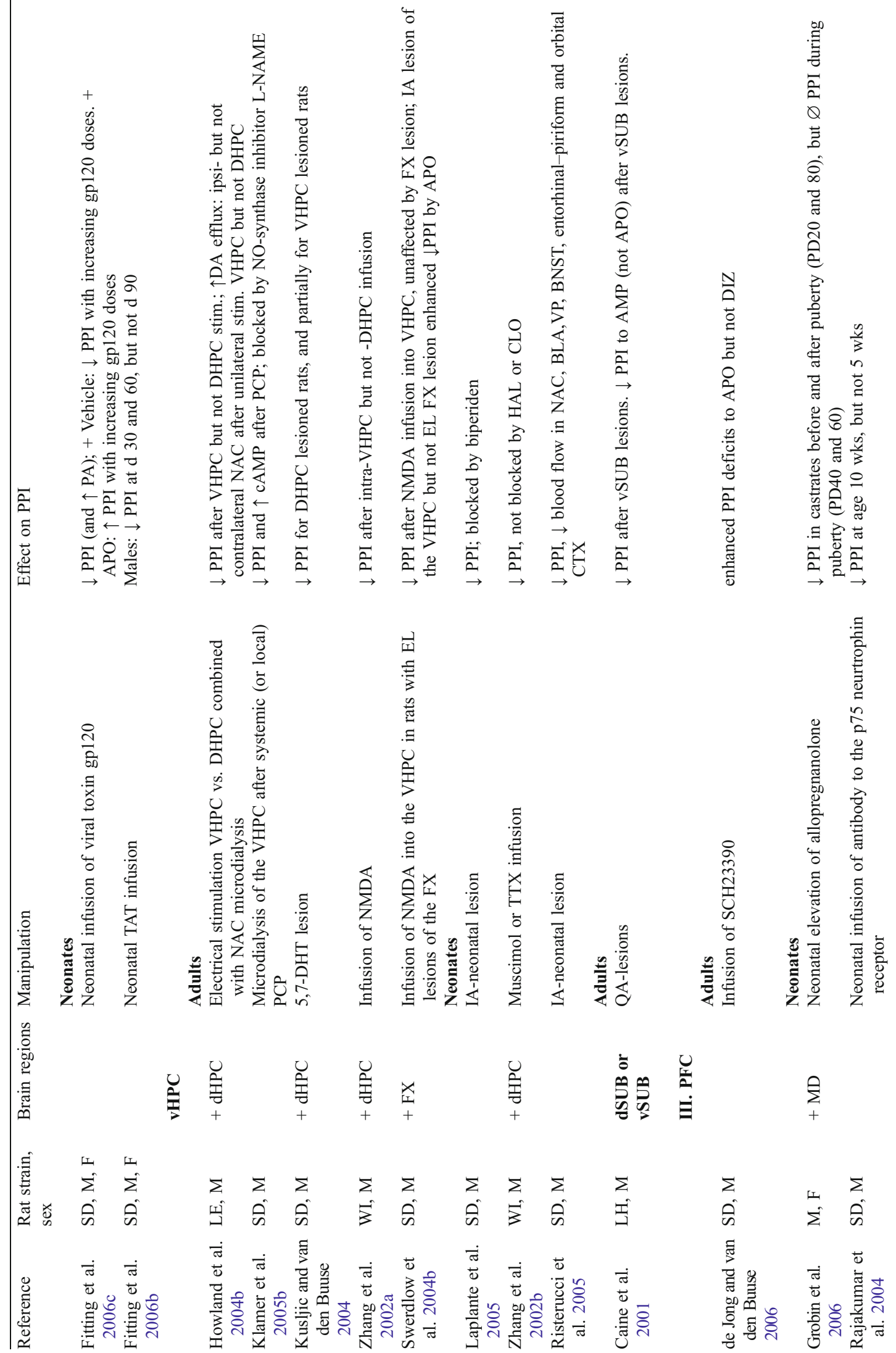




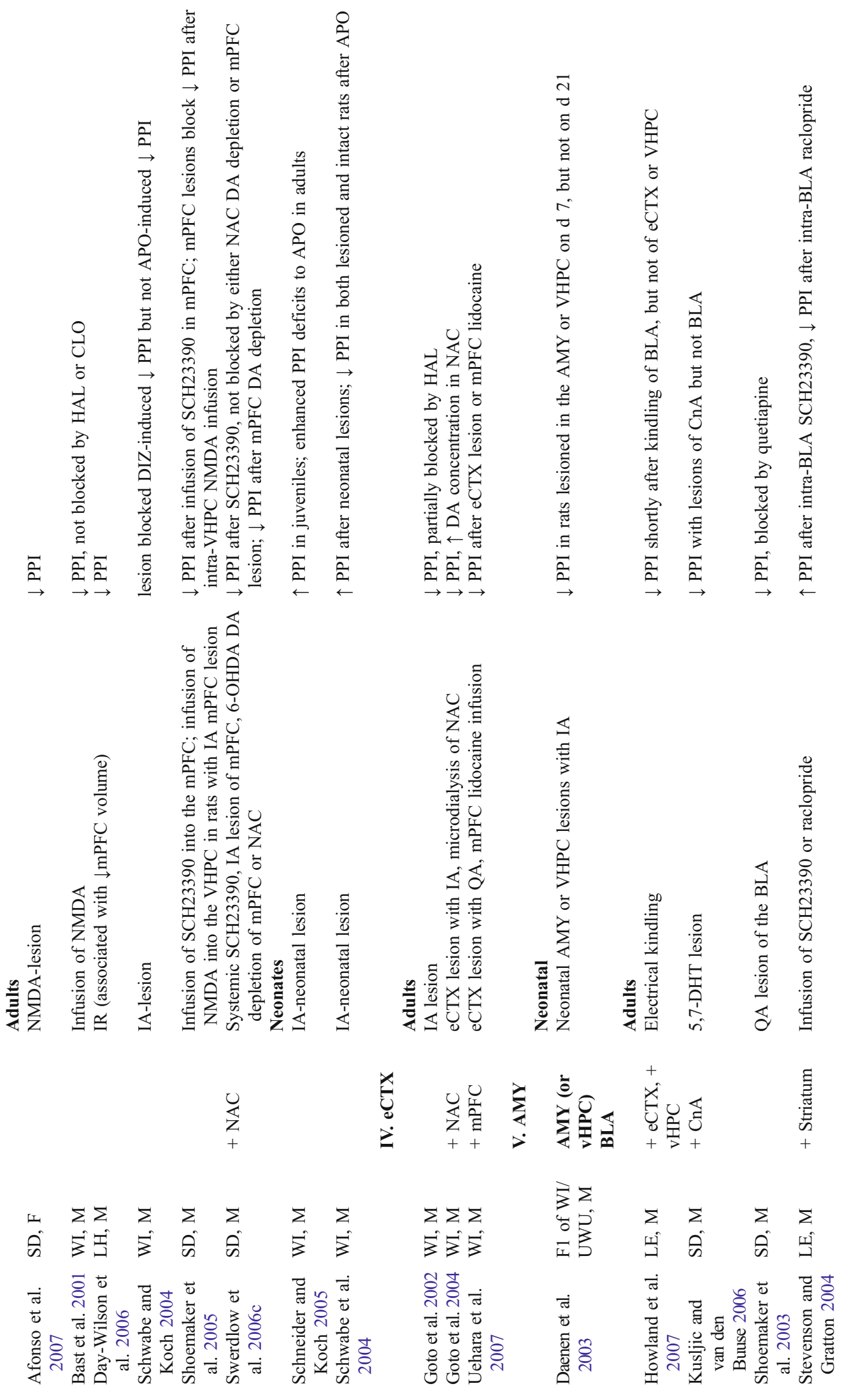




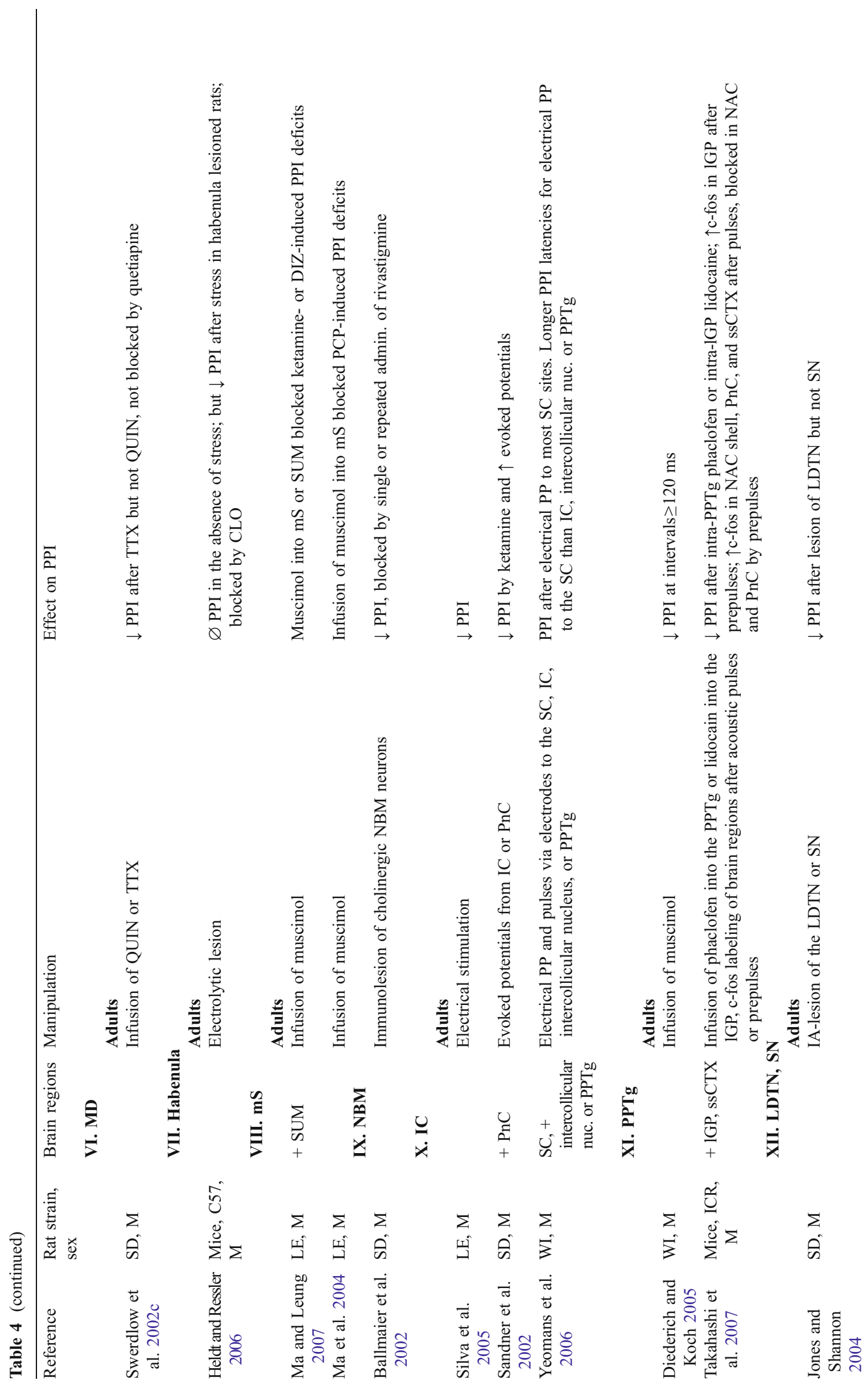




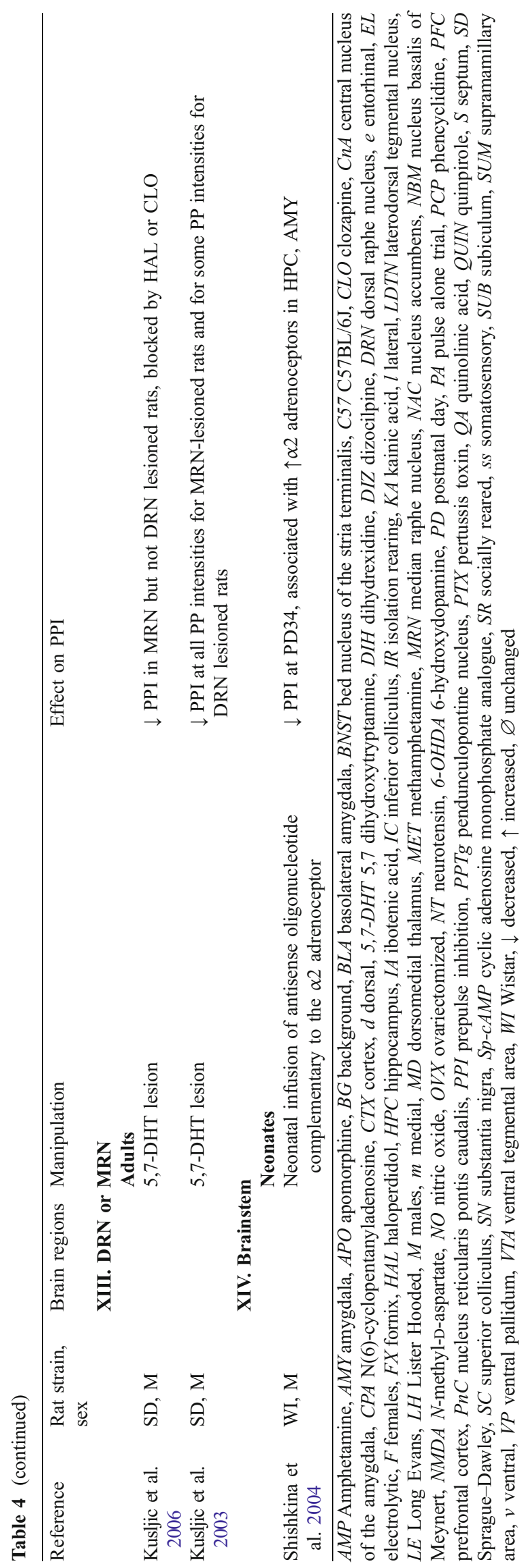


positive or negative symptoms scores (Table 1). Certainly, there is much interest in determining whether, with repeated or longitudinal measures, a change in PPI predicts or accompanies clinical deterioration or improvement, including the prediction of illness onset in prodromal subjects (Cadenhead 2002; Addington et al. 2007; Cannon et al. 2008). Very few studies have collected longitudinal measures of PPI in schizophrenia populations with adequate sample size and duration to be informative, although some are in progress. One might predict a relationship between PPI and psychosis in extreme conditions, such as the shift from euthymic to manic bipolar disorder, but even in this case, studies have been limited to cross-sectional comparisons, and results across studies have not been consistent (Perry et al. 2001; Rich et al. 2005; Barrett et al. 2005; Carroll et al. 2007). Duncan et al. (2006a, b) did detect an association between lower levels of PPI, and greater levels of psychotic symptoms and psychological discomfort among unmedicated schizophrenia patients.

Interestingly, while robust relationships between PPI and the most common clinical indices of schizophrenia have been hard to detect, reports have identified significant correlations between PPI and a number of relatively complex clinical measures, ranging from quantitative Rorschach ink blot indices of thought disturbance (Perry and Braff 1994) to scales of distractibility and attention (Karper et al. 1996). One report (Swerdlow et al. 2006f) identified a significant positive correlation between PPI and global functioning levels (GAF score) in schizophrenia patients, but this relationship was evident only among male patients, and the correlation —while highly significant $(p<0.005)$ - accounted for a relatively modest amount of the total PPI variance. In addition, PPI levels were associated with levels of independent living, also perhaps reflecting its relationship to global functioning. As a result, more sophisticated and sensitive analyses of PPI, related gating measures, and function in schizophrenia patients are being pursued (Light et al. 2007a; Braff et al. 2007a). Studies have detected modest but statistically significant relationships between PPI and measures of executive function in some patient groups [e.g., children with 22q11DS (Sobin et al. 2005a, b)]. A preliminary qualitative article by Butler et al. (1991) noted a nonsignificant trend toward greater tactile (but not acoustic) PPI among six (predominantly male) patients with schizophrenia and low levels of Wisconsin Card Sorting Test perseverative responses than among nine (predominantly female) patients distinguished by high levels of Wisconsin Card Sorting Test (WCST) perseverative responses. Kumari et al. (2007a) recently reported a significant $(p<0.03)$ correlation between tactile PPI and WCST perseverative responses in male schizophrenia patients. Significant positive relationships between acoustic PPI and working memory as well as other formal indices of neurocognitive function have been detected among clinically normal individuals (Bitsios et al. 2006; Light et al. 2007b, 2008; Csomor et al. 2008), although no such relationships have been reported for schizophrenia patients.

The relative insensitivity of PPI to clinical state speaks of the importance of trait features of this measure, which may reflect more "hard-wired" anatomical and genetic determinants. The fact that some relationships can be detected between PPI and relatively global measures of function in schizophrenia patients, but not between PPI and clinical state per se, is consistent with the hypothesis that the causal link between genes and functional outcome in schizophrenia reflects the impact of forebrain circuits that regulate basic gating mechanisms, more than those that control the expression of specific symptom states (Light et al. 2004; Braff and Light 2004; Light and Braff 2005). Thus, while diagnosis in schizophrenia will remain symptom-based for the foreseeable future, it could be argued that studies of the biology of schizophrenia and its relationship to functional outcome may be best advanced through quantitative measures of forebrain inhibitory function such as PPI.

\section{Treatment}

As PPI deficits in schizophrenia reflect dysfunction in forebrain circuitry and are linked to both cognitive and functional deficits in schizophrenia patients, can PPI or its potentiation by drugs in patients be used to predict individualized treatment for this disorder? Certainly, in terms of preclinical predictive models, PPI has been quite powerful, as discussed below. In schizophrenia patients, cross-sectional data and some longitudinal findings demonstrate that antipsychotic treatment is associated with elevated (i.e., "normalized") PPI and that this association is most robust with atypical antipsychotics as a class, compared to first generation antipsychotics (Table 1). Of course, interpreting medication effects in most of these reports is difficult because patients are uniformly being treated with complex multidrug regimens across a range of doses, and medication compliance is known to be poor among schizophrenia outpatients (Lieberman et al. 2005). A recent controlled study with a multidrug cross-over design detected PPI-increasing effects of olanzapine (but not risperidone or haloperidol) in chronically ill schizophrenia patients (Wynn et al. 2007). Findings of PPIincreasing effects of both quetiapine and clozapine in clinically normal, "low-gating" subjects suggests that the PPI-increasing effects of these drugs in schizophrenia patients may not reflect disorder-specific processes (Swerdlow et al. 2006a; Vollenweider et al. 2006). We do not know if the PPI-enhancing effects of these drugs, and conceivably some of their clinical benefit, may reflect their ability to optimize function within spared (intact) 
gating mechanisms, rather than their ability to correct or normalize activity within dysfunctional mechanisms.

Still, it is reasonable to ask whether the ability of drugs to normalize PPI in patients, or to increase PPI in "lowgating" normals, might reflect their impact on brain processes and resulting cognitive abilities that ultimately would have clinical utility and perhaps cognitive-enhancing effects in schizophrenia. While clinically effective antipsychotics (particularly atypical antipsychotics) are associated with increased PPI in patients and low-gating normals (Table 1), PPI is also increased in non-patients by ketamine and methylenedioxymethamphetamine (MDMA; discussed below; Duncan et al. 2001; Abel et al. 2003; Vollenweider et al. 1999), neither of which would be on anyone's list of likely antipsychotic agents. Nicotine is associated with increased PPI in schizophrenia patients (Kumari et al. 2001; Swerdlow et al. 2006f), but despite the hypothesis that smoking reflects a form of "self-medication" in schizophrenia patients, there is no clear evidence for either antipsychotic or cognitive-enhancing effects of nicotine in these patients. While there is an active quest by many groups to develop cognitively enhancing nicotinic receptorspecific agonists, based on the putative relationship between the alpha-7 nicotinic receptor subtype and schizophrenia (Freedman et al. 1997), there is presently no evidence that such compounds either increase PPI or enhance cognition in patients. Thus, screening compounds as effective antipsychotics based on their PPI-enhancing effects in clinical or special populations is likely to yield both true and false positives. At this point, there is an inferential, but not empirical, basis for using PPI enhancement as a basis for predicting the ability of a compound to enhance cognition and real-world daily functioning in schizophrenia. Clearly, this is an area of active investigation, and such empirical evidence might emerge based on these efforts.

A reliable, robust quantitative phenotype

While the realistic expectations for PPI as a clinically useful biomarker may be somewhat limited, it is very realistic to expect that PPI will continue to be a valuable tool for investigating brain functions relevant to several neuropsychiatric disorders, including schizophrenia. The many strengths of PPI as an experimental measure have been reviewed elsewhere (Braff et al. 2001b), and none of the realistic limitations described above detract from its attributes as an objective, quantifiable, reliable, robust, neurochemically and parametrically sensitive cross-species measure of a neurobiologically important process. Nonetheless, even in its use as an investigative experimental tool in humans, there should be a realistic assessment of what we can and cannot expect from PPI.
Two types of studies speak strongly to the general reliability of this quantitative phenotype. First, test-retest reliability has been established for PPI in normal comparison subjects (NCS), across days (Abel et al. 1998; Swerdlow et al. 2001c; Flaten 2002), weeks, and months (Cadenhead et al. 1999; Ludewig et al. 2002). More recently, 1-year retest data collected in 68 schizophrenia patients yielded intra-class correlations of $0.75(30 \mathrm{~ms})$ 0.89 (120 ms; Light et al. 2007a), suggesting a very high stability of this phenotype in patients. Second, a multisite study of PPI in NCS was conducted, using carefully standardized equipment, test methods, and inclusion/exclusion criteria. No significant differences in PPI were detected across seven geographically dispersed test sites, despite some modest methodological drift that was detected via rigorous quality assurance efforts (Swerdlow et al. 2007). Thus, within individuals, and across test samples, PPI appears to be a reliable phenotype.

While PPI is a reliable phenotype, at least among NCS, it is not reasonable to expect that every schizophrenia patient will exhibit a "deficient-PPI" phenotype. In fact, as noted above, there is no way to test this possibility because there is no absolute value that defines "deficient" PPI. Under commonly used test conditions, there is substantial overlap in the distribution of PPI values, between schizophrenia patients and community comparison subjects (cf. Braff et al. 2001b). Clearly, there are schizophrenia patients who have higher levels of PPI compared to many NCS. The overlapping group distributions with this measure likely reflect the many influences on PPI, other than schizophrenia-related pathology, such as sex, hormonal status, smoking, withdrawal from caffeine or nicotine, fatigue, and medications. There are also normal interindividual differences in activity within brain circuitry (e.g., in the pallidum, pons, or cerebellum) that regulates PPI, but is not primarily involved in schizophrenia. With typical testing parameters, NCS vs. unmedicated patients or patients receiving only typical antipsychotics, group separation in mean percent PPI might be reasonably expected to reach 1 SD (e.g., Kumari et al. 1999; Ludewig et al. 2003; Swerdlow et al. 2006f), which corresponds to 55\% nonoverlap. However, when patients taking atypical antipsychotics are included, group separation drops dramatically, to about $0.3 \mathrm{SD}$ (e.g. Swerdlow et al. 2006f) - or 21\% nonoverlap. This latter fact is particularly important, given that upwards of $90 \%$ of schizophrenia patients in most current open-enrollment studies report taking atypical antipsychotic medications [although true compliance is likely lower (Dolder et al. 2002; Lacro et al. 2002)].

In addition to medication status, studies have reported many other variables in patient selection that influence group separation in comparisons of schizophrenia patients vs. NCS. One issue that may ultimately impact the utility of 
PPI as a quantitative phenotype is its potential sensitivity to ascertainment bias. As noted above, PPI correlates positively with global function in schizophrenia patients. Thus, on average, studies of lower functioning patients will detect greater separation vs. NCS, and those of higher functioning patients will detect less group separation. For this reason, investigators are considering the impact of study designs that select for higher- vs. lower-functioning schizophrenia patients, such as those that require a proband within an intact family structure (and who thus may be relatively higher functioning) vs. those utilizing patients without intact families, who are often homeless or medically indigent (Calkins et al. 2007).

Perhaps equally important as the selection of patients is the selection of NCS. Comparison samples differ substantially across studies and can range from generally healthy, young college students, to "professional controls", who are often low-functioning and unemployed, beyond their activities as test subjects in biomedical research. The latter group is more likely to have histories of disorders that are associated with reduced PPI, such as anxiety disorders (OCD, panic disorder or post-traumatic stress disorder) or "cluster A" personality disorders; they may also be more likely to carry vulnerability genes for neuropsychiatric disorders, take psychotropic medications that influence PPI, and have histories of substance use or brain trauma that might impact PPI-regulatory brain circuitry. Much has been written about the considerations in selecting a "matched", "representative", "normal" or "supernormal" comparison group in biomedical research (e.g., Roy et al. 1997; Calkins et al. 2004), and without belaboring this point, these same considerations apply to studies of PPI and may greatly impact group separation in comparisons of control vs. schizophrenia populations.

As reviewed in Braff et al. (2001b) and elsewhere, the amount of separation between schizophrenia and NCS populations in PPI is highly dependent on testing conditions, and specifically, on stimulus parameters. Thus, if all else is equal, schizophrenia-linked PPI deficits are most pronounced under conditions in which prepulse salience, often based on its intensity over background, is within a "dynamic range": not too high, but not too low. For example, most studies find this "sweet spot" of maximal schizophrenia vs. NCS separation using discrete white noise prepulses 8$16 \mathrm{~dB}$ over a 70-dB(A) background, with about $60 \mathrm{~ms}$ prepulse intervals [or stimulus onset asynchronies (SOAs; Table 1)]. Some studies failing to detect PPI deficits in schizophrenia samples have used prepulses in the absence of a background white noise, effectively creating very large prepulse intensities of 25-40 dB(A; Hazlett et al. 2003, Wynn et al. 2004, 2005). In addition to prepulse intensity relative to background, prepulse frequency (e.g., tone vs. white noise), duration (discrete vs. continuous) and other variables (including the use of binaural vs. mono-aural stimuli) may contribute to maximizing the group separation in PPI between schizophrenia and NCS populations (Braff et al. 2001a; Hsieh et al. 2006; Kumari et al. 2005b, 2007b).

As noted above, the temporal "sweet spot" for detecting automatic (uninstructed) PPI deficits in schizophrenia patients appears to occur with prepulse intervals between 30 and $240 \mathrm{~ms}$, depending somewhat on other stimulus characteristics. The temporal range around $60 \mathrm{~ms}$ appears to be most sensitive in several studies (Braff et al. 1978, 1992, 2005; Weike et al. 2000; Leumann et al. 2002; Swerdlow et al. 2006f) and may be the range in which PPI deficits are most resistant to normalization by antipsychotic medications. Interestingly, this interval sits at the juncture between preconscious and conscious information processing, based on perceptual detection thresholds (Libet et al. 1979; Kanabus et al. 2002). The possibility that PPI in this temporal range may be most deficient in schizophrenia suggests that automatic inhibitory mechanisms may be most "porous" at a critical barrier between preconscious processing and conscious awareness. While clearly a point for more systematic analysis, such a notion suggests a biological mechanism that is syntonic with psychological models for the intrusion of unedited, preconscious content into conscious awareness in this disorder (Libet et al. 1979; Gray 1995; Swerdlow 1996; Grobstein 2005).

A useful tool for probing the neurobiology and genetics of gating deficits in schizophrenia

Perhaps the most realistic expectation is that PPI is and will remain a useful tool for studying the neurobiology of information processing abnormalities in schizophrenia. While the PPI deficit "signal" in genetic studies of schizophrenia has been blunted by the widespread use of atypical antipsychotics, investigators are increasingly well informed about the many other factors affecting the measurement of PPI and the detection of schizophreniaassociated deficits, and in this way are better positioned to study the basis for these deficits at the levels of their neurobiological and genetic substrates. These studies will be aided by special populations, including "low-gating" normals (Swerdlow et al. 2006a; Vollenweider et al. 2006) and asymptomatic relatives of schizophrenia probands (Kumari et al. 2005b), and by patients with related disorders, such as 22q11 deletion syndrome and unmedicated "prodromal" individuals (Sobin et al. 2005a, b).

As a relatively robust and reliable quantitative phenotype, PPI will be used to map genes associated with deficient sensorimotor gating in schizophrenia probands and families (Swerdlow et al. 2007; Greenwood et al. 2007). The strength of this "endophenotype" approach to understanding disease genetics has been described by many, 
including Gottesman and Gould (2003), Gould and Gottesman (2006), and Braff et al. (2007a), and largely reflects the fact that the quantitative laboratory measure (in this case, PPI), is closer to the underlying biology (i.e., aberrant neural circuits and their regulation by disease genes), compared to the more variable clinical phenotype (Braff et al. 2007a). There are a small but growing number of examples in which this strategy has proven successful, in identifying genes that confer risk for colon cancer (Leppert et al. 1990) and Type II diabetes (Scott et al. 2007). Whether this strategy can succeed in identifying vulnerability genes for more complex neuropsychiatric disorders is a question at the core of several large ongoing investigative efforts.

Gains will likely be made through the combined use of PPI with sophisticated neurocognitive, neuroimaging, and genetic/genomic tools in schizophrenia and normal populations. It is realistic to expect that these various applications will converge in a top down or bottom up fashion, i.e., to link: (1) genes with (2) brain substrates that cause (3) gating deficits responsible for (4) neurocognitive disturbances and (5) the resulting daily functional impairment in schizophrenia. Based on the genes and brain substrates identified in these studies, one might reasonably expect that novel treatments will be identified, perhaps acting on intracellular G-protein-coupled signal transduction mechanisms that have already been implicated in the regulation of PPI (van den Buuse et al. 2005a; Kelly et al. 2007; Swerdlow et al. 2006d; Culm et al. 2004; Svenningsson et al. 2003), and which may also be abnormal in some schizophrenia patients (cf. Catapano and Manji 2007). There are also mature lines of research suggesting that novel treatments may target neuropeptides, such as neurotensin (Kinkead et al. 2005; Feifel et al. 2004), that potently regulate PPI and its dopaminergic control, or may target specific dopamine receptors subtypes that regulate PPI via relatively localized effects within mesolimbic and limbic-fronto-striatal circuits (e.g., Zhang et al. 2006). At some stage, it is reasonable to expect that the development of any one of these or other novel treatments might be guided by their effects on PPI in control or clinical populations.

A surrogate measure for neural processes with wide-reaching psychological implications

The frontal, limbic, and mesolimbic circuitry that regulates PPI also regulates many higher-order psychological processes. Thus, PPI can be viewed as a simple surrogate "readout" of activity in this circuitry-an experimentally generated signal from the forebrain, detected through efferents descending through a "pontine portal". Alternatively, PPI can be viewed as a measure of a fundamental psychological process - sensorimotor gating-with broadreaching implications for the structure of complex behavior and thoughts. In truth, both views are at least partly accurate, under specific uses of the PPI paradigm.

"Gating" can be a very specific process when operationalized in the laboratory, but is less precisely defined when used as a psychological construct. How broadly can we extrapolate from the laboratory measure of one type of gating - sensorimotor gating - to other forms of automatic inhibition of sensory, cognitive, or motor information? There is credible evidence that PPI correlates significantly with a form of perceptual "gating", measured by the degree to which the prepulse reduces the perceived intensity of the startling stimulus (Peak 1939; Swerdlow et al. 2005b). On the other hand, PPI does not correlate strongly with the most structurally similar form of "gating"- - sensory gating-measured by suppression of the P50 auditory event-related potential (ERP; Light et al. 2006; Hong et al. 2007). Nor does PPI in normal humans correlate strongly with other measures thought to assess inhibitory processes that contribute to forms of "cognitive gating", such as latent inhibition (Murphy et al. 2001; Leumann et al. 2002; Peleg-Raibstein et al. 2006a, b) or visuospatial or semantic priming (Swerdlow et al. 1995b). Certainly, there is little evidence that PPI assesses processes that are strong determinants of normal personality structure and dimensions (Swerdlow et al. 2003d). At the least, it is important to recognize that the construct of "gating" is applied to many different processes and that it is reasonable to expect PPI to be informative about some, but not all or even most of these processes.

\section{Summary: human studies}

Human studies of PPI will continue to provide one important level of information within a top down or bottom up understanding of the biology of schizophrenia. PPI offers great promise as a quantitative phenotype for genetic studies and will be used in combination with other measures to connect an aberrant physiological signal (impaired startle inhibition) with its underlying neural substrates (via neuroimaging studies) and with its consequences in terms of cognitive deficits (via neurocognitive measures) and real-life impairment (via functional measures). It is realistic to expect that as we gain a better understanding of its modulating variables and optimal experimental methods, PPI in humans will continue its evolution, started in 1978 (Braff et al. 1978) from an isolated laboratory-based psychophysiological phenomenon, into a productive clinical research tool for understanding psychopathology. As we learn more about PPI, our scientific approaches to its use will continue to become more sophisticated, and we will be better positioned to take 
full advantage of what it can tell us about normal and abnormal brain functions.

\section{Animal studies: What can our field realistically expect to learn about schizophrenia based on studies of PPI in laboratory animals?}

\section{Etiology}

Two general applications of animal studies of PPI will be considered here: (1) the use of PPI to evaluate models or model organisms relevant to the etiology of schizophrenia; and (2) the use of PPI to "map" the neural substrates of deficient PPI in schizophrenia.

Model organisms, created via genetic, developmental, surgical, pharmacological, or immune manipulations, have been a mainstay of studies of the etiology, pathophysiology, and treatment of schizophrenia. Of course, schizophreniaas defined clinically - is a uniquely human disorder (least we ascribe to rats the ability to have "two or more voices conversing with one another or voices maintaining a running commentary on the [rat's] thoughts or behavior," or the ability to conceptualize that "alien thoughts have been put into his or her mind...", or to have homologous complex social cognitive deficits; APA 2000). However, investigators can apply schizophrenia-linked constructs to these models and test whether the resulting animal reproduces laboratory-based phenotypes exhibited by schizophrenia patients. The degree to which these phenotypes are reproduced in the model organism provides a level of validity to the construct, even if it is specific to the laboratory-based phenotype, rather than the broader clinical disorder.

For example, given a particular schizophrenia candidate gene " $X$ ", it is reasonable to ask whether manipulations of gene " $X$ " produce an animal that exhibits reduced levels of PPI compared to a wild-type animal. If so, then the gene " $X$ " mutant would be a valid model for PPI deficits in schizophrenia. Such an approach has been taken with many different animal models (Table 3). There are obvious limitations to the specificity and sensitivity of this approach, which could be deduced from the above discussions of the PPI findings in humans.

Because deficient PPI is not unique to schizophrenia populations, there is no a priori justification for claiming that such a mutant specifically models the PPI deficits in schizophrenia, rather than OCD (Swerdlow et al. 1993a; Hoenig et al. 2005), Tourette Syndrome (Smith and Lees 1989; Castellanos et al. 1996; Swerdlow et al. 2001b), Blepharospasm (Gomez-Wong et al. 1998), or a number of other conditions. The specificity of the linkage of the model with schizophrenia, and hence with PPI deficits in schizophrenia, must come from the construct. For example, the finding of PPI deficits in a murine model of 22q11 deletion syndrome (22q11DS) links this model to PPI deficits in schizophrenia (Paylor et al. 2006; Sobin et al. $2005 \mathrm{a}, \mathrm{b}$ ), on the basis of the clinical relationship between 22q11DS and schizophrenia. Without this clinical relationship, this would just be a mouse with low PPI, and the model would most likely be a "false positive" for the schizophrenia phenotype.

Certainly, it is unlikely that most genes associated with low vs. high levels of PPI will be related to reduced PPI in schizophrenia or any one other disease states. This is because the most potent influences regulating baseline PPI involve physiological substrates that are probably not relevant to schizophrenia. For example, a very potent determinant of acoustic PPI is hearing threshold, as an organism that cannot hear a prepulse will not exhibit PPI. Thus, many candidate "PPI genes" identified via gene inactivation or mapping strategies of drug-free PPI in inbred and recombinant rodents will likely be associated with hearing threshold. Beyond the level of sensory detection, the most potent neural control of baseline PPI is exerted by the pedunculopontine nucleus (PPTg) (Swerdlow and Geyer 1993a), which mediates PPI via its impact on the nucleus reticularis pontis caudalis (NRPC; Koch et al. 1993). For the same reasons noted for hearing threshold, genetic studies of PPI will likely be influenced strongly by genes coding for the normal function of the PPTg-a structure that does not play a central role in any model for the pathophysiology of schizophrenia. In contrast, the prefrontal cortex (PFC) - which is viewed as a critical substrate for some core symptoms of schizophrenia (e.g., cognitive disorganization, deficient working memory, executive functioning, abstract reasoning, cognitive flexibility and context processing, and negative symptoms) - is likely to be three or four synapses removed from the primary startle circuit; in a normal human or rodent, genes controlling the PFC will likely contribute only weakly to a genetic "signal" based on levels of baseline PPI.

One might argue that a finding of PPI deficits provides additional validation that a particular model reproduces one of the quantitative phenotypes associated with schizophrenia. But as noted above, there is no definitive evidence that PPI deficits - or the neural abnormalities that produce themare necessary for the expression of the broader schizophrenia phenotype. Rather, it is almost certainly true that there are large numbers of functionally impaired, symptomatic schizophrenia patients who exhibit levels of PPI in the "normal" range. Thus, rejecting animal models on the basis of "normal" PPI levels would likely result in a number of "false-negative" models - i.e., ones in which some features 
of the model accurately recreate important aspects of the biology of schizophrenia, but do not result in reduced PPI.

Perhaps the most realistic expectation of PPI in the assessment of animal models of schizophrenia is that it can provide validation for specific existing constructs-i.e., that the construct can reproduce PPI deficits exhibited by a significant subgroup of the heterogeneous population of schizophrenia patients. On the other hand, "normal" or unaltered PPI should not be used as the basis for rejecting a model: even in the presence of "normal" (i.e., wild-type, sham lesioned or placebotreated) PPI levels, it is very possible that a model might be highly informative about the biology of schizophrenia.

Animal studies are also used to explicate the neural regulation of PPI, as a means of understanding the neural basis of PPI deficits in schizophrenia and other disorders. In this case, the manipulations are selected not necessarily based on a "construct" of schizophrenia, but rather based on the extant PPI neural "map", and the understanding of anatomical and neurochemical properties of that map. In general, the organism used in these studies is not a schizophrenia "model" per se, but is more akin to a canvas on which a neural map can be painted. A reasonably comprehensive understanding of this "map", ca. 2000, is found in Swerdlow et al. (2001a), and an updated list of studies of "PPI anatomy" is found in Table 4.

Much can be gleaned about PPI and its broader context by considering two facts related to its anatomical substrates.

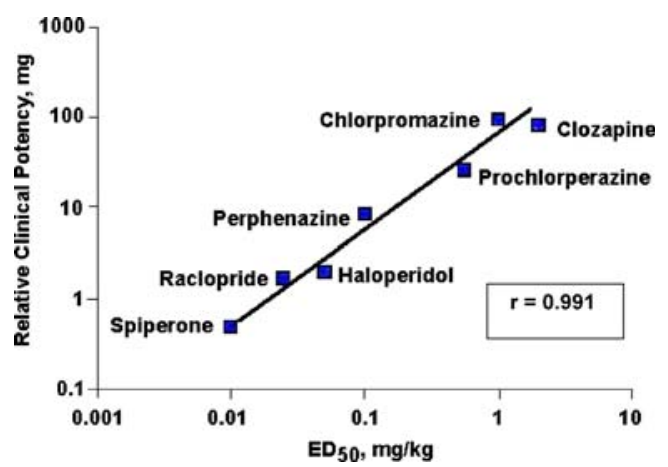

Fig. 2 Evidence supporting the predictive validity of one "rapidthroughput" animal model of PPI deficits. In these studies (Swerdlow et al. 1994), PPI was disrupted in adult male Sprague-Dawley rats by the mixed D1/D2 agonist, apomorphine $(0.5 \mathrm{mg} / \mathrm{kg} \mathrm{sc})$. The ED50 of a number of drugs to reverse this apomorphine effect correlated significantly with their clinical potency. Subsequent studies have identified many other clinically effective antipsychotic agents from different chemical classes that prevent the PPI-disruptive effects of apomorphine in rats [see Table 2 and Geyer et al. (2001)]. A small number of potential "false-positive" compounds have also been detected, primarily in other species or strains. Other predictive models have been developed using PPI as a dependent measure, as described in the text and Table 2, each with different sensitivity, specificity, and logistical complexities
First, PPI remains intact after acute trans-collicular decerebration in the rat (Davis et al. 1982). In other words, the expression of unimodal acoustic PPI in rats does not require any part of the forebrain, and therefore, it must be mediated at or below the pons. The prepulse does not (and by physical and temporal constraints, cannot) "travel" to the forebrain to generate its inhibitory impact on the simple startle reflex (see discussion in Swerdlow et al. 2001a). Second, PPI can be regulated, and even eliminated, by subtle pharmacological manipulations at the most rostral tip of the forebrain [e.g., D1 receptor blockade within the medial prefrontal cortex (Ellenbroek et al. 1996; Shoemaker et al. 2005; Swerdlow et al. 2005c)]. Thus, brain substrates at the furthest point from the PPI "mediating" circuitry in the pons are capable of potently regulating the amount of inhibition generated by the prepulse, presumably via tonic, "thermostat"-like stimulus-independent changes in activity within descending circuitry.

These two facts lead to a simple conclusion: while PPI is mediated via the pons, it can be regulated by the forebrain. A relative loss of PPI in clinical populations, and in the animal models that are used to study them, can be a consequence of aberrant activity within this descending circuitry-somewhere "between" the cortex and pons-or within substrates that impinge upon it. The efforts to "map" this PPI-regulatory circuitry, point-to-point, from cortex to pons, are aimed to help investigators identify candidate substrates that contribute to the loss of PPI in patient populations and candidate targets for therapeutic interventions. Of the many words of caution related to this use of animals to "map PPI", two will be noted here.

First, rodent brains and human brains are not the same. Thus, a map of neural circuitry regulating PPI in rodents cannot be expected to translate exactly to human brains. Indeed, it is surprising how much overlap is suggested across species, based on neuroimaging findings in humans (Kumari et al. 2003a, 2005, 2007a; Postma et al. 2006), and based on examples of localized neuropathology associated with PPI deficits in brain disorders such as HD and in rat and murine models of this disorder (Swerdlow et al. 1995a; Carter et al. 1999; Van Raamsdonk et al. 2005). These findings notwithstanding, it is clear that species differences will be most pronounced in phylogenetically newest regions, some of which-e.g., frontal cortex - may be of most relevance to schizophrenia. As we attempt to interpret these circuit maps at higher levels of resolution to guide drug development-i.e., beyond simple efferent/afferent patterns, and down to the receptor- and subcellular levels - these cross-species differences may become increasingly important. A number of these differences are already suggested based on simple pharmacological challenge studies, described below. 
Second, all rodent brains are not the same. Strain differences in PPI, and in sensitivity to drug effects on PPI, are quite remarkable across inbred and outbred rat strains, and across inbred and outbred mouse strains. These differences must reflect differences in the PPIregulatory brain circuitry, potentially at any level from the presence of different cell types within a larger circuit organization, down to differences in the activity of specific enzymes within signal transduction pathways. Inbred Brown Norway rats exhibit significantly more PPI at short prepulse intervals and significantly less PPI at long prepulse intervals, compared to outbred Sprague Dawley (SD) rats (Swerdlow et al. 2006a). These differences are heritable (Swerdlow et al. 2008), and must reflect genetically mediated differences in brain organization. Albino SD and hooded Long Evans (LE) rats differ significantly in their sensitivity to the PPI-disruptive effects of dopamine (DA) agonists (e.g., Swerdlow et al. 2004a, 2006d) and in the expression of DA-regulatory enzymes [e.g., catechol-o-methyl transferase (COMT)] and signal transduction enzymes (e.g., protein kinase) within the nucleus accumbens (Shilling et al. 2008). Which of these strains provides an anatomical/neurochemical "map" of PPI that is most informative about human PPI circuitry, and hence, about PPI circuit abnormalities in schizophrenia? The answer is likely to differ, based on the neural systems and levels of resolution being studied, and the models being applied.

\section{Treatment}

It is reasonable to expect that studies of PPI in laboratory animals will continue to play a major role in the discovery and development of novel therapeutics for schizophrenia. As noted above, there is no compelling empirically based reason to expect that increased PPI per se might be desirable or functionally enhancing, nor that the ability of a drug to increase PPI in schizophrenia patients should be necessary or sufficient for clinical benefit. Despite this caveat, there is clear empirical evidence that the ability of drugs to "normalize" PPI levels after they have been reduced experimentally by specific drugs or perhaps by other manipulations (e.g., developmental manipulations) strongly predicts clinical utility and even potency of antipsychotic agents (Swerdlow et al. 1994; Swerdlow and Geyer 1998; Fig. 2). Towards this end, PPI has been used in several different types of predictive models, which differ in their sensitivity, specificity, logistical complexity, and even in the types of antipsychotics that they appear to identify. These issues are reviewed in Geyer et al. (2001), and an update of studies using PPI for its predictive validity since 2000 are found in Table 2.

The four most common variations of the PPI paradigm in models predictive of antipsychotic effects involve the use of
(1) DA agonists (Fig. 2), (2) NMDA antagonists, (3) isolation rearing (IR), and (4) neonatal ventral hippocampal lesions (NVHLs). While each of these variations is based on a biological "construct" for the etiology of schizophrenia, i.e., hyperdopaminergia, hypoglutamatergia, and specific neurodevelopmental insults, they have all been applied towards predicting antipsychotic properties in novel compounds. In truth, only the former two variants are well suited to traditional "rapid throughput" drug screens, based on the amount of time and resources necessary for the developmental models, and the relatively small (and often strain- or sex-dependent) effects of isolation rearing on PPI (Weiss et al. 1999, 2000; Powell et al. 2002). In each of these variations, the ability of a drug to "normalize" PPI is interpreted as evidence for antipsychotic potential. Some second generation antipsychotics, such as clozapine, quetiapine, and olazapine, tend to increase PPI in otherwise intact animals (Swerdlow and Geyer 1993b; cf. Geyer et al. 2001), particularly in mice, adding some interpretative complexity to their ability to normalize PPI after pharmacological, developmental, or surgical manipulations. In fact, the ability to enhance baseline PPI is a signal that has been used as a predictor of antipsychotic potential in mice, in some normally "low-gating" mouse strains (cf. Ouagazzal et al. 2001a), rat strains (Feifel et al. 2001, 2004), and even in normal "low-gating" humans (Swerdlow et al. 2006a; Vollenweider et al. 2006).

Beyond the dopamine system, some new targets of antipsychotics have emerged in recent years, based in part on studies using variations of PPI paradigms as predictive models. Examples of these targets include (but are not limited to) selective $5-\mathrm{HT}_{2 \mathrm{C}}$ receptor agonists (Marquis et al. 2007), CB1 cannabinoid receptor antagonists (Nagai et al. 2006), neurotensin-1 receptor agonists (Shilling et al. 2003, 2004; Caceda et al. 2005), selective adenosine A(2A) receptor agonists (Wardas et al. 2003), alpha-7 nicotinic receptor agonists (Suemara et al. 2004), and selective histamine $\mathrm{H} 3$ receptor antagonists (Fox et al. 2005; Table 2). It should be emphasized that in some cases, these targets were identified based on PPI assays with less compelling predictive validity, such as the ability of compounds to increase basal PPI levels in mice, or to normalize PPI after its disruption by 5HT agonists or NMDA antagonists. These assays may have strong sensitivity, particularly for identifying compounds with potentially novel mechanisms, but they also may lack specificity for detecting antipsychotic properties, at least in comparison to assays based on the ability to block the PPI-disruptive effects of apomorphine and perhaps other DA agonists (Fig. 2). We will have to await clinical evidence to determine whether these reports reflect "false positives" of these models.

PPI has only more recently begun to be used in models for detecting preventative or neuroprotective interventions, 
to identify strategies that would prevent the neuropathological and clinical consequences of a vulnerability gene or developmental insult involved in the prodrome and onset of schizophrenia. Some studies are approaching such an application, using early neuroimmune challenges to yield PPI deficits during adulthood (e.g., Borrell et al. 2002), or using sustained early life antipsychotic exposure to blunt the PPI-disruptive effects of developmental insults (Powell et al. 2006a, b). Assuming that these models succeed, it remains to be determined how one would test or apply such interventions in a clinical setting.

\section{A reliable, robust, quantitative phenotype}

In any given rodent species and strain, both PPI and its drug sensitivity are quite robust and reliable phenotypes. Within a range of 30-120 ms prepulse intervals, and 2$16 \mathrm{~dB}$ noise prepulses over a 65- to $70-\mathrm{dB}(\mathrm{A})$ noise background, and $105-120 \mathrm{~dB}(\mathrm{~A})$ noise pulses, PPI in rats exhibits a magnitude and parametric sensitivity that are strikingly similar across a number of studies from different laboratories and, conveniently, are also quite similar to those exhibited by humans. Similarly, PPI-disruptive effects of a number of simple manipulations (e.g., administration of a direct DA agonist) have been replicated across laboratories to the point that they have become "standard assays", in predictive models for antipsychotic development. The PPI-disruptive effects of more complex manipulations, including early developmental lesions or isolation rearing, tend to be more variable across laboratories (discussed above), perhaps due to the complexities (and hence variability) of the methods and uncontrolled sources of variance. Some differences in reports of PPI drug sensitivity and sensitivity to developmental manipulations clearly seem to result from differences in rat strain or even supplier (e.g., Swerdlow et al. 1998, 2000b, 2003a, 2004a), and these differences are being explicated at the levels of heritable differences in neural substrates regulating PPI.

Some disparities in reported drug or other manipulation effects on PPI may also reflect differences in the recording properties of a variety of "home built" and commercially available startle response acquisition systems. While there is no "gold standard" for such an apparatus, there are a number of characteristics that should be evaluated in interpreting whether response measurements "obey the laws of physiology", e.g., intensity- and interval-dependence of PPI, and relative insensitivity of PPI to weight differences across animals. These issues are reviewed in Geyer and Swerdlow (1998).

Startle and PPI data can be deceptively complex, and some disparities in reported effects on PPI in rodents undoubtedly reflect these complexities and resulting interpretative differences across studies. Despite the impressive degree of automation in laboratory measures of PPI, one cannot automatically enter startle data into an equation and reasonably expect the calculated percent PPI to be informative. For example, we have previously reviewed the importance of considering the impact of changes in startle magnitude on changes in PPI (Swerdlow et al. 2000a). Simply put, the only unambiguous changes in sensorimotor gating are ones that can be demonstrated in the absence of changes in startle magnitude. In this case, reduced sensorimotor gating reflects a diminished impact of the prepulse on startle magnitude and, hence, an increase in startle magnitude on prepulse + pulse trials only. Any other related pattern of results, involving significantly reduced or increased startle magnitude on pulse-alone trials, must be interpreted in the context of additional supportive evidence. Such evidence might come from the use of low and high pulse intensities or from subgroups of rats that are matched based on comparable levels of startle magnitude.

Another interpretative issue that has been discussed in several recent reports relates to the potential impact of prepulse-induced startle activity on PPI and its modification by drugs or other experimental manipulations (Yee et al. 2004; Swerdlow et al. 2004c). A stimulus is only considered a "prepulse" in relationship to a second stimulus. By any other metric, it is simply a stimulus and can elicit motor activity including a startle reflex, depending on its properties. If the prepulse intensity exceeds the startle threshold, a "prepulse + pulse" configuration is better described as a "paired-pulse" configuration, and the resulting decrement in the startle response elicited by the second pulse is described as "paired-pulse inhibition", comparable to the phenomenon used to study "blink excitability" (e.g., Kimura and Harada 1976; Valls-Sole et al. 2004). The similarities and differences of PPI and paired-pulse inhibition have been described for a small number of drug effects (e.g. Swerdlow et al. 2002a), but relatively little is known about this relationship for the long list of manipulations that have been applied towards PPI studies.

The interpretative ambiguities created by "prepulseelicited startle" are most relevant to conditions in which the prepulse exceeds startle threshold. In a rat, for $20 \mathrm{~ms}$ noise prepulses over a $70-\mathrm{dB}(\mathrm{A})$ noise background, this threshold is generally between 12 and $15 \mathrm{~dB}$, although the precise value varies with strain, sex, age, and other factors. Other prepulse characteristics, including frequency (pure tone vs. white noise), duration, and configuration (continuous vs. discrete) can impact its motor-inhibiting and activating properties. For the vast majority of published PPI studies, prepulses are used at levels that elicit no or little detectable motor activity; even relatively intense prepulses (e.g., 10-15 dB salience, based on the stimulus conditions described above) might elicit a motor "signal" 
that is $<1 \%$ of the total startle signal (Swerdlow et al. 2004c). In fact, this signal is comparable to that detected on "NOSTIM" trials, i.e., when no motor activity is recorded in the absence of stimulus delivery, suggesting that this small signal reflects ongoing motor activity rather than a prepulse-elicited motor response (e.g. Swerdlow et al. 2004c; Weber and Swerdlow 2008). Importantly, only a small fraction of studies utilize prepulses with suprathreshold intensities, and among these, most also utilize much weaker prepulses as internal comparisons. PPI is used to assess many things, and in some cases, a range of prepulse intensities is used to create a complete parametric characterization for purposes unrelated to drug effects (e.g., QTL analyses). Clearly, in these cases, the use of intense prepulses is not a "confound", but simply a way to fully characterize a phenotype.

It is argued that potentially confounding effects might arise if a drug or other manipulation lowers startle threshold and, hence, transforms a non-startling prepulse into one that elicits a motor response (Yee et al. 2004). Specifically, a potentially confounding interaction might arise if increases in prepulse-evoked motor responses diminished the prepulse's inhibitory effects on a subsequent startle response. In fact, there is no reason to predict such an effect: full startle responses elicited by an $\mathrm{S} 1$ in a paired-pulse paradigm do not interfere with the inhibitory impact of S1 on the startle response to S2 (e.g., Swerdlow et al. 2002a), so there is no credible reason to predict that such interference would result from a prepulse-evoked response that is 100 -fold less intense. Nonetheless, under drug conditions, a number of control comparisons can be conductedanalogous to those used to understand the impact on PPI of drug-induced changes in startle magnitude - to determine whether drug effects on prepulse-evoked motor activity and PPI can be "dissociated". We might predict that a common drug receptor (e.g., D1 or D2) might mediate two processes (reduced PPI and increased prepulse-induced motor activity), via effects within different brain substrates. Similar to changes in startle magnitude, a given drug might elicit either increases, decreases, or no change in prepulseinduced motor responses, yet have a consistent effect on PPI (e.g., Weber and Swerdlow 2008); even in cases where drug-induced changes in prepulse-induced activity are detected, they amount to shifts of less than $1 \%$ of the total "signal" of the startle response and, as noted above, are comparable to changes observed in "NOSTIM" activity. Thus, while it is a reasonable precaution to consider measuring prepulse-elicited motor activity to ascertain whether it is significantly greater than ongoing background motor activity, and whether it might potentially interact with the startling effects of the startle pulse, in our experience, such an exercise amounts to "much ado about [almost] nothing" (Swerdlow 2005).
A useful tool for modeling the neurobiology and gating and its deficits in humans

The most compelling contribution of animal studies of PPI towards the understanding of the basis for PPI deficits in schizophrenia comes in the ability to directly manipulate neural and genetic substrates and test hypotheses in a controlled experimental setting. The challenges of extrapolating such findings across species are not trivial, as discussed above in relationship to neural circuit maps. Still, for understanding the contribution to PPI deficits in schizophrenia of pathology in medial prefrontal cortex, hippocampus, amygdala or ventral striatum, or of specific candidate genes or early developmental insults, crossspecies studies are a unique, powerful tool.

PPI studies have also identified neurobiological bridges across species that may reveal potential limitations of these studies and, perhaps, more generally of animal models of schizophrenia. For example, several drugs potently disrupt PPI in rats and yet increase PPI in normal humans. This is most notable because the drugs in question-ketamine (Abel et al. 2003; Duncan et al. 2001), MDMA (Vollenweider et al. 1999) and under some conditions, DA agonists (Bitsios et al. 2005)-have pharmacological and clinical properties that are central to models for the pathophysiology of schizophrenia. These findings raise both experimental and conceptual issues.

At an experimental level, drug doses, routes of administration, and pharmacokinetic/dynamic properties differ substantially across species. As one example, amphetamine reliably decreases PPI in rats only at doses above $2 \mathrm{mg} / \mathrm{kg}$ administered subcutaneously (Mansbach et al. 1988; Sills 1999; Swerdlow et al. 2006d), while the oral dose of amphetamine given to normal humans in PPI studies rarely exceeds $0.29 \mathrm{mg} / \mathrm{kg}$ (20 mg total; e.g., Hutchison and Swift 1999; Swerdlow et al. 2003b). Species differences in drug effects might also reflect contextual differences in the test setting. Humans volunteer and are paid for study participation, have the test conditions explained by a supportive research assistant, swallow a pill, and sit in a comfortable chair during testing; by contrast, rats are removed from a cage, injected with a drug, and then placed alone in a plastic tube inside an unfamiliar box where they are exposed to loud, unexpected noises. One might imagine that drug effects on a fight-or-flight reflex (startle) might differ in these two conditions, independent of species. Furthermore, while the parametric properties of PPI (e.g., sensitivity to prepulse intensity and interval) are strikingly similar across species, drug effects might reveal some crossspecies differences in these parametric effects. For example, at 120 ms prepulse intervals, ketamine has opposite effects on PPI in rats (disrupts PPI; Mansbach and Geyer 1989) and humans (increases PPI; Abel et al. 2003; Duncan et al. 2001); 
on the other hand, ketamine can increase PPI in rats at shorter prepulse intervals (e.g., 30 ms; Mansbach and Geyer 1989). Our group has detected similar species- and intervaldependent effects with the NMDA antagonist, memantine (Swerdlow et al. 2003c, 2005a). Conceivably, NMDA-related mechanisms of drug effects on gating at $30 \mathrm{~ms}$ in rats might best approximate those at $120 \mathrm{~ms}$ in humans.

However, this explanation does not address the conceptual dilemma created by the fact that psychotomimetic drugs increase PPI in normal humans, while schizophrenia is associated with reduced PPI. While PPI deficits in schizophrenia might possibly reflect the consequences of sustained deficiencies in glutamatergic activity in the context of developmentally aberrant neural connections, it does not follow that such effects would be reproduced by an acute challenge of an NMDA antagonist to a normal individual with normal neural connectivity. Furthermore, one might easily imagine that acute drug effects on an intact brain might enhance sensorimotor gating via a mechanism that is very distinct from (e.g., "upstream" or "downstream" from) those responsible for reduced gating in the brain of a schizophrenia patient. Nonetheless, faced with these discrepant effects of psychotomimetic drugs on PPI, it is difficult to know whether the failings lie in the cross-species translation of the PPI model, in the validity of the acute ketamine/ glutamate antagonist model of schizophrenia, or both.

An additional challenge in building neurobiological bridges of PPI studies across species comes from the human side of the bridge-from the observations that drug effects on PPI in humans can differ significantly, depending on basal levels of PPI. A number of drugs-including amphetamine (Swerdlow et al. 2003b), pergolide, amantadine (Bitsios et al. 2005), quetiapine (Swerdlow et al. 2006a), and clozapine (Vollenweider et al. 2006) - have been demonstrated to have effects that differ significantly (and in some cases, are arithmetically opposite) in normal humans with low vs. high PPI levels, relative to the overall test population. Similar findings may be emerging from animal studies, e.g., among inbred strains with low basal levels of PPI (cf. Ouagazzal et al. 2001a). How we interpret this "rate dependency" of drug effects on PPI in humans and laboratory animals and what it means about the many reported drug effects on PPI that have not considered or tested the impact of basal PPI levels, are issues that remain to be resolved.

While this discussion has focused primarily on crossspecies comparisons between rodents and humans, and we discussed earlier the strain differences in PPI that have been detected in both rats and mice, it is also worth noting that there are also a number of important cross-species differences in PPI and its parametric and pharmacological sensitivity between rats and mice. Just as one example, while PPI is disrupted by DA agonists in both rats and mice, there is some evidence that this effect primarily reflects activation of $\mathrm{D} 2$ receptors in rats (Swerdlow et al. 1994; cf. Geyer et al. 2001), but of D1 receptors in mice (Ralph-Williams et al. 2003a; Ralph and Caine 2005). Within a restricted set of stimulus parameters (particularly prepulse intervals), infusion of D2 agonists into the nucleus accumbens decreases PPI in rats and increases PPI in mice (Mohr et al. 2007). This issue is not yet settled, as mice lacking D2 receptors are insensitive to the PPI-disruptive effects of $d$-amphetamine (Ralph et al. 1999), and some mouse strains exhibit "rat-like" PPI sensitivity to D2 agonists (Ralph and Caine 2007). Nonetheless, enough data exists that we can be fairly confident that a similar drug effect on PPI in rats and mice does not necessarily reflect a common underlying brain substrate. This raises the dilemma that when modeling the loss of PPI in schizophrenia, we are almost certainly studying very different neurobiological substrates, depending on the model species; this makes it very difficult to identify a clear, a priori rationale for selecting one species over another.

A surrogate measure for neural processes with wide-reaching psychological implications

Models of higher cognitive processes are only now being developed in rodents. Given the limited size and processing capacity of the frontal cortex in mice and rats vs. primates, and its relatively weaker contribution to the organization of behavior, there is reason to be skeptical that rodent models of higher cognitive processes will provide meaningful homology to human cognition. Nonetheless, mice and rats are amenable to complex conditioning schedules and are capable of performing choices and sophisticated behavioral sequences, and it is certain that studies will assess the potential relationship of PPI to these processes (e.g., Roegge et al. 2007; Depoortere et al. 2007a, b; Garner et al. 2007; Paine et al. 2007). Extrapolating these findings to humans will present many challenges. In general, the farther forward one moves in the brain, the greater the anatomical and functional differences between rodents and humans. For example, one might imagine a scenario in which "cognitive" control in rodents involves a prominent role for subcortical (e.g., basal ganglia) functions that overlap with PPI-regulatory circuitry, while in humans, higher cognitive control is "encephalized" to discrete frontal circuits that participate less in the regulation of startle gating.

There is already some evidence for both convergence and divergence of PPI and other operational animal models of "gating", in terms of their underlying neural substrates. For example, contemporaneous measures of PPI and N40 gating - an animal model of P50 ERP gating in humans - revealed that apomorphine, phencyclidine, and DOI each disrupt PPI and reduce ERP responsivity to the $\mathrm{S} 1$ stimulus in the N40-gating 
paradigm, but do not specifically disrupt N40 gating per se (Swerdlow et al. 2006b). Some overlap has been reported in the pharmacological sensitivity of PPI and [some of the various forms of] latent inhibition to DA agonists and NMDA antagonists (Mansbach and Geyer 1989; Bakshi et al. 1995; Razoux et al. 2007), although many conditions lead to a loss of PPI in rats but leave latent inhibition intact (e.g., amphetamine withdrawal (PelegRaibstein et al. 2006a, b) and D2 blockade in the basolateral amygdala (Stevenson and Gratton 2004)). Thus, neurobiological mechanisms of PPI cannot be assumed to be common to experimental measures of either sensory or cognitive gating in rats. The potential overlap in the neurobiology of PPI and higher-order functions in rats, such as working memory, is an area of ongoing investigation. At present, there is no compelling evidence that such an overlap exists or that PPI is informative about higher cognitive functions in rodents.

\section{Summary: animal studies}

Animal models will remain an important tool in developing and testing hypotheses for the pathogenesis of brain disorders. As a reliable, quantitative "read out" of relatively well-defined neural circuitry, measures of PPI in laboratory animals will continue to be used to test and validate these hypotheses and to generate important new hypotheses regarding cellular mechanisms and therapeutic strategies. PPI models provide predictive validity in drug discovery and development, both as rapid through-put screens and as components of more biologically sophisticated models involving developmental, immunologic, and genetic manipulations. Areas of convergence and divergence are being identified in the cross-species pharmacology of PPI; areas of convergence will be exploited so that human drug effects can be predicted and understood based on PPI drug effects in rodents and their underlying cellular and molecular substrates. Finally, the relationship of PPI to higher-order learning processes is being explored in rodents, and the findings will be used to generate and test hypotheses regarding the interplay of sensorimotor gating and cognition in normal and disordered humans.

\section{Conclusions}

The construct of gating deficits in neuropsychiatric disorders has empirical support and intuitive appeal, and serves as a unifying heuristic for understanding the psychological and neural substrates shared by otherwise apparently unrelated disorders. PPI is an operational measure of basic, brain-based gating processes. It is robust, reliable, easily quantified, and versatile as an experimental tool, and is abnormal in several brain disorders including schizophrenia, that are characterized by clinical evidence of impaired gating of sensory, cognitive, motor of affective information. PPI can be measured across species and is regulated in laboratory animals by neurochemical, anatomical, developmental, and genetic substrates that can be systematically studied and used as the basis for developing and testing hypotheses for the biological basis of PPI deficits in patients.

For all of these reasons, studies of PPI in humans and laboratory animals have multiplied and expanded, and this measure is being used to explore many new questions at many different levels of analysis. While our field does not yet face the floods of the "Sorcerer's Apprentice" (von Goethe 1779), it is clear that findings have amassed at an exponential rate and are testing our collective ability to critically integrate results, to identify areas of consistency, redundancy, and disagreement. Based on a review of the present literature, we reached several conclusions: (1) in humans, PPI is not "diagnostic"; levels of PPI do not predict clinical course, specific symptoms, or individual medication responses; (2) in preclinical studies, PPI is valuable for evaluating models or model organisms relevant to schizophrenia, "mapping" neural substrates of deficient PPI in schizophrenia, and advancing the discovery and development of novel therapeutics; (3) across species, PPI is a reliable, robust quantitative phenotype that is useful for probing the neurobiology and genetics of gating deficits in schizophrenia. In this review, we also identify some realistic expectations of this paradigm, describing its considerable strengths but also limitations, and stress some interpretative issues for consideration as we move forward with this powerful tool for translational neuropsychiatric research.

Acknowledgements The authors of this study were supported by grants from the NIMH (NRS, DLB, GAL: MH 42228, MH 65571; NRS: MH 68366, MH 53484, MH 58903, MH 69589; GAL: MH 79777) and the VISN 22 MIRECC (DLB, GAL). DLB also was supported by a NARSAD Distinguished Investigator Award. The authors have also served as paid consultants to pharmaceutical companies or have had research supported by these companies (NRS, DLB, GAL: Allergan Pharmaceuticals, Pfizer Pharmaceuticals; DLB: Acadia Pharmaceuticals; GAL: Memory Pharmaceuticals, Sepacor and Astra-Zeneca). No funding entity provided any input to, oversight of, or influence over the contents of this review. The authors thank Ms. Maria Bongiovanni and Mr. David Ko for their expert assistance in manuscript preparation.

\section{References}

Aasen I et al (2005) Sex effects in prepulse inhibition and facilitation of the acoustic startle response: implications for pharmacological and treatment studies. J Psychopharmacol 19:39-45

Abel K et al (1998) Repeated testing of prepulse inhibition and habituation of the startle reflex: a study in healthy human controls. J Psychopharmacol 12:330-337

Abel KM et al (2003) Low dose ketamine increases prepulse inhibition in healthy men. Neuropharmacology 44:729-737 
Adage T et al (2007) In vitro and in vivo pharmacological profile of AS057278, a selective d-amino acid oxidase inhibitor with potential anti-psychotic properties. Eur Neuropsychopharmacol (in press)

Addington $J$ et al (2007) North American Prodrome Longitudinal Study. North American Prodrome Longitudinal Study: a collaborative multisite approach to prodromal schizophrenia research. Schizophr Bull 33:665-672

Adler LE et al (1982) Neurophysiological evidence for a defect in neuronal mechanisms involved in sensory gating in schizophrenia. Biol Psychiatry 17:639-654

Afonso VM et al (2007) Medial prefrontal cortex lesions in the female rat affect sexual and maternal behavior and their sequential organization. Behav Neurosci 121:515-526

American Psychiatric Association (APA) (2000) Diagnostic and Statistical Manual of Mental Disorders DSM-IV-TR Fourth Edition (Text Revision)

Andreasen JT et al (2006) Nicotine and clozapine selectively reverse a $\mathrm{PCP}-$ induced deficit of PPI in BALB/cByJ but not NMRI mice: comparison with risperidone. Behav Brain Res 167:118-127

Auclair AL et al (2006) Actions of novel antipsychotic agents on apomorphine-induced PPI disruption: influence of combined serotonin 5-HT1A receptor activation and dopamine D2 receptor blockade. Neuropsychopharmacology 31:1900-1909

Auclair AL et al (2007) Putative antipsychotics with pronounced agonism at serotonin 5-HT1A and partial agonist activity at dopamine D2 receptors disrupt basal PPI of the startle reflex in rats. Psychopharmacology (Berl) 193:45-54

Bakshi VP et al (1995) A comparison of the effects of amphetamine, strychnine and caffeine on prepulse inhibition and latent inhibition. Behav Pharmacol 6:801-809

Ballmaier M et al (2001a) Combined alpha 2-adrenergic/D2 dopamine receptor blockade fails to reproduce the ability of clozapine to reverse phencyclidine-induced deficits in prepulse inhibition of startle. Psychopharmacology (Berl) 159:105-110

Ballmaier M et al (2001b) Selective immunolesioning of cholinergic neurons in nucleus basalis magnocellularis impairs prepulse inhibition of acoustic startle. Neuroscience 108:299-305

Ballmaier M et al (2002) Rivastigmine antagonizes deficits in prepulse inhibition induced by selective immunolesioning of cholinergic neurons in nucleus basalis magnocellularis. Neuroscience 114:91-98

Ballmaier M et al (2007) Cannabinoid receptor antagonists counteract sensorimotor gating deficits in the phencyclidine model of psychosis. Neuropsychopharmacology 32:2098-2107

Barr AM et al (2004) The selective serotonin-2A receptor antagonist M100907 reverses behavioral deficits in dopamine transporter knockout mice. Neuropsychopharmacology 29:221-228

Barr AM et al (2006) Iloperidone reduces sensorimotor gating deficits in pharmacological models, but not a developmental model, of disrupted prepulse inhibition in rats. Neuropharmacology $51: 457-465$

Barr AM et al (2007) The reelin receptors VLDLR and ApoER2 regulate sensorimotor gating in mice. Neuropharmacology 52:1114-1123

Barrett SL et al (2005) Normal levels of prepulse inhibition in the euthymic phase of bipolar disorder. Psychol Med 35:1737-1746

Bast T et al (2001) Hyperactivity and disruption of prepulse inhibition induced by $N$-methyl-D-aspartate stimulation of the ventral hippocampus and the effects of pretreatment with haloperidol and clozapine. Neuroscience 103:325-335

Beglopoulos V et al (2005) Neurexophilin 3 is highly localized in cortical and cerebellar regions and is functionally important for sensorimotor gating and motor coordination. Mol Cell Biol 25:7278-7288

Bell RL et al (2003) Amphetamine-modified acoustic startle responding and prepulse inhibition in adult and adolescent alcohol- preferring and -nonpreferring rats. Pharmacol Biochem Behav $75: 163-171$

Bickel S et al (2008) Early auditory sensory processing deficits in mouse mutants with reduced NMDA receptor function. Neuropsychopharmacology (in press)

Bitsios P et al (2005) The effects of dopamine agonists on prepulse inhibition in healthy men depend on baseline PPI values. Psychopharmacology (Berl) 182:144-152

Bitsios P et al (2006) Increased prepulse inhibition of the acoustic startle response is associated with better strategy formation and execution times in healthy males. Neuropsychologia 44:2494-2499

Bleuler E (1911/1950) Dementia praecox; or, the group of schizophrenias. International Universities Press, New York

Boeckler F et al (2004) FAUC 213, a highly selective dopamine D4 receptor full antagonist, exhibits atypical antipsychotic properties in behavioural and neurochemical models of schizophrenia. Psychopharmacology (Berl) 175:7-17

Bontekoe CJ et al (2002) Knockout mouse model for Fxr2: a model for mental retardation. Hum Mol Genet 11:487-498

Borrell J et al (2002) Prenatal immune challenge disrupts sensorimotor gating in adult rats. Implications for the etiopathogenesis of schizophrenia. Neuropsychopharmacology 26:204-215

Bortolato $\mathrm{M}$ et al (2004) Baclofen reverses the reduction in prepulse inhibition of the acoustic startle response induced by dizocilpine, but not by apomorphine. Psychopharmacology (Berl) 171:322330

Bortolato $\mathrm{M}$ et al (2005) Kappa opioid receptor activation disrupts prepulse inhibition of the acoustic startle in rats. Biol Psychiatry $57: 1550-1558$

Bortolato $\mathrm{M}$ et al (2006) Anxiolytic-like properties of the anandamide transport inhibitor AM404. Neuropsychopharmacology 31:26522659

Bortolato $\mathrm{M}$ et al (2007) Activation of GABA(B) receptors reverses spontaneous gating deficits in juvenile DBA/2J mice. Psychopharmacology (Berl) 194:361-369

Boucher AA et al (2007) Heterozygous neuregulin 1 mice are more sensitive to the behavioural effects of Delta9-tetrahydrocannabinol. Psychopharmacology (Berl) 192:325-336

Bowers BJ et al (2005) Deletion of the alpha7 nicotinic receptor subunit gene results in increased sensitivity to several behavioral effects produced by alcohol. Alcohol Clin Exp Res 29:295-302

Boyce-Rustay JM, Holmes A (2006) Genetic inactivation of the NMDA receptor NR2A subunit has anxiolytic- and antidepressant-like effects in mice. Neuropsychopharmacology 31:24052414

Braff DL, Light GA (2004) Preattentional and attentional cognitive deficits as targets for treating schizophrenia. Psychopharmacology (Berl) 174:75-85

Braff D et al (1978) Prestimulus effects on human startle reflex in normals and schizophrenics. Psychophysiology 15:339-343

Braff DL et al (1992) Gating and habituation of the startle reflex in schizophrenic patients. Arch Gen Psychiatry 49:206-215

Braff DL et al (2001a) Impact of prepulse characteristics on the detection of sensorimotor gating deficits in schizophrenia. Schizophr Res 49:171-178

Braff DL et al (2001b) Human studies of prepulse inhibition of startle: normal subjects, patient groups, and pharmacological studies. Psychopharmacology 156:234-258

Braff DL et al (2005) Female schizophrenia patients have prepulse inhibition deficits. Biol Psychiatry 57:817-820

Braff DL et al (2007a) Deconstructing schizophrenia: an overview of the use of endophenotypes in order to understand a complex disorder. Schizophr Bull 33:21-32

Braff DL et al (2007b) Prepulse Inhibition and P50 Suppression are both deficient but not correlated in schizophrenia patients. Biol Psychiatry 61:1204-1207 
Braff et al (2008) One-year longitudinal study of 200 schizophrenia patients: no clinical, cognitive, neurophysiological or functional differences at intake in retested vs. non-retested patients. Abstr Society for Neuroscience (in press)

Brea J et al (2006) QF2004B, a potential antipsychotic butyrophenone derivative with similar pharmacological properties to clozapine. Neuropharmacology 51:251-262

Brody SA, Geyer MA (2004b) Interactions of the mGluR5 gene with breeding and maternal factors on startle and prepulse inhibition in mice. Neurotox Res 6:79-90

Brody SA et al (2003a) Disruption of prepulse inhibition in mice lacking mGluR1. Eur J Neurosci 18:3361-3366

Brody SA et al (2003b) Lamotrigine prevents ketamine but not amphetamine-induced deficits in prepulse inhibition in mice. Psychopharmacology (Berl) 169:240-246

Brody SA et al (2004a) Effect of antipsychotic treatment on the prepulse inhibition deficit of mGluR5 knockout mice. Psychopharmacology (Berl) 172:187-195

Brody SA et al (2005) A developmental influence of the $N$-methyl-Daspartate receptor NR3A subunit on prepulse inhibition of startle. Biol Psychiatry 57:1147-1152

Browman KE et al (2004) Enhancement of prepulse inhibition of startle in mice by the $\mathrm{H} 3$ receptor antagonists thioperamide and ciproxifan. Behav Brain Res 153:69-76

Brunskill EW et al (2005) Abnormal neurodevelopment, neurosignaling and behaviour in Npas3-deficient mice. Eur $\mathrm{J}$ Neurosci 22:1265-1276

Bubenikova V et al (2005) The effect of zotepine, risperidone, clozapine and olanzapine on MK-801-disrupted sensorimotor gating. Pharmacol Biochem Behav 80:591-596

Burne TH et al (2004) Combined prenatal and chronic postnatal vitamin $\mathrm{D}$ deficiency in rats impairs prepulse inhibition of acoustic startle. Physiol Behav 81:651-655

Burne TH et al (2005) Behavioural characterization of vitamin D receptor knockout mice. Behav Brain Res 157:299-308

Burton C et al (2006) Early adversity alters attention and locomotion in adult Sprague-Dawley rats. Behav Neurosci 120:665-675

Butler RW, Jenkins MA, Geyer MA, Braff D (1991) Wisconsin card sorting deficits and diminished sensorimotor gating in a discrete subgroup of schizophrenic patients. In: Tamminga CA, Schulz SC (eds) Advances in neuropsychiatry and psychopharmacology. New York, NY: Raven Press, pp 163-168

Byrnes EM et al (2007) Sensorimotor gating and dopamine function in postpartum rats. Neuropsychopharmacology 32:1021-1031

Caceda R et al (2005) Virally mediated increased neurotensin 1 receptor in the nucleus accumbens decreases behavioral effects of mesolimbic system activation. J Neurosci 25: $11748-11756$

Cadenhead KS (2002) Vulnerability markers in the schizophrenia spectrum: implications for phenomenology, genetics, and the identification of the schizophrenia prodrome. Psychiatr Clin North Am 25:837-853

Cadenhead KS et al (1999) Prepulse inhibition and habituation of the startle response are stable neurobiological measures in a normal male population. Biol Psychiatry 45:360-364

Cadenhead KS et al (2002) Neurobiological measures of schizotypal personality disorder: defining an inhibitory endophenotype. Am J Psychiatry 159:869-871

Caine SB et al (2001) Behavioral effects of psychomotor stimulants in rats with dorsal or ventral subiculum lesions: locomotion, cocaine self-administration, and prepulse inhibition of startle. Behav Neurosci 115:880-894

Calkins ME et al (2004) Antisaccade performance is impaired in medically and psychiatrically healthy biological relatives of schizophrenia patients. Schizophr Res 71:167-178
Calkins ME et al (2007) The consortium on the genetics of endophenotypes in schizophrenia: model recruitment, assessment, and endophenotyping methods for a multi-site collaboration. Schiz Bull 33:33-48

Cannon TD et al (2008) Prediction of psychosis in youth at high clinical risk: a multi-site longitudinal study in North America. Arch Gen Psychiatry 65:28-37

Cao BJ, Li Y (2002) Reduced anxiety- and depression-like behaviors in Emx1 homozygous mutant mice. Brain Res 937:32-40

Carroll CA et al (2007) Sensorimotor gating in manic and mixed episode bipolar disorder. Bipolar Disord 9:221-229

Carter RJ et al (1999) Characterization of progressive motor deficits in mice transgenic for the human Huntington's disease mutation. J Neurosci 19:3248-3257

Castellanos FX et al (1996) Sensorimotor gating in boys with Tourette's syndrome and ADHD: preliminary results. Biol Psychiatry 39:33-41

Catapano LA, Manji HK (2007) G protein-coupled receptors in major psychiatric disorders. Biochim Biophys Acta 1768:976-993

Chen L, Toth M (2001) Fragile X mice develop sensory hyperreactivity to auditory stimuli. Neuroscience 103:1043-1050

Chiu CS et al (2005) GABA transporter deficiency causes tremor, ataxia, nervousness, and increased GABA-induced tonic conductance in cerebellum. J Neurosci 25:3234-3245

Choy KH, van den Buuse M (2007) Attenuated disruption of prepulse inhibition by dopaminergic stimulation after maternal deprivation and adolescent corticosterone treatment in rats. Eur Neuropsychopharmacol 18:1-13

Cilia J et al (2005) Reversal of isolation-rearing-induced PPI deficits by an alpha7 nicotinic receptor agonist. Psychopharmacology (Berl) 182:214-219

Cilia J et al (2007) (+/-) Ketamine-induced prepulse inhibition deficits of an acoustic startle response in rats are not reversed by antipsychotics. J Psychopharmacol 21:302-311

Clapcote SJ et al (2007) Behavioral phenotypes of Disc1 missense mutations in mice. Neuron 54:387-402

Conti LH et al (2005) Effects of a typical and an atypical antipsychotic on the disruption of prepulse inhibition caused by corticotropinreleasing factor and by rat strain. Behav Neurosci 119:1052-1060

Csomor PA et al (2008) Haloperidol differentially modulates prepulse inhibition and P50 suppression in healthy humans stratified for low and high gating levels. Neuropsychopharmacology 33:497-512

Cui $\mathrm{C}$ et al (2003) The beta3 nicotinic receptor subunit: a component of alpha-conotoxin MII-binding nicotinic acetylcholine receptors that modulate dopamine release and related behaviors. J Neurosci 23:11045-11053

Culm KE et al (2003) Reduced G(i) and G(o) protein function in the rat nucleus accumbens attenuates sensorimotor gating deficits. Brain Res 982:12-18

Culm KE et al (2004) Repeated quinpirole treatment increases cAMP-dependent protein kinase activity and CREB phosphorylation in nucleus accumbens and reverses quinpirole-induced sensorimotor gating deficits in rats. Neuropsychopharmacology 29:1823-1830

Czyrak A et al (2003) 8-OHDPAT-induced disruption of prepulse inhibition in rats is attenuated by prolonged corticosterone treatment. Neuropsychopharmacology 28:1300-1310

Daenen EW et al (2003) Neonatal lesions in the amygdala or ventral hippocampus disrupt prepulse inhibition of the acoustic startle response; implications for an animal model of neurodevelopmental disorders like schizophrenia. Eur Neuropsychopharmacol 13:187-197

Dai $\mathrm{H}$ et al (2004) Social isolation stress significantly enhanced the disruption of prepulse inhibition in mice repeatedly treated with methamphetamine. Ann NY Acad Sci 1025:257-266 
Dai H et al (2005) Blockage of histamine H1 receptor attenuates social isolation-induced disruption of prepulse inhibition: a study in $\mathrm{H} 1$ receptor gene knockout mice. Psychopharmacology (Berl) 183:285-293

Davis M (1984) The mammalian startle response. In: Eaton RC (ed) Neural mechanisms of startle behavior. Plenum Press, New York, pp 287-342

Davis M et al (1982) A primary acoustic startle circuit: lesion and stimulation studies. J Neurosci 2:791-805

Day-Wilson KM et al (2006) Medial prefrontal cortex volume loss in rats with isolation rearing-induced deficits in prepulse inhibition of acoustic startle. Neuroscience 141:1113-1121

de Jong IE, van den Buuse M (2006) SCH 23390 in the prefrontal cortex enhances the effect of apomorphine on prepulse inhibition of rats. Neuropharmacology 51:438-446

Depoortere R et al (2005) Neurochemical, electrophysiological and pharmacological profiles of the selective inhibitor of the glycine transporter-1 SSR504734, a potential new type of antipsychotic. Neuropsychopharmacology 30:1963-1985

Depoortere R et al (2007a) F15063, a compound with D2/D3 antagonist, 5-HT 1A agonist and D4 partial agonist properties. III. Activity in models of cognition and negative symptoms. Br J Pharmacol 151:266-277

Depoortere R et al (2007b) F15063, a compound with $\mathrm{D}(2) / \mathrm{D}(3)$ antagonist, 5-HT(1A) agonist and $\mathrm{D}(4)$ partial agonist properties: (II) Activity in models of positive symptoms of schizophrenia. $\mathrm{Br}$ J Pharmacol 151:253-265

Diederich K, Koch M (2005) Role of the pedunculopontine tegmental nucleus in sensorimotor gating and reward-related behavior in rats. Psychopharmacology 179:402-408

Dirks A et al (2002) Reduced startle reactivity and plasticity in transgenic mice overexpressing corticotrophin-releasing hormone. Biol Psychiatry 51:583-590

Dirks A et al (2003) Reversal of startle gating deficits in transgenic mice overexpressing corticotrophin-releasing factor by antipsychotic drugs. Neuropsychopharmacology 28:1790-1708

Dolder CR et al (2002) Antipsychotic medication adherence: is there a difference between typical and atypical agents. Am J Psychiatry 159:103-108

Duncan EJ et al (2001) Clinical and sensorimotor gating effects of ketamin in normals. Neuropsychopharmacology 25:72-83

Duncan E et al (2003a) Prepulse inhibition of acoustic startle in subjects with schizophrenia treated with olanzapine or haloperidol. Psychiatry Res 120:1-12

Duncan EJ et al (2003b) Effect of treatment status on prepulse inhibition of acoustic startle in schizophrenia. Psychopharmacology (Berl) 167:63-71

Duncan GE et al (2004) Deficits in sensorimotor gating and tests of social behavior in a genetic model of reduced NMDA receptor function. Behav Brain Res 153:507-519

Duncan EJ et al (2006a) Medication status affects the relationship of symptoms to prepulse inhibition of acoustic startle in schizophrenia. Psychiatry Res 145:137-145

Duncan GE et al (2006b) Typical and atypical antipsychotic drug effects on locomotor hyperactivity and deficits in sensorimotor gating in a genetic model of NMDA receptor hypofunction. Pharmacol Biochem Behav 85:481-491

Eells JB et al (2006) Early postnatal isolation reduces dopamine levels, elevates dopamine turnover and specifically disrupts prepulse inhibition in Nurr1-null heterozygous mice. Neuroscience 140: $1117-1126$

Egashira N et al (2005) Disruption of the prepulse inhibition of the startle reflex in vasopressin $\mathrm{V} 1 \mathrm{~b}$ receptor knockout mice: reversal by antipsychotic drugs. Neuropsychopharmacology 30:1996-2005

Ehlers CL et al (2007) Increased alcohol drinking in isolate-housed alcohol-preferring rats. Behav Neurosci 121:111-119
Ellenbroek BA, Cools AR (2002) Early maternal deprivation and prepulse inhibition: the role of the postdeprivation environment. Pharmacol Biochem Behav 73:177-184

Ellenbroek BA et al (1996) Prepulse inhibition and latent inhibition: the role of dopamine in the medial prefrontal cortex. Neuroscience 75:535-542

Ellenbroek BA et al (2001) Effects of JL13, a pyridobenzoxazepine with potential atypical antipsychotic activity, in animal models for schizophrenia. J Pharmacol Exp Ther 298:386-391

Ellenbroek BA et al (2002b) The role of hippocampal dopamine receptors in prepulse inhibition. Eur J Neurosci 15:1237-1243

Elmer GI et al (2004) Altered prepulse inhibition in rats treated prenatally with the antimitotic Ara-C: an animal model for sensorimotor gating deficits in schizophrenia. Psychopharmacology (Berl) 174:177-189

Erbel-Sieler C et al (2004) Behavioral and regulatory abnormalities in mice deficient in the NPAS1 and NPAS3 transcription factors. Proc Natl Acad Sci USA 101:13648-13653

Erhardt S et al (2004) Endogenous kynurenic acid disrupts prepulse inhibition. Biol Psychiatry 56:255-260

Ewers $\mathrm{M}$ et al (2006) Associative and motor learning in 12-month-old transgenic APP+PS1 mice. Neurobiol Aging 27:1118-1128

Feifel D, Priebe K (2001) Vasopressin-deficient rats exhibit sensorimotor gating deficits that are reversed by subchronic haloperidol. Biol Psychiatry 50:425-433

Feifel D et al (2001) Startle and sensorimotor gating in rats lacking CCK-A receptors. Neuropsychopharmacology 24:663-670

Feifel D et al (2004) Reversal of sensorimotor gating deficits in Brattleboro rats by acute administration of clozapine and a neurotensin agonist, but not haloperidol: a potential predictive model for novel antipsychotic effects. Neuropsychopharmacology 29:731-738

Fejgin K et al (2007) The atypical antipsychotic, aripiprazole, blocks phencyclidine-induced disruption of prepulse inhibition in mice. Psychopharmacology (Berl) 191:377-385

Ferguson SA, Cada AM (2004) Spatial learning/memory and social and nonsocial behaviors in the spontaneously hypertensive, WistarKyoto and Sprague-Dawley rat strains. Pharmacol Biochem Behav 77:583-594

Finamore TL et al (2001) Contributions of hippocampal cellular damage and NMDA receptor dysfunction to behavioral markers of schizophrenia. Int J Neurosci 109:61-70

Fitting S et al (2006a) Intrahippocampal injections of Tat: effects on prepulse inhibition of the auditory startle response in adult male rats. Pharmacol Biochem Behav 84:189-196

Fitting $S$ et al (2006b) Neonatal hippocampal Tat injections: developmental effects on prepulse inhibition (PPI) of the auditory startle response. Int J Dev Neurosci 24:275-283

Fitting $\mathrm{S}$ et al (2006c) Neonatal intrahippocampal glycoprotein 120 injection: the role of dopaminergic alterations in prepulse inhibition in adult rats. J Pharmacol Exp Ther 318:1352-1358

Flaten MA (2002) Test-retest reliability of the somatosensory blink reflex and its inhibition. Int J Psychophysiol 45:261-265

Flood DG et al (2008) Variables affecting prepulse inhibition of the startle reflex and the response to antipsychotics in DBA/2NCrl mice. Psychopharmacology (Berl) 195:203-211

Fortier ME et al (2007) Effects of prenatal infection on prepulse inhibition in the rat depend on the nature of the infectious agent and the stage of pregnancy. Behav Brain Res 181:270-277

Fox GB et al (2005) Pharmacological properties of ABT-239 [4-(2- $\{2-$ [(2R)-2-Methylpyrrolidinyl]ethyl\}-benzofuran-5-yl)benzonitrile]: II. Neurophysiological characterization and broad preclinical efficacy in cognition and schizophrenia of a potent and selective histamine $\mathrm{H} 3$ receptor antagonist. J Pharmacol Exp Ther 313:176-190

Fradley RL et al (2005) STOP knockout and NMDA NR1 hypomorphic mice exhibit deficits in sensorimotor gating. Behav Brain Res 163:257-264 
Frankland PW et al (2004) Sensorimotor gating abnormalities in young males with fragile $\mathrm{X}$ syndrome and Fmr1-knockout mice. Mol Psychiatry 9:417-425

Frau R et al (2007) Effects of topiramate on the prepulse inhibition of the acoustic startle in rats. Neuropsychopharmacology 32:320-331

Freedman R et al (1997) Linkage of a neurophysiological deficit in schizophrenia to a chromosome 15 locus. Proc Natl Acad Sci USA 94:587-592

Freudenberg F et al (2007) Selective breeding for deficient sensorimotor gating is accompanied by increased perseveration in rats. Neuroscience 148:612-622

Fujiwara $\mathrm{N}$ et al (2006) Effects of copper metabolism on neurological functions in Wistar and Wilson's disease model rats. Biochem Biophys Res Commun 349:1079-1086

Futamura $\mathrm{T}$ et al (2003) Neonatal perturbation of neurotrophic signaling results in abnormal sensorimotor gating and social interaction in adults: implication for epidermal growth factor in cognitive development. Mol Psychiatry 8:19-29

Galici R et al (2005) A selective allosteric potentiator of metabotropic glutamate (mGlu) 2 receptors has effects similar to an orthosteric mGlu2/3 receptor agonist in mouse models predictive of antipsychotic activity. J Pharmacol Exp Ther 315:1181-1187

Garner B et al (2007) Early maternal deprivation reduces prepulse inhibition and impairs spatial learning ability in adulthood: no further effect of post-pubertal chronic corticosterone treatment. Behav Brain Res 176:323-332

George TP et al (2006) A preliminary study of the effects of cigarette smoking on prepulse inhibition in schizophrenia: involvement of nicotinic receptor mechanisms. Schizophr Res 87:307-315

Geyer MA, Swerdlow NR (1998) Measurement of startle response, prepulse inhibition, and habituation. In: Crawley JN, Skolnick P (eds) Current protocols in neuroscience, Unit 8.7. Wiley, New York, pp 1-15

Geyer MA et al (1993) Isolation rearing of rats produces a deficit in prepulse inhibition of acoustic startle similar to that in schizophrenia. Biol Psychiatry 34:361-372

Geyer MA et al (2001) Pharmacological studies of prepulse inhibition models of sensorimotor gating deficits in schizophrenia: a decade in review. Psychopharmacology 156:117-154

Geyer MA et al (2002) Mouse genetic models for prepulse inhibition: an early review. Mol Psychiatry 7:1039-1053

Gizerian SS et al (2006) Neonatal neurosteroid administration results in development-specific alterations in prepulse inhibition and locomotor activity: neurosteroids alter prepulse inhibition and locomotor activity. Psychopharmacology (Berl) 186:334-342

Gogos A, Van den Buuse M (2004) Estrogen and progesterone prevent disruption of prepulse inhibition by the serotonin-1A receptor agonist 8-hydroxy-2-dipropylaminotetralin. J Pharmacol Exp Ther 309:267-274

Gogos A et al (2006) Oestrogen modulation of the effect of 8-OHDPAT on prepulse inhibition: effects of aromatase deficiency and castration in mice. Psychopharmacology (Berl) 188:100-110

Gomez-Wong E et al (1998) Sensory modulation of the blink reflex in patients with blepharospasm. Arch Neurol 55:1233-1237

Goto K et al (2002) Reduced prepulse inhibition in rats with entorhinal cortex lesions. Behav Brain Res 134:201-207

Goto K et al (2004) Involvement of nucleus accumbens dopaminergic transmission in acoustic startle: observations concerning prepulse inhibition in rats with entorhinal cortex lesions. Psychiatry Clin Neurosci 58:441-445

Gottesman II, Gould TD (2003) The endophenotype concept in psychiatry: etymology and strategic intentions. Am J Psychiatry 160:636-645

Gould TD, Gottesman II (2006) Psychiatric endophenotypes and the development of valid animal models. Genes Brain Behav 5: 113-119
Gould TJ et al (2004) Sensorimotor gating deficits in transgenic mice expressing a constitutively active form of Gs alpha. Neuropsychopharmacology 29:494-501

Graham F (1975) The more or less startling effects of weak prestimuli. Psychophysiology 12:238-248

Gray JA (1995) The contents of consciousness: a neuropsychological conjecture. Behav Brain Sci 18:659-722

Greenwood TA et al (2007) The Consortium on the Genetics of Schizophrenia (COGS): Preliminary heritability analyses of endophenotypic measures for schizophrenia. Arch Gen Psychiatry 33:33-48

Grillon C et al (1998) Effects of experimental context and explicit threat cues on acoustic startle in Vietnam veterans with posttraumatic stress disorder. Biol Psychiatry 44:1027-1036

Grobin AC et al (2006) Perinatal allopregnanolone influences prefrontal cortex structure, connectivity and behavior in adult rats. Neuroscience 138:809-819

Grobstein P (2005) Making the unconscious conscious: a bidirectional bridge between neuroscience/ cognitive science and psychotherapy. Cortex 41:663-668

Groenink L et al (2008) CRF(1) not glucocorticoid receptors mediate prepulse inhibition deficits in mice overexpressing CRF. Biol Psychiatry 63:360-368

Harris LW et al (2003) Long-term behavioural, molecular and morphological effects of neonatal NMDA receptor antagonism. Eur J Neurosci 18:1706-1710

Harrison SM et al (2003) LPA1 receptor-deficient mice have phenotypic changes observed in psychiatric disease. Mol Cell Neurosci 24:1170-1179

Harte MK et al (2007) Deficits in parvalbumin and calbindin immunoreactive cells in the hippocampus of isolation reared rats. J Neural Transm 114:893-898

Hauser J et al (2005) Hippocampal alpha5 subunit-containing GABAA receptors modulate the expression of prepulse inhibition. Mol Psychiatry 10:201-207

Hauser J et al (2006) Prenatal dexamethasone exposure, postnatal development, and adulthood prepulse inhibition and latent inhibition in Wistar rats. Behav Brain Res 175:51-61

Hazlett EA et al (2003) Deficient attentional modulation of the startle response in patients with schizotypal personality disorder. Am J Psychiatry 160:1621-1626

Heldt SA, Ressler KJ (2006) Lesions of the habenula produce stressand dopamine-dependent alterations in prepulse inhibition and locomotion. Brain Res 1073-1074:229-239

Heldt SA et al (2004) Prepulse inhibition deficits in GAD65 knockout mice and the effect of antipsychotic treatment. Neuropsychopharmacology 29:1610-1619

Henck JW et al (2001) Growth and development in rats given recombinant human epidermal growth factor(1-48) as neonates. Toxicol Sci 62:80-91

Heresco-Levy U et al (2007) High glycine levels are associated with prepulse inhibition deficits in chronic schizophrenia patients. Schizophr Res 91:14-21

Hoenig K et al (2005) Impaired prepulse inhibition of acoustic startle in obsessive-compulsive disorder. Biol Psychiatry 57:1153-1158

Hohnadel E et al (2007) Galantamine and donepezil attenuate pharmacologically induced deficits in prepulse inhibition in rats. Neuropharmacology 52:542-551

Holmes A et al (2001) Behavioral characterization of dopamine D5 receptor null mutant mice. Behav Neurosci 115:1129-1144

Hong LE et al (2007) Independent domains of inhibitory gating in schizophrenia and the effect of stimulus interval. Am J Psychiatry 164:61-65

Howland JG et al (2004a) Delayed onset of prepulse inhibition deficits following kainic acid treatment on postnatal day 7 in rats. Eur J Neurosci 20:2639-2648 
Howland JG et al (2004b) Electrical stimulation of the hippocampus disrupts prepulse inhibition in rats: frequency- and site-dependent effects. Behav Brain Res 152:187-197

Howland JG et al (2007) Kindling of basolateral amygdala but not ventral hippocampus or perirhinal cortex disrupts sensorimotor gating in rats. Behav Brain Res 177:30-36

Hsieh MH et al (2006) Effects of background and prepulse characteristics on prepulse inhibition and prepulse facilitation: implications for neuropsychiatric research. Biol Psychiatry 15 59(6):555-559

Husum $\mathrm{H}$ et al (2002) Early maternal deprivation alters hippocampal levels of neuropeptide $\mathrm{Y}$ and calcitonin-gene related peptide in adult rats. Neuropharmacology 42:798-806

Hutchison KE, Swift R (1999) Effect of $d$-amphetamine on prepulse inhibition of the startle reflex in humans. Psychopharmacology (Berl) 143:394-400

Inada $\mathrm{K}$ et al (2003) Antisense hippocampal knockdown of NMDANR1 by HVJ-liposome vector induces deficit of prepulse inhibition but not of spatial memory. Neurosci Res 45:473-481

Irintchev A et al (2004) Impairment of sensorimotor gating in mice deficient in the cell adhesion molecule L1 or its close homologue, CHL1. Brain Res 1029:131-134

Iso $\mathrm{H}$ et al (2007) Environmental change during postnatal development alters behaviour, cognitions and neurogenesis of mice. Behav Brain Res 179:90-98

Jaworski DM et al (2005) Prepulse inhibition and fear-potentiated startle are altered in tissue inhibitor of metalloproteinase-2 (TIMP-2) knockout mice. Brain Res 1051:81-89

Jones CK, Shannon HE (2004) Lesions of the laterodorsal tegmental nucleus disrupt prepulse inhibition of the acoustic startle reflex. Pharmacol Biochem Behav 78:229-237

Jones CK et al (2005) Pharmacologic interactions between the muscarinic cholinergic and dopaminergic systems in the modulation of prepulse inhibition in rats. J Pharmacol Exp Ther 312:1055-1063

Jongen-Relo AL et al (2004) The prenatal methylazoxymethanol acetate treatment: a neurodevelopmental animal model for schizophrenia. Behav Brain Res 149:159-181

Jovanovic $T$ et al (2004) Menstrual cycle phase effects on prepulse inhibition of acoustic startle. Psychophysiology 41:401-406

Kaifu T et al (2003) Osteopetrosis and thalamic hypomyelinosis with synaptic degeneration in DAP12-deficient mice. J Clin Invest 111:323-332

Kanabus $\mathrm{M}$ et al (2002) Temporal order judgement for auditory and visual stimuli. Acta Neurobiol Exp 62:263-270

Kanes SJ et al (2007) Rolipram: a specific phosphodiesterase 4 inhibitor with potential antipsychotic activity. Neuroscience 144:239-246

Karper LP et al (1996) Preliminary evidence of an association between sensorimotor gating and distractibility in psychosis. J Neuropsychiatry Clin Neurosci 8:60-66

Kedzior KK, Martin-Iverson MT (2007) Attention-dependent reduction in prepulse inhibition of the startle reflex in cannabis users and schizophrenia patients - a pilot study. Eur J Pharmacol 560:176-182

Kelly MP et al (2007) Constitutive activation of Galphas within forebrain neurons causes deficits in sensorimotor gating because of PKA-dependent decreases in cAMP. Neuropsychopharmacology 32:577-588

Kimura J, Harada O (1976) Recovery curves of the blink reflex during wakefulness and sleep. J Neurol 213:189-198

Kinkead B et al (2005) Neurotensin-deficient mice have deficits in prepulse inhibition: restoration by clozapine but not haloperidol, olanzapine, or quetiapine. J Pharmacol Exp Ther 315:256-264

Kinney GG et al (2003) The glycine transporter type 1 inhibitor $N$-[3-(4'fluorophenyl)-3-(4'-phenylphenoxy)propyl]sarcosine potentiates NMDA receptor-mediated responses in vivo and produces an antipsychotic profile in rodent behavior. J Neurosci 23:7586-7591
Kinney GG et al (2005) A novel selective positive allosteric modulator of metabotropic glutamate receptor subtype 5 has in vivo activity and antipsychotic-like effects in rat behavioral models. J Pharmacol Exp Ther 313:199-206

Klamer D et al (2004a) Phencyclidine-induced behaviour in mice prevented by methylene blue. Basic Clin Pharmacol Toxicol 94:65-72

Klamer D et al (2004b) The neuronal selective nitric oxide synthase inhibitor, Nomega-propyl-L-arginine, blocks the effects of phencyclidine on prepulse inhibition and locomotor activity in mice. Eur J Pharmacol 503:103-107

Klamer D et al (2005a) Activation of a nitric-oxide-sensitive cAMP pathway with phencyclidine: elevated hippocampal cAMP levels are temporally associated with deficits in prepulse inhibition. Psychopharmacology (Berl) 179:479-488

Klamer D et al (2005b) Effects of phencyclidine on acoustic startle and prepulse inhibition in neuronal nitric oxide synthase deficient mice. Eur Neuropsychopharmacol 15:587-590

Klejbor I et al (2006) Fibroblast growth factor receptor signaling affects development and function of dopamine neurons - inhibition results in a schizophrenia-like syndrome in transgenic mice. J Neurochem 97:1243-1258

Koch M, Schnitzler HU (1997) The acoustic startle response in ratscircuits mediating evocation, inhibition and potentiation. Behav Brain Res 89:35-49

Koch M et al (1993) Cholinergic neurons in the pedunculopontine tegmental nucleus are involved in the mediation of prepulse inhibition of the acoustic startle response in the rat. Exp Brain Res 97:71-82

Koenig JI et al (2005) Prenatal exposure to a repeated variable stress paradigm elicits behavioral and neuroendocrinological changes in the adult offspring: potential relevance to schizophrenia. Behav Brain Res 156:251-261

Koh HY et al (2008) Deficits in social behavior and sensorimotor gating in mice lacking phospholipase Cbeta1. Genes Brain Behav 7:120-128

Kraepelin E, Robertson GM (1919) Dementia praecox and paraphrenia. Livingstone Edinburgh

Krebs-Thomson K et al (2006) The roles of 5-HT1A and 5-HT2 receptors in the effects of 5-MeO-DMT on locomotor activity and prepulse inhibition in rats. Psychopharmacology (Berl) 189:319-329

Kumari V et al (1999) Normalization of information processing deficits in schizophrenia with clozapine. Am J Psychiatry 156:1046-1051

Kumari V et al (2001) Influence of cigarette smoking on prepulse inhibition of the acoustic startle response in schizophrenia. Hum Psychopharmacol 16:321-326

Kumari V et al (2002) Prepulse inhibition of the startle response in risperidone-treated patients: comparison with typical antipsychotics. Schizophr Res 55:139-146

Kumari V et al (2003a) Neural correlates of tactile prepulse inhibition: a functional MRI study in normal and schizophrenic subjects. Psychiatry Res 122:99-113

Kumari V et al (2003b) Effects of acute procyclidine administration on prepulse inhibition of the startle response in schizophrenia: a doubleblind, placebo-controlled study. J Psychopharmacol 17:89-95

Kumari V et al (2004) Sex differences in prepulse inhibition deficits in chronic schizophrenia. Schizophr Res 69:219-235

Kumari V et al (2005a) Association between violent behaviour and impaired prepulse inhibition of the startle response in antisocial personality disorder and schizophrenia. Behav Brain Res 158:159-166

Kumari V et al (2005b) Lack of association between prepulse inhibition and antisaccadic deficits in chronic schizophrenia: implications for identification of schizophrenia endophenotypes. J Psychiatr Res 39:227-240 
Kumari V et al (2005c) Structural brain correlates of prepulse inhibition of the acoustic startle response in healthy humans. Neuroimage 26:1052-1058

Kumari V et al (2005d) Reduced prepulse inhibition in unaffected siblings of schizophrenia patients. Psychophysiology 42:588 594

Kumari V et al (2007a) A fMRI investigation of startle gating deficits in schizophrenia patients treated with typical or atypical antipsychotics. Int J Neuropsychopharmacol 10:463-477

Kumari V et al (2007b) Startle gating in antipsychotic-naive first episode schizophrenia patients: one ear is better than two. Psychiatry Res 151:21-28

Kusljic S, van den Buuse M (2004) Functional dissociation between serotonergic pathways in dorsal and ventral hippocampus in psychotomimetic drug-induced locomotor hyperactivity and prepulse inhibition in rats. Eur J Neurosci 20:3424-3432

Kusljic S, van den Buuse M (2006) Differential involvement of 5-HT projections within the amygdala in prepulse inhibition but not in psychotomimetic drug-induced hyperlocomotion. Behav Brain Res 168:74-82

Kusljic S et al (2003) Differential role of serotonergic projections arising from the dorsal and median raphe nuclei in locomotor hyperactivity and prepulse inhibition. Neuropsychopharmacology 28:2138-2147

Kusljic S et al (2006) Effects of haloperidol and clozapine on sensorimotor gating deficits induced by 5-hydroxytryptamine depletion in the brain. Br J Pharmacol 147:800-807

Lacro JP et al (2002) Prevalence of and risk factors for medication nonadherence in patients with schizophrenia: a comprehensive review of recent literature. J Clin Psychiatry 63:892-909

Lahdesmaki J et al (2004) Alpha2A-adrenoceptors are important modulators of the effects of D-amphetamine on startle reactivity and brain monoamines. Neuropsychopharmacology 29:1282-1293

Laplante $\mathrm{F}$ et al (2005) Alterations in behavioral responses to a cholinergic agonist in post-pubertal rats with neonatal ventral hippocampal lesions: relationship to changes in muscarinic receptor levels. Neuropsychopharmacology 30:1076-1087

Le Pen G, Moreau JL (2002) Disruption of prepulse inhibition of startle reflex in a neurodevelopmental model of schizophrenia: reversal by clozapine, olanzapine and risperidone but not by haloperidol. Neuropsychopharmacology 27:1-11

Le Pen G et al (2003) Prepulse inhibition deficits of the startle reflex in neonatal ventral hippocampal-lesioned rats: reversal by glycine and a glycine transporter inhibitor. Biol Psychiatry $54: 1162-1170$

Le Pen G et al (2006) Peri-pubertal maturation after developmental disturbance: a model for psychosis onset in the rat. Neuroscience 143:395-405

Leppert M et al (1990) Genetic analysis of an inherited predisposition to colon cancer in a family with a variable number of adenomatous polyps. N Engl J Med 322:904-908

Leumann L et al (2002) Effects of typical and atypical antipsychotics on prepulse inhibition and latent inhibition in chronic schizophrenia. Biol Psychiatry 52:729-739

Libet B et al (1979) Subjective referral of the timing for a conscious sensory experience. Brain 102:192-224

Lieberman JA et al (2005) Clinical Antipsychotic Trials of Intervention Effectiveness (CATIE) Investigators. Effectiveness of antipsychotic drugs in patients with chronic schizophrenia. N Engl J Med 353:1209-1223

Light GA, Braff DL (2005) Mismatch negativity deficits are associated with poor functioning in schizophrenia patients. Arch Gen Psychiatry 62:127-136

Light GA et al (2004) Probing cortical-cortical interactions that underlie the multiple sensory, cognitive, and "real-world" functional deficits in schizophrenia. Behav Brain Sci 27:799
Light GA et al (2007a) One year stability of neurophysiological and cognitive endophenotypes of schizophrenia. Proc Am Col Neuropsychopharmacology (in press)

Light GA et al (2007b) Prepulse inhibition of startle is positively associated with higher order cognition in women. Abstr Soc Neurosciences 806.17

Light GA et al (2008) Preattentive sensory processing is associated with cognitive and psychosocial functioning in healthy adults. J Cog Neurosci 7:120-128

Ligneau X et al (2007) Brain histamine and schizophrenia: potential therapeutic applications of H3-receptor inverse agonists studied with BF2.649. Biochem Pharmacol 73:1215-1224

Linn GS et al (2003) Reversal of phencyclidine-induced prepulse inhibition deficits by clozapine in monkeys. Psychopharmacology (Berl) 169:234-239

Lipina $\mathrm{T}$ et al (2005) Modulators of the glycine site on NMDA receptors, D-serine and ALX 5407, display similar beneficial effects to clozapine in mouse models of schizophrenia. Psychopharmacology (Berl) 179:54-67

Lipina $T$ et al (2007) The ampakine CX546 restores the prepulse inhibition and latent inhibition deficits in mGluR5-deficient mice. Neuropsychopharmacology 32:745-756

Lipska BK et al (1995) Neonatal excitotoxic hippocampal damage in rats causes post-pubertal changes in prepulse inhibition of startle and its disruption by apomorphine. Psychopharmacology 122:35-43

Long LE et al (2006) Cannabidiol reverses MK-801-induced disruption of prepulse inhibition in mice. Neuropsychopharmacology 31: $795-803$

Lovic V, Fleming AS (2004) Artificially-reared female rats show reduced prepulse inhibition and deficits in the attentional set shifting task-reversal of effects with maternal-like licking stimulation. Behav Brain Res 148:209-219

Ludewig K, Vollenweider FX (2002) Impaired sensorimotor gating in schizophrenia with deficit and with nondeficit syndrome. Swiss Med Wkly 132:159-165

Ludewig K et al (2002) Stability of the acoustic startle reflex, prepulse inhibition, and habituation in schizophrenia. Schizophr Res 55:129-137

Ludewig K et al (2003) Deficits in prepulse inhibition and habituation in never-medicated, first-episode schizophrenia. Biol Psychiatry $54: 121-128$

Ma J, Leung LS (2004) Schizophrenia-like behavioral changes after partial hippocampal kindling. Brain Res 997:111-118

Ma J, Leung LS (2007) The supramammillo-septal-hippocampal pathway mediates sensorimotor gating impairment and hyperlocomotion induced by MK-801 and ketamine in rats. Psychopharmacology (Berl) 191:961-974

Ma J et al (2004) The medial septum mediates impairment of prepulse inhibition of acoustic startle induced by a hippocampal seizure or phencyclidine. Behav Brain Res 155:153-166

Mackeprang T et al (2002) Effects of antipsychotics on prepulse inhibition of the startle response in drug-naive schizophrenic patients. Biol Psychiatry 52:863-873

Malone DT et al (2004) The effect of SR 141716 and apomorphine on sensorimotor gating in Swiss mice. Pharmacol Biochem Behav 77:839-845

Mansbach RS, Geyer MA (1989) Effects of phencyclidine and phencyclidine biologs on sensorimotor gating in the rat. Neuropsychopharmacology 2:299-308

Mansbach RS et al (1988) Dopaminergic stimulation disrupts sensorimotor gating in the rat. Psychopharmacology (Berl) 94:507-514

Marquis KL et al (2007) WAY-163909 [(7bR,10aR)-1,2,3,4,8,9,10,10aoctahydro-7bH-cyclopenta-[b][1,4]diazepino[6,7,1 hi] indole]: a novel 5-hydroxytryptamine $2 \mathrm{C}$ receptor-selective agonist with preclinical antipsychotic-like activity. J Pharmacol Exp Ther 320:486-496 
McCool MF et al (2003) Increased auditory startle response and reduced prepulse inhibition of startle in transgenic mice expressing a double mutant form of amyloid precursor protein. Brain Res 994:99-106

McDonald MP et al (2001) Motor deficits in fibroblast growth factor receptor-3 null mutant mice. Behav Pharmacol 12:477-486

McGhie A, Chapman J (1961) Disorders of attention and perception in early schizophrenia. Brit J Med Psychol 34:103-116

Meincke U et al (2004) Prepulse inhibition of the acoustically evoked startle reflex in patients with an acute schizophrenic psychosisa longitudinal study. Eur Arch Psychiatry Clin Neurosci 254:415-421

Metzger KL et al (2007) Pharmacokinetic and behavioral characterization of a long-term antipsychotic delivery system in rodents and rabbits. Psychopharmacology (Berl) 190:201-211

Minassian A et al (2007) The relationship between sensorimotor gating and clinical improvement in acutely ill schizophrenia patients. Schizophr Res 89:225-231

Miyakawa $\mathrm{T}$ et al (2003) Conditional calcineurin knockout mice exhibit multiple abnormal behaviors related to schizophrenia. Proc Natl Acad Sci USA 100:8987-8992

Mohr D et al (2007) Accumbal dopamine D2 receptors are important for sensorimotor gating in C3H mice. Neuroreport 18:1493-1497

Moy SS et al (2006) Amphetamine-induced disruption of prepulse inhibition in mice with reduced NMDA receptor function. Brain Res 1089:186-194

Mukai J et al (2004) Evidence that the gene encoding ZDHHC8 contributes to the risk of schizophrenia. Nat Genet 36:725-731

Murphy CA et al (2001) Latent inhibition, but not prepulse inhibition, is reduced during withdrawal from an escalating dosage schedule of amphetamine. Behav Neurosci 115:1247-1256

Myers KM et al (2005) Partial reversal of phencyclidine-induced impairment of prepulse inhibition by secretin. Biol Psychiatry 58:67-73

Nagai $\mathrm{H}$ et al (2006) Antipsychotics improve Delta9-tetrahydrocannabinol-induced impairment of the prepulse inhibition of the startle reflex in mice. Pharmacol Biochem Behav 84:330-336

Nagel J et al (2003) Effects of an adenosine A2A receptor blockade in the nucleus accumbens on locomotion, feeding, and prepulse inhibition in rats. Synapse 49:279-286

Nunes Mamede Rosa ML et al (2005) Isolation-induced changes in ultrasonic vocalization, fear-potentiated startle and prepulse inhibition in rats. Neuropsychobiology 51:248-255

Nyffeler $M$ et al (2006) Maternal immune activation during pregnancy increases limbic GABAA receptor immunoreactivity in the adult offspring: implications for schizophrenia. Neuroscience 143:51-62

Ojima T et al (2004) Effects of serotonin-dopamine antagonists on prepulse inhibition and neurotransmitter contents in the rat cortex. Neurosci Lett 366:130-134

Ong JC et al (2005) An investigation of the efficacy of mood stabilizers in rodent models of prepulse inhibition. J Pharmacol Exp Ther 315:1163-1171

Oranje B et al (2002) Effects of typical and atypical antipsychotics on the prepulse inhibition of the startle reflex in patients with schizophrenia. J Clin Psychopharmacol 22:359-365

Ouagazzal AM et al (2001a) Drug-induced potentiation of prepulse inhibition of acoustic startle reflex in mice: a model for detecting antipsychotic activity. Psychopharmacology (Berl) 156:273-283

Ouagazzal AM et al (2001b) Effect of LSD on prepulse inhibition and spontaneous behavior in the rat. a pharmacological analysis and comparison between two rat strains. Neuropsychopharmacology 25:565-575

Ozawa $\mathrm{K}$ et al (2006) Immune activation during pregnancy in mice leads to dopaminergic hyperfunction and cognitive impairment in the offspring: a neurodevelopmental animal model of schizophrenia. Biol Psychiatry 59:546-554
Paine TA et al (2007) Sensitivity of the five-choice serial reaction time task to the effects of various psychotropic drugs in SpragueDawley rats. Biol Psychiatry 62:687-693

Palmer AA et al (2000) Prepulse startle deficit in the Brown Norway rat: a potential genetic model. Behav Neurosci 114:374-388

Palmer AA et al (2004) Prenatal protein deprivation in rats induces changes in prepulse inhibition and NMDA receptor binding. Brain Res 996:193-201

Palsson E et al (2007) The amino acid L-lysine blocks the disruptive effect of phencyclidine on prepulse inhibition in mice. Psychopharmacology (Berl) 192:9-15

Park C et al (2002) Deletion in Catna2, encoding alpha N-catenin, causes cerebellar and hippocampal lamination defects and impaired startle modulation. Nat Genet 31:279-284

Park WK et al (2005) KKHA-761, a potent D3 receptor antagonist with high 5-HT1A receptor affinity, exhibits antipsychotic properties in animal models of schizophrenia. Pharmacol Biochem Behav 82:361-372

Paylor R et al (2006) Tbx1 haploinsufficiency is linked to behavioral disorders in mice and humans: implications for $22 q 11$ deletion syndrome. Proc Natl Acad Sci USA 103:7729-7734

Peak H (1939) Time order error in successive judgements and in reflexes. I. Inhibition of the judgement and the reflex. J Exper Psychol 25:535-565

Peleg-Raibstein D et al (2006a) Differential effects on prepulse inhibition of withdrawal from two different repeated administration schedules of amphetamine. Int J Neuropsychopharmacol 9:737-749

Peleg-Raibstein D et al (2006b) Withdrawal from repeated amphetamine administration leads to disruption of prepulse inhibition but not to disruption of latent inhibition. J Neural Transm 113:1323-1336

Perry W, Braff DL (1994) Information-processing deficits and thought disorder in schizophrenia. Am J Psychiatry 151:363-367

Perry W et al (2001) Sensorimotor gating deficits in bipolar disorder patients with acute psychotic mania. Biol Psychiatry $50418-424$

Perry W et al (2002) Information processing deficits in acutely psychotic schizophrenia patients medicated and unmedicated at the time of admission. Am J Psychiatry 159:1375-1381

Perry W et al (2004) Prepulse inhibition in patients with non-psychotic major depressive disorder. J Affect Disord 81:179-184

Petitto JM et al (2002a) IL-2/15 receptor-beta gene deletion alters neurobehavioral performance. Brain Res 929:218-225

Petitto JM et al (2002b) Relationship between the development of autoimmunity and sensorimotor gating in MRL-lpr mice with reduced IL-2 production. Neurosci Lett 328:304-308

Pijlman FT et al (2003) Behavioural changes after different stress paradigms: prepulse inhibition increased after physical, but not emotional stress. Eur Neuropsychopharmacol 13:369-380

Pillai-Nair N et al (2005) Neural cell adhesion molecule-secreting transgenic mice display abnormalities in GABAergic interneurons and alterations in behavior. J Neurosci 25:4659-4671

Pletnikov MV et al (2002) Effects of genetic background on neonatal Borna disease virus infection-induced neurodevelopmental damage. I. Brain pathology and behavioral deficits. Brain Res 944: $97-107$

Podhorna J, Didriksen M (2004) The heterozygous reeler mouse: behavioural phenotype. Behav Brain Res 153:43-54

Porras-Garcia E et al (2005) Purkinje cell loss affects differentially the execution, acquisition and prepulse inhibition of skeletal and facial motor responses in Lurcher mice. Eur J Neurosci 21:979-988

Postma P et al (2006) A behavioural and functional neuroimaging investigation into the effects of nicotine on sensorimotor gating in healthy subjects and persons with schizophrenia. Psychopharmacology 184:589-599 
Pothuizen HH et al (2005) The effects of temporary inactivation of the core and the shell subregions of the nucleus accumbens on prepulse inhibition of the acoustic startle reflex and activity in rats. Neuropsychopharmacology 30:683-696

Pothuizen HH, Neumann KR, Feldon J, Yee BK (2006) Selective nucleus accumbens core lesions enhance dizocilpine-induced but not apomorphine-induced disruption of prepulse inhibition in rats. Behav Pharmacol 17:107-117

Pouzet B et al (2002a) Effects of the 5-HT(6) receptor antagonist, SB271046, in animal models for schizophrenia. Pharmacol Biochem Behav 71:635-643

Pouzet B et al (2002b) Effects of the 5-HT(7) receptor antagonist SB258741 in animal models for schizophrenia. Pharmacol Biochem Behav 71:655-665

Powell KJ et al (2006) Neonatal ventral hippocampal lesions produce an elevation of DeltaFosB-like protein(s) in the rodent neocortex. Neuropsychopharmacology 31:700-711

Powell SB et al (2002) Isolation rearing-induced deficits in prepulse inhibition and locomotor habituation are not potentiated by water deprivation. Physiol Behav 77:55-64

Powell SB et al (2003) Dopamine depletion of the nucleus accumbens reverses isolation-induced deficits in prepulse inhibition in rats. Neuroscience 119:233-240

Powell SB et al (2006a) Antipsychotic prophylaxis: initial studies on prepulse inhibition and weight gain with sustained clozapine treatment. Society for Neuroscience Atlanta, GA, Program No. 587.12

Powell SB et al (2006b) Startle gating deficits after isolation rearing: strain differences and effects of sustained clozapine treatment. Biol Psychiatry 59:221S

Quednow BB et al (2006) Sensorimotor gating and habituation of the startle response in schizophrenic patients randomly treated with amisulpride or olanzapine. Biol Psychiatry 59:536-545

Radant AD et al (2007) Successful multi-site measurement of antisaccade performance deficits in schizophrenia. Schizophr Res 89:320-329

Rajakumar N et al (2004) Altered neurotrophin receptor function in the developing prefrontal cortex leads to adult-onset dopaminergic hyperresponsivity and impaired prepulse inhibition of acoustic startle. Biol Psychiatry 55:797-803

Ralph RJ, Caine SB (2005) Dopamine D1 and D2 agonist effects on prepulse inhibition and locomotion: comparison of SpragueDawley rats to Swiss-Webster, 129X1/SvJ, C57BL/6J, and DBA/ 2J mice. J Pharmacol Exp Ther 312:733-741

Ralph RJ, Caine SB (2007) Effects of selective dopamine D1-like and D2-like agonists on prepulse inhibition of startle in inbred $\mathrm{C} 3 \mathrm{H} /$ HeJ, SPRET/EiJ, and CAST/EiJ mice. Psychopharmacology (Berl) 191:731-739

Ralph RJ et al (1999) The dopamine D2, but not D3 or D4, receptor subtype is essential for the disruption of prepulse inhibition produced by amphetamine in mice. J Neurosci 19:4627-4633

Ralph-Williams RJ et al (2002) Differential effects of direct and indirect dopamine agonists on prepulse inhibition: a study in D1 and D2 receptor knock-out mice. J Neurosci 22:9604-9611

Ralph-Williams RJ et al (2003a) Dopamine D1 rather than D2 receptor agonists disrupt prepulse inhibition of startle in mice. Neuropsychopharmacology 28:108-118

Ralph-Williams RJ et al (2003b) Valproate attenuates hyperactive and perseverative behaviors in mutant mice with a dysregulated dopamine system. Biol Psychiatry 53:352-359

Rasmussen BA et al (2007) Long-term effects of developmental PCP administration on sensorimotor gating in male and female rats. Psychopharmacology (Berl) 190:43-49

Razoux F et al (2007) Ketamine, at a dose that disrupts motor behavior and latent inhibition, enhances prefrontal cortex synaptic efficacy and glutamate release in the nucleus accumbens. Neuropsychopharmacology 32:719-727
Rehn AE et al (2004) An animal model of chronic placental insufficiency: relevance to neurodevelopmental disorders including schizophrenia. Neuroscience 129:381-391

Rich BA et al (2005) An investigation of prepulse inhibition in pediatric bipolar disorder. Bipolar Disord 7:198-203

Risbrough VB et al (2004) Corticotropin-releasing factor receptors CRF1 and CRF2 exert both additive and opposing influences on defensive startle behavior. J Neurosci 24:6545-6552

Risterrucci $\mathrm{C}$ et al (2005) Functional magnetic resonance imaging reveals similar brain activity changes in two different animal models of schizophrenia. Psychopharmacology 180:724-734

Roegge CS et al (2007) Histamine H1 receptor involvement in prepulse inhibition and memory function: relevance for the antipsychotic actions of clozapine. Pharmacol Biochem Behav 86:686-692

Romero E et al (2007) Neurobehavioral and immunological consequences of prenatal immune activation in rats. Influence of antipsychotics. Neuropsychopharmacology 32:1791-1804

Rosa ML et al (2005) Routine post-weaning handling of rats prevents isolation rearing-induced deficit in prepulse inhibition. Braz $\mathrm{J}$ Med Biol Res 38:1691-1696

Roy MA et al (1997) Selecting a control group in studies of the familial coaggregation of two disorders: a quantitative genetics perspective. Am J Med Genet 74:296-303

Rueter LE et al (2004) Chronic low dose risperidone and clozapine alleviate positive but not negative symptoms in the rat neonatal ventral hippocampal lesion model of schizophrenia. Psychopharmacology (Berl) 176:312-319

Russig H et al (2004) Apomorphine-induced disruption of prepulse inhibition that can be normalised by systemic haloperidol is insensitive to clozapine pretreatment. Psychopharmacology (Berl) 175:143-147

Sakaue $M$ et al (2003) The 5-HT1A receptor agonist MKC-242 reverses isolation rearing-induced deficits of prepulse inhibition in mice. Psychopharmacology (Berl) 170:73-79

Sallinen J et al (2007) Pharmacological characterization and CNS effects of a novel highly selective alpha2C-adrenoceptor antagonist JP-1302. Br J Pharmacol 150:391-402

Salum C et al (2006) Dopamine and nitric oxide interaction on the modulation of prepulse inhibition of the acoustic startle response in the Wistar rat. Psychopharmacology (Berl) 185: 133-141

Sandager-Nielsen K et al (2004) Effects of postnatal anoxia on striatal dopamine metabolism and prepulse inhibition in rats. Pharmacol Biochem Behav 77:767-774

Sandner G et al (2002) Effects of ketamine and apomorphine on inferior colliculus and caudal pontine reticular nucleus evoked potentials during prepulse inhibition of the startle reflex in rats. Behav Brain Res 128:161-168

Schmitt A et al (2007) Altered NMDA receptor expression and behavior following postnatal hypoxia: potential relevance to schizophrenia. J Neural Transm 114:239-248

Schneider M, Koch M (2003) Chronic pubertal, but not adult chronic cannabinoid treatment impairs sensorimotor gating, recognition memory, and the performance in a progressive ratio task in adult rats. Neuropsychopharmacology 28:1760-1769

Schneider M, Koch M (2005) Behavioral and morphological alterations following neonatal excitotoxic lesions of the medial prefrontal cortex in rats. Exp Neurology 195:185-198

Schneider M et al (2005) Behavioral effects in adult rats of chronic prepubertal treatment with the cannabinoid receptor agonist WIN 55,212-2. Behav Pharmacol 16:447-454

Schneider T et al (2006) Environmental enrichment reverses behavioral alterations in rats prenatally exposed to valproic acid: issues for a therapeutic approach in autism. Neuropsychopharmacology 31:36-46

Schwabe K, Koch M (2004) Role of the medial prefrontal cortex in $\mathrm{N}$ methyl-D-aspartate receptor antagonist induced sensorimotor gating deficit in rats. Neurosci Lett 355:5-8 
Schwabe K et al (2004) Effects of neonatal lesions of the medial prefrontal cortex on adult rat behaviour. Behav Brain Res 153:21-34

Schwienbacher I et al (2002) Dopamine D1 receptors and adenosine A1 receptors in the rat nucleus accumbens regulate motor activity but not prepulse inhibition. Eur J Pharmacol 444:161-169

Scott LJ et al (2007) A genome-wide association study of type 2 diabetes in Finns detects multiple susceptibility variants. Science 316:1341-1345

Semenova S et al (2008) Inactivation of the 5-HT(7) receptor partially blocks phencyclidine-induced disruption of prepulse inhibition. Biol Psychiatry 63:98-105

Shi L et al (2003) Maternal influenza infection causes marked behavioral and pharmacological changes in the offspring. $\mathrm{J}$ Neurosci 23:297-302

Shilling PD, Feifel D (2002) SR146131, a cholecystokinin-A receptor agonist, antagonizes prepulse inhibition deficits produced by dizocilpine and DOI. Psychopharmacology (Berl) 164:285-293

Shilling PD et al (2003) The effects of systemic NT69L, a neurotensin agonist, on baseline and drug-disrupted prepulse inhibition. Behav Brain Res 143:7-14

Shilling PD et al (2004) Neurotensin agonists block the prepulse inhibition deficits produced by a 5-HT2A and an alphal agonist. Psychopharmacology (Berl) 175:353-359

Shilling PD et al (2008) Strain differences in gating-disruptive effects of apomorphine: relationship to accumbens gene expression. Abstr Soc Biol Psychiatry (in press)

Shishkina GT et al (2004) Influence of neonatal short-term reduction in brainstem alpha2A-adrenergic receptors on receptor ontogenesis, acoustic startle reflex, and prepulse inhibition in rats. Behav Neurosci 118:1285-1292

Shoemaker JM et al (2003) Quetiapine produces a prolonged reversal of the sensorimotor gating-disruptive effects of basolateral amygdala lesions in rats. Behav Neurosci 117:136-143

Shoemaker JM et al (2005) Prefrontal D1 and ventral hippocampal $N$ methyl-D-aspartate regulation of startle gating in rats. Neuroscience 135:385-394

Shum FW et al (2005) Genetic alteration of anxiety and stress-like behavior in mice lacking CaMKIV. Mol Pain 1:22

Sills TL (1999) Amphetamine dose dependently disrupts prepulse inhibition of the acoustic startle response in rats within a narrow time window. Brain Res Bull 48:445-448

Silva RC et al (2005) Unilateral electrical stimulation of the inferior colliculus of rats modifies the prepulse modulation of the startle response (PPI): effects of ketamine and diazepam. Behav Brain Res 160:323-330

Siuciak JA et al (2007) CP-809,101, a selective 5-HT2C agonist, shows activity in animal models of antipsychotic activity. Neuropharmacology 52:279-290

Slawecki CJ, Ehlers CL (2005) Enhanced prepulse inhibition following adolescent ethanol exposure in Sprague-Dawley rats. Alcohol Clin Exp Res 29:829-836

Smith SJ, Lees AJ (1989) Abnormalities of the blink reflex in Gilles de la Tourette syndrome. J Neurol Neurosurg Psychiatry. 52:895-898

Sobin $\mathrm{C}$ et al (2005a) Associations between prepulse inhibition and executive visual attention in children with the 22q11 deletion syndrome. Mol Psychiatry 10:553-562

Sobin C et al (2005b) Lower prepulse inhibition in children with the 22q11 deletion syndrome. Am J Psychiatry 162:1090-1099

Sontag TA et al (2003) Removal of short-term isolation stress differentially influences prepulse inhibition in APO-SUS and APO-UNSUS rats. Behav Brain Res 141:171-175

Sorenson CA, Swerdlow NR (1982) The effect of tail pinch on the acoustic startle response in rats. Brain Res 247:105-113

Sotoyama $\mathrm{H}$ et al (2007) Neonatal exposure to epidermal growth factor induces dopamine $\mathrm{D}(2)$-like receptor supersensitivity in adult sensorimotor gating. Psychopharmacology 191:783-792
Spencer CM et al (2006) Exaggerated behavioral phenotypes in Fmr1/ Fxr2 double knockout mice reveal a functional genetic interaction between Fragile X-related proteins. Hum Mol Genet 15:1984-1994

Spielewoy C, Markou A (2004) Strain-specificity in nicotine attenuation of phencyclidine-induced disruption of prepulse inhibition in mice: relevance to smoking in schizophrenia patients. Behav Genet 34:343-354

Spooren W et al (2004) Pharmacological and genetic evidence indicates that combined inhibition of NR2A and NR2B subunit containing NMDA receptors is required to disrupt prepulse inhibition. Psychopharmacology (Berl) 175:99-105

Stanhope KJ et al (2001) The muscarinic receptor agonist xanomeline has an antipsychotic-like profile in the rat. J Pharmacol Exp Ther 299:782-792

Stevenson CW, Gratton A (2004) Role of basolateral amygdala dopamine in modulating prepulse inhibition and latent inhibition in the rat. Psychopharmacology 176:139-145

Suemaru K et al (2004) Nicotine blocks apomorphine-induced disruption of prepulse inhibition of the acoustic startle in rats: possible involvement of central nicotinic alpha7 receptors. Br J Pharmacol 142:843-850

Sugar C et al (2007) Subtyping the group of schizophrenias using neurophysiological endophenotypes. Abstr Soc Neuroscience 226.6

Svenningsson P et al (2003) Diverse psychotomimetics act through a common signaling pathway. Science 302:1412-1415

Swerdlow NR (1996) Cortico-striatal substrates of cognitive, motor and sensory gating: Speculations and implications for psychological function and dysfunction. In: Panksepp J (ed) Advances in biological psychiatry, vol. 2. JAI Press Inc, Greenwich CT, pp 179-208

Swerdlow NR (2005) Much ado about (almost) nothing: response to 'prepulse lost and regained'. Psychopharmacology 179:893-894

Swerdlow NR, Geyer MA (1993a) Prepulse inhibition of acoustic startle in rats after lesions of the pedunculopontine nucleus. Behav Neurosci 107:104-117

Swerdlow NR, Geyer MA (1993b) Clozapine and haloperidol in an animal model of sensorimotor gating deficits in schizophrenia. Pharmacol Biochem Behav 44:741-744

Swerdlow NR, Geyer MA (1998) Using an animal model of deficient sensorimotor gating to study the pathophysiology and new treatments of schizophrenia. Schizphr Bull 24:285-301

Swerdlow et al (1986) Central dopamine hyperactivity in rats mimics abnormal acoustic startle response in schizophrenics. Biol Psychiatry 21:23-33

Swerdlow NR et al (1992) The neural substrates of sensorimotor gating of the startle reflex: a review of recent findings and their implications. J Psychopharmacol 6:176-190

Swerdlow NR et al (1993a) A preliminary assessment of sensorimotor gating in patients with Obsessive Compulsive Disorder (OCD). Biol Psychiatry 33:298-301

Swerdlow NR et al (1993b) Men are more inhibited than women by weak prepulses. Biol Psychiatry 34:253-261

Swerdlow NR et al (1994) Assessing the validity of an animal model of sensorimotor gating deficits in schizophrenic patients. Arch Gen Psychiatry 51:139-154

Swerdlow NR et al (1995a) Impaired prepulse inhibition of acoustic and tactile startle in patients with Huntington's Disease. J Neurol Neurosurg Psychiat 58:192-200

Swerdlow NR et al (1995b) "Normal" personality correlates of sensorimotor, cognitive, and visuospatial gating. Biol Psychiatry 37:286-299

Swerdlow NR et al (1997) Changes in sensorimotor inhibition across the menstrual cycle: Implications for neuropsychiatric disorders. Biol. Psychiatry 41:452-460

Swerdlow NR et al (1998) Discrepant findings of clozapine effects on prepulse inhibition of startle: is it the route or the rat. Neuropsychopharmacology 18:50-56 
Swerdlow NR et al (2000a) Animal models of deficient sensorimotor gating: What we know, what we think we know, and what we hope to know soon. Behav Pharmacol 111:185-204

Swerdlow NR et al (2000b) Towards understanding the biology of a complex phenotype: rat strain and substrain differences in the sensorimotor gating-disruptive effects of dopamine agonists. J Neurosci 20:4325-4336

Swerdlow NR et al (2001a) Neural circuit regulation of prepulse inhibition of startle in the rat: current knowledge and future challenges. Psychopharmacology (Berl) 156:194-215

Swerdlow NR et al (2001b) Tactile prepuff inhibition of startle in children with Tourette's syndrome: in search of an "fMRIfriendly" startle paradigm. Biol. Psychiatry 50:578-585

Swerdlow NR et al (2001c) Matching strategies for drug studies of prepulse inhibition in humans. Behav Pharmacol. 12:45-52

Swerdlow NR et al (2002a) Prestimulus effects on startle magnitude: sensory or motor. Behavioral Neuroscience 116:672-681

Swerdlow NR et al (2002b) Prestimulus modification of the startle reflex: Relationship to personality and physiological markers of dopamine function. Biol Psychology 62:17-26

Swerdlow NR et al (2002c) Startle gating in rats is disrupted by chemical inactivation but not D2 stimulation of the dorsomedial thalamus. Brain Research 953:246-254

Swerdlow NR et al (2003a) Sensitivity to sensorimotor gatingdisruptive effects of apomorphine in two outbred parental rat strains and their F1 and N2 progeny. Neuropsychopharmacology 28:226-234

Swerdlow NR et al (2003b) Amphetamine effects on prepulse inhibition across species: Replication and parametric extension. Neuropsychopharmacology 28:640-650

Swerdlow NR et al (2003c) Memantine effects on startle gating in rats: pretreatments with quetiapine and haloperidol. Society for Neuroscience, Program No. 858.17, Washington, DC

Swerdlow NR et al (2003d) Prestimulus modification of the startle reflex: relationship to personality and physiological markers of dopamine function. Biol Psychology 62:17-26

Swerdlow NR et al (2004a) Sensitivity to drug effects on prepulse inhibition in inbred and outbred rat strains. Pharmacol Biochem Behav 77:291-302

Swerdlow NR et al (2004b) The ventral hippocampal regulation of prepulse inhibition and its disruption by apomorphine in rats are not mediated via the fornix. Neuroscience 123:675-85

Swerdlow NR et al (2004c) Weak prepulses inhibit but do not elicit startle in rats and humans. Biol Psychiatry 55:1195-1198

Swerdlow NR et al (2004d) Heritable differences in the dopaminergic regulation of sensorimotor gating: II. Temporal, pharmacologic and generational analyses of apomorphine effects on prepulse inhibition. Psychopharmacology 174:452-462

Swerdlow NR et al (2005a) Effects of memantine on startle gating in normal adult men. Proc Am Coll Neuropsychopharm, Waikoloa, $\mathrm{HI}$

Swerdlow NR et al (2005b) Prepulse inhibition of perceived stimulus intensity: paradigm assessment. Biol Psychology 69:133-147

Swerdlow NR et al (2005c) Reduced startle gating after D1 blockade: effects of concomitant D2 blockade. Pharm Biochem Behav 82:293-299

Swerdlow NR et al (2006a) Antipsychotic effects on prepulse inhibition in normal 'low gating' humans and rats. Neuropsychopharmacology 31:2011-2021

Swerdlow NR et al (2006b) Convergence and divergence in the neurochemical regulation of prepulse inhibition of startle and N40 suppression in rats. Neuropsychopharmacology 31:506-515

Swerdlow NR et al (2006c) Forebrain D1 function and sensorimotor gating in rats: effects of D1 blockade, frontal lesions and dopamine denervation. Neurosci Lett 402:40-45
Swerdlow NR et al (2006d) Heritable differences in the dopaminergic regulation of behavior in rats: relationship to D2-like receptor Gprotein function. Neuropsychopharmacology 31:721-729

Swerdlow NR et al (2006e) Separable noradrenergic and dopaminergic regulation of prepulse inhibition in rats: implications for predictive validity and Tourette Syndrome. Psychopharmacology (Berl) 186:246-254

Swerdlow NR et al (2006f) Startle gating deficits in a large cohort of patients with schizophrenia: relationship to medications, symptoms, neurocognition, and level of function. Arch Gen Psychiatry 63:1325-1335

Swerdlow NR et al (2006g) The "low gating" phenotype in rats: antipsychotic sensitivity, heritability and sex differences. Biol Psychiatry 59:220S

Swerdlow NR et al (2007) Multi-site studies of acoustic startle and prepulse inhibition in humans: Initial experience and methodological considerations based on studies by the Consortium on the Genetics of Schizophrenia. Schizophrenia Research 92:237-251

Swerdlow NR et al (2008) A novel rat strain with enhanced sensitivity to the effects of dopamine agonists on startle gating. Pharmacol Biochem Behav 88:280-290

Szumlinski KK et al (2005) Behavioral and neurochemical phenotyping of Homer1 mutant mice: possible relevance to schizophrenia. Genes Brain Behav 4:273-288

Tadros MG et al (2005) Neuroprotective effect of taurine in 3nitropropionic acid-induced experimental animal model of Huntington's disease phenotype. Pharmacol Biochem Behav $82: 574-582$

Takahashi M et al (2006) Sustained brain-derived neurotrophic factor up-regulation and sensorimotor gating abnormality induced by postnatal exposure to phencyclidine: comparison with adult treatment. J Neurochem 99:770-780

Takahashi K et al (2007) Neural circuits containing pallidotegmental GABAergic neurons are involved in the prepulse inhibition of the startle reflex in mice. Biol Psychiatry 62:148-157

Takeuchi T et al (2001) Roles of the glutamate receptor epsilon2 and delta 2 subunits in the potentiation and prepulse inhibition of the acoustic startle reflex. Eur J Neurosci 14:153-160

Tan SE (2003) Prenatal amphetamine exposure alters behavioral reactivity to amphetamine in rats. Neurotoxicol Teratol 25:579-585

Tanaka K et al (2006) Psychostimulant-induced attenuation of hyperactivity and prepulse inhibition deficits in Adcyap1deficient mice. J Neurosci 26:5091-5097

Taniguchi T et al (2005) Transgenic mice expressing mutant (N279K) human tau show mutation dependent cognitive deficits without neurofibrillary tangle formation. FEBS Lett 579:5704-5712

Tejkalova $\mathrm{H}$ et al (2007) Does neonatal brain ischemia induces schizophrenia-like behaviour in young adult rats? Physiol Res $56: 815-823$

Tenn CC et al (2003) Amphetamine-sensitized animals show a sensorimotor gating and neurochemical abnormality similar to that of schizophrenia. Schizophr Res 64:103-114

Terry AV Jr et al (2007) Chronic, intermittent exposure to chlorpyrifos in rats: protracted effects on axonal transport, neurotrophin receptors, cholinergic markers, and information processing. $\mathrm{J}$ Pharmacol Exp Ther 322:1117-1128

Thomsen $M$ et al (2007) Decreased prepulse inhibition and increased sensitivity to muscarinic, but not dopaminergic drugs in M5 muscarinic acetylcholine receptor knockout mice. Psychopharmacology (Berl) 192:97-110

Tremolizzo L et al (2005) Valproate corrects the schizophrenia-like epigenetic behavioral modifications induced by methionine in mice. Biol Psychiatry 57:500-509

Tsai G et al (2004) Gene knockout of glycine transporter 1: characterization of the behavioral phenotype. Proc Natl Acad Sci USA $101: 8485-8490$ 
Uehara $\mathrm{T}$ et al (2007) Effect of prefrontal cortex inactivation on behavioral and neurochemical abnormalities in rats with excitotoxic lesions of the entorhinal cortex. Synapse 61:391-400

Ukai M, Okuda A (2003) Endomorphin-1, an endogenous mu-opioid receptor agonist, improves apomorphine-induced impairment of prepulse inhibition in mice. Peptides 24:741-744

Umeda K et al (2006) Effects of mood stabilizers on the disruption of prepulse inhibition induced by apomorphine or dizocilpine in mice. Eur J Pharmacol 553:157-162

Valls-Sole J et al (2004) Abnormalities of prepulse inhibition do not depend on blink reflex excitability: a study in Parkinson's disease and Huntington's disease. Clin Neurophysiol 115:1527-1536

van den Buuse M (2004) Prepulse inhibition of acoustic startle in spontaneously hypertensive rats. Behav Brain Res 154:331-337

van den Buuse M, Gogos A (2007) Differential effects of antipsychotic drugs on serotonin-1A receptor-mediated disruption of prepulse inhibition. J Pharmacol Exp Ther 320:1224-1236

van den Buuse $\mathrm{M}$ et al (2003) Prepulse inhibition of acoustic startle in aromatase knock-out mice: effects of age and gender. Genes Brain Behav 2:93-102

van den Buuse $\mathrm{M}$ et al (2004) Effect of adrenalectomy and corticosterone replacement on prepulse inhibition and locomotor activity in mice. Br J Pharmacol 142:543-550

van den Buuse $M$ et al (2005a) Enhanced effect of dopaminergic stimulation on prepulse inhibition in mice deficient in the alpha subunit of G(z). Psychopharmacology 183:358-367

van den Buuse M et al (2005b) Reduced effects of amphetamine on prepulse inhibition of startle in gastrin-deficient mice. Neurosci Lett 373:237-242

van der Elst MC et al (2006) Cocaine strongly reduces prepulse inhibition in apomorphine-susceptible rats, but not in apomorphine-unsusceptible rats: regulation by dopamine D2 receptors. Behav Brain Res 175:392-398

van der Elst MC et al (2007) Differences in the cellular mechanism underlying the effects of amphetamine on prepulse inhibition in apomorphine-susceptible and apomorphine-unsusceptible rats. Psychopharmacology (Berl) 190:93-102

van der Linden D et al (2006) Disrupted sensorimotor gating due to mental fatigue: preliminary evidence. Int $\mathrm{J}$ Psychophysiol 62:168-174

Van Raamsdonk JM et al (2005) Cognitive dysfunction precedes neuropathology and motor abnormalities in the YAC128 mouse model of Huntington's disease. J Neurosci 25:4169-4180

Vanover KE et al (2006) Pharmacological and behavioral profile of $N$-(4-fluorophenylmethyl)- $N$-(1-methylpiperidin-4-yl)- $N$ '-(4(2-methylpropylo xy)phenylmethyl) carbamide (2R,3R)-dihydroxybutanedioate (2:1) (ACP-103), a novel 5-hydroxytryptamine (2A) receptor inverse agonist. J Pharmacol Exp Ther 317:910-918

Varty GB et al (2006) Isolation rearing of mice induces deficits in prepulse inhibition of the startle response. Behav Brain Res 169:162-167

Venables P (1964) Input dysfunction in schizophrenia. Prog Exp Pers Res $1: 1-47$

Vollenweider FX et al (1999) Opposite effects of 3,4-methylenedioxymethamphetamine (MDMA) on sensorimotor gating in rats versus healthy humans. Psychopharmacology (Berl) 143: 365-372

Vollenweider FX et al (2006) Clozapine enhances prepulse inhibition in healthy humans with low but not with high prepulse inhibition levels. Biol Psychiatry 60:597-603

Volz M et al (2003) Temporal course of emotional startle modulation in schizophrenia patients. Int J Psychophysiol 49:123-137

von Goethe JW (1779) The sorcerer's apprentice

Wang C et al (2003a) Blockade of phencyclidine-induced cortical apoptosis and deficits in prepulse inhibition by M40403, a superoxide dismutase mimetic. J Pharmacol Exp Ther 304:266-271
Wang JH et al (2003b) Reduced startle habituation and prepulse inhibition in mice lacking the adenosine A2A receptor. Behav Brain Res 143:201-207

Wardas J et al (2003) Influence of CGS 21680, a selective adenosine $\mathrm{A}(2 \mathrm{~A})$ agonist, on the phencyclidine-induced sensorimotor gating deficit and motor behaviour in rats. Psychopharmacology (Berl) 168:299-306

Watanabe $Y$ et al (2004) Neonatal impact of leukemia inhibitory factor on neurobehavioral development in rats. Neurosci Res 48:345-353

Weber M, Swerdlow NR (2008) Rat strain differences in startle gatingdisruptive effects of apomorphine occur with both acoustic and visual prepulses. Pharmacol Biochem Behav 88:306-311

Weike AI et al (2000) Effective neuroleptic medication removes prepulse inhibition deficits in schizophrenia patients. Biol. Psychiatry 47:61-70

Weike AI et al (2001) Sensorimotor gating and attitudes related to schizotypal proneness. Psychol Rep 88:1035-1045

Weil ZM et al (2006) Melatonin receptor (MT1) knockout mice display depression-like behaviors and deficits in sensorimotor gating. Brain Res Bull 68:425-429

Weiss IC et al (1999) Isolation rearing-induced disruption of prepulse inhibition: further evidence for fragility of the response. Behav Pharmacol 10:139-149

Weiss IC et al (2000) Strain differences in the isolation-induced effects on prepulse inhibition of the acoustic startle response and on locomotor activity. Behav Neurosci 114:364-373

Wiedholz LM et al (2008) Mice lacking the AMPA GluR1 receptor exhibit striatal hyperdopaminergia and 'schizophrenia-related' behaviors. Mol Psychiatry (in press)

Wilmouth CE, Spear LP (2006) Withdrawal from chronic nicotine in adolescent and adult rats. Pharmacol Biochem Behav 85: $648-657$

Wolf R et al (2007) Acute or subchronic clozapine treatment does not ameliorate prepulse inhibition (PPI) deficits in CPB-K mice with low levels of hippocampal NMDA receptor density. Psychopharmacology (Berl) 194:93-102

Wolinsky TD et al (2007) The trace amine 1 receptor knockout mouse: an animal model with relevance to schizophrenia. Genes Brain Behav 6:628-639

Wynn JK et al (2004) Prepulse facilitation and prepulse inhibition in schizophrenia patients and their unaffected siblings. Biol Psychiatry 55:518-523

Wynn JK et al (2005) Sensorimotor gating, orienting and social perception in schizophrenia. Schizophr Res 73:319-325

Wynn JK et al (2007) Effects of olanzapine, risperidone and haloperidol on prepulse inhibition in schizophrenia patients: A double-blind, randomized controlled trial. Schizophr Res 95: 134-142

Yamashita $\mathrm{M}$ et al (2006) Norepinephrine transporter blockade can normalize the prepulse inhibition deficits found in dopamine transporter knockout mice. Neuropsychopharmacology 31:21322139

Yee BK et al (2004) Apomorphine-induced prepulse inhibition disruption is associated with a paradoxical enhancement of prepulse stimulus reactivity. Neuropsychopharmacology 29:240-248

Yee BK et al (2005) A schizophrenia-related sensorimotor deficit links alpha 3-containing GABAA receptors to a dopamine hyperfunction. Proc Natl Acad Sci USA 102:17154-17159

Yeomans JS et al (2006) Midbrain pathways for prepulse inhibition and startle activation in rat. Neuroscience 142:921-929

Yukawa K et al (2005) Reduced prepulse inhibition of startle in STAT6-deficient mice. Int J Mol Med 16:673-675

Zajaczkowski W et al (2003) A competitive antagonist of NMDA receptors CGP 40116 attenuates experimental symptoms of schizophrenia evoked by MK-801. Pol J Pharmacol 55:703711 
Zhang WN et al (2002a) Effects of hippocampal $N$-methyl-D-aspartate infusion on locomotor activity and prepulse inhibition: differences between the dorsal and ventral hippocampus. Behav Neurosci 116:72-84

Zhang WN et al (2002b) Prepulse inhibition in rats with temporary inhibition/inactivation of ventral or dorsal hippocampus. Pharmacol Biochem Behav 73:929-940

Zhang $\mathrm{M}$ et al (2006) Effect of dopamine D3 antagonists on PPI in $\mathrm{DBA} / 2 \mathrm{~J}$ mice or PPI deficit induced by neonatal ventral hippocampal lesions in rats. Neuropsychopharmacology 31: $1382-1392$

Zhang L et al (2007a) Minocycline attenuates hyperlocomotion and prepulse inhibition deficits in mice after administration of the NMDA receptor antagonist dizocilpine. Neuropsychopharmacology 32:2004-2010

Zhang $M$ et al (2007b) Effects of antipsychotics and selective $\mathrm{D}(3)$ antagonists on PPI deficits induced by PD 128907 and apomorphine. Behav Brain Res 182:1-11 